C [2008]

Kathryn Xiaozhao Wang

ALL RIGHTS RESERVED 


\title{
Osteopontin: Role in immune regulation and stress responses
}

\author{
by \\ Kathryn X. Wang \\ A dissertation submitted to the Graduate-School New Brunswick \\ RUTGERS, the State University of New Jersey \\ and \\ The Graduate School of Biomedical Sciences \\ University of Medicine and Dentistry of New Jersey \\ in partial fulfillment of the requirements for the degree of \\ Doctor of Philosophy \\ in the Graduate Program in Cell and Developmental Biology
}

Written under the direction of

Thesis Advisor: Dr. David T. Denhardt

and approved by

New Brunswick, New Jersey

May 2008 


\title{
ABSTRACT OF THE DISSERTATION
}

\section{Osteopontin: Role in immune regulation and stress responses}

\author{
BY KATHRYN XIAOZHAO WANG
}

Dissertation Director:

David T. Denhardt

\begin{abstract}
Osteopontin (OPN) is a pluripotent soluble protein found in all body fluids and expressed in many tissues and cells. It stimulates signal transduction pathways via integrins and CD44 variants that regulate various cellular activities including the cell's interaction with extracellular matrix, cell survival and immune responses. OPN deficiency is linked to a reduced Th1 immune response in infectious diseases, autoimmunity and delayed type hypersensitivity. OPN is also involved in various physiological stress situations such as mechanical stress, oxidative stress and cellular stress. However, OPN's role in physical and psychological stress is largely unexplored.
\end{abstract}


In this dissertation, I used OPN-deficient mice to evaluate OPN's role in physical stress responses and to determine its influence on immune organ lymphocyte homeostasis in response to stress. Using a hindlimb-unloading (HU) stress model, I compared $\mathrm{OPN}^{-/-}$ (knockout) mice with $\mathrm{OPN}^{+/+}$mice subjected to $\mathrm{HU}$ for 3 days. Whereas $\mathrm{OPN}^{+/+}$mice suffered a marked reduction of body weight and significant spleen and thymus atrophy, $\mathrm{OPN}^{-/}$mice exhibited minor weight loss and much less spleen and thymus atrophy. The HU-induced lymphoid organ atrophy was the result of dramatically diminished numbers of $\mathrm{T}$ and $\mathrm{B}$ cells in the spleen and $\mathrm{CD} 4^{+} / \mathrm{CD} 8^{+}$double-positive cells in the thymus of $\mathrm{OPN}^{+/+}$mice but not in $\mathrm{OPN}^{-/}$mice. Increased levels of corticosterone, which modulate lymphocyte activation responses and apoptosis during stress, were found only in $\mathrm{OPN}^{+/+}$ mice. Apoptotic cell death was evident in the spleen and thymus tissue of $\mathrm{OPN}^{+/+}$mice subjected to $\mathrm{HU}$ but not in $\mathrm{OPN}^{-/}$mice and untreated controls.

In a different stress model, chronic restraint stress (CRS), I have demonstrated that OPN-deficient mice are resistant to CRS-induced lymphoid organ atrophy and unable to mount a significant up-regulation of corticosterone production in response to stress. Another HPA (Hypothalamus Pituitary Adrenal) axis hormone, ACTH, was also found to be unable to respond to stress challenge in the absence of OPN. Administration of soluble OPN into $\mathrm{OPN}^{-/}$mice led to a further reduction of lymphoid organ mass in response to stress whereas administration of anti-OPN antibody $2 \mathrm{C} 5$ in wild type mice alleviated stress-induced organ atrophy. Taken together, these results indicate that OPN is critical in mediating stress-induced immune organ atrophy, likely through influencing the HPA axis hormone pathway. 


\section{Acknowledgements}

First, I would like to thank my advisor, Dr. David Denhardt, for his invaluable guidance and immense support throughout my study and research work. He has helped me in many ways and made this thesis possible by working with me whenever necessary, including early in the morning and late in the evening.

I am very grateful to Dr. Yufang Shi for his advice and significant suggestions on my research work. I thank both him for providing laboratory space and equipment and members of his laboratory especially Guangwen Ren, Dr.George Xu and Dr. Zhenrong Yuan for their assistance in many ways.

I thank the other members of my committee, Drs. Yacov Ron, Guy Werlen, Alexander Kusnecov and John Lenard for providing valuable advice as well as for their enlightening and interesting discussions on improving the quality of my research.

I acknowledge Sanofi-Aventis for providing the opportunity, the financial support and flexible working hours for me to pursue a $\mathrm{PhD}$ degree. Especially I am grateful to $\mathrm{Dr}$. Ray Jupp and Dr. Paul Eynott for their encouragement and inspiration. I also thank Jinjun Liang for his assistance in histopathological analysis.

I thank my husband Chris and son Brian for their encouragement and support throughout the years. Especially I thank my younger son David for his company, patience and superior expertise in graphic editing and English grammar.

Finally, and most importantly, I express my gratitude to my parents for believing in me and providing inspiration and enthusiasm to motivate me to pursue and accomplish my dream as well as theirs. I did it for you! 


\section{Table of contents}

\section{Copyright}

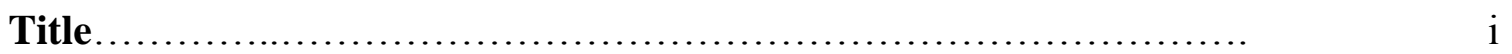

Abstract.......................................................

Acknowledgements ............................................... iv

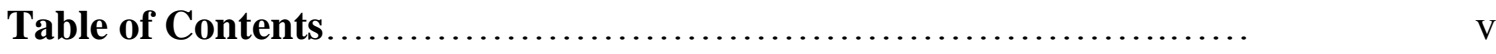

List of Figures.................................................... vii

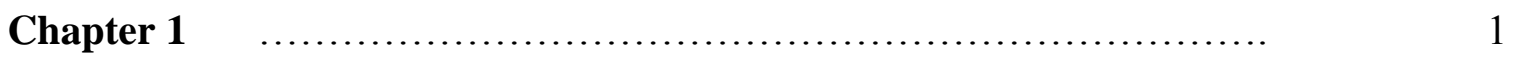

Literature Review: OPN in Immune and Stress Responses

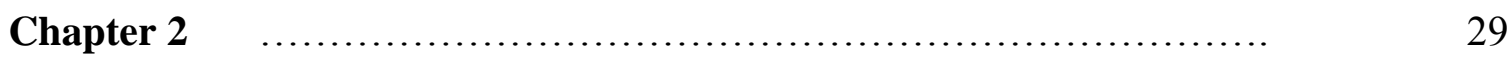

Osteopontin Regulates Hindlimb-unloading-induced Lymphoid Organ Atrophy and

Weight Loss by Modulating Corticosteroid Production

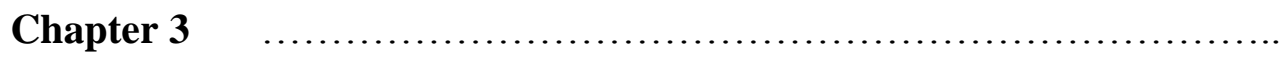

Plasma OPN Levels Affect the Response of the Immune Organs to Stress

Chapter 4

OPN and Immune Cell Functions 


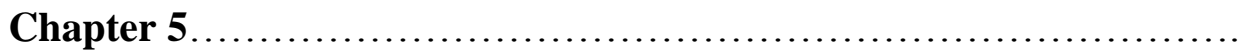

Conclusion and Future Directions

References........................................................... 101

Curriculum Vita....................................................... 115 


\section{List of Figures}

\section{Chapter 1}

\section{OPN's Role in Immune and Stress Response}

Fig. 1.1. Schematic representation of the structure features of osteopontin....

Fig. 1.2. OPN interacts with different signaling pathways to mediate immune responses.

Fig. 1.3. Regulation of innate and adaptive immunity by OPN

\section{Chapter 2}

\section{Osteopontin Regulates Hindlimb-unloading-induced Weight Loss and Lymphoid Organ Atrophy by Modulating Corticosteroid Production}

Fig. 2.1. Schematic presentation of the HU model protocol................

Fig 2.2. HU causes significant body weight loss and HU causes significant lymphoid organ atrophy

Fig. 2.3. HU leads to significant reduction in the cellularity of both thymus and spleen in $\mathrm{OPN}^{+/+}$but not $\mathrm{OPN}^{-/-}$mice.

Fig. 2.4. $\mathrm{OPN}^{-/-}$mice are resistant to HU-induced apoptotic cell death in both thymus and spleen.

Fig. 2.5. Analysis of lymphocyte subpopulations by flow cytometry............

Fig. 2. 6. Serum corticosterone levels are elevated in $\mathrm{OPN}^{+/+}$mice but not in $\mathrm{OPN}^{-/-}$mice after HU.......................................................... 45

Fig. 2.7. Dexamethasone-induced cell death is not impaired in $\mathrm{OPN}^{-/-}$mice. ... 47

Fig. 2.8. Lymphocyte proliferation and cytokine production induced by anti-CD3/CD28

stimulation. 


\section{Chapter 3}

\section{Plasma OPN level affects the response of the immune organs to stress}

Fig. 3.1 Diagram of the CRS protocol. ......................................... 59

Fig. 3.2 CRS-induced body weight loss in Balb/c OPN WT and KO mice ...... 65

Fig. 3.3 CRS-induced organ atrophy in 129 mice and Balb/c mice ............. 66

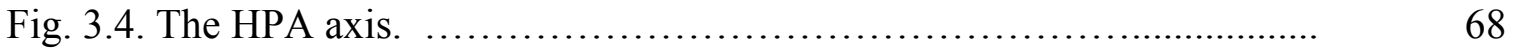

Fig. 3.5. Corticosterone levels in plasma of CRS-treated mice...................... $\quad 69$

Fig. 3.6. Plasma ACTH level in $129 \mathrm{OPN}^{-/ .}$mice.............................. $\quad 70$

Fig. 3.7. Plasma CRH levels in $129 \mathrm{OPN}^{-/}$mice. ............................ 70

Fig. 3.8 Production of certain cytokines in control and stressed 129 mice...

Fig. 3.8. Effect of CRS on lymphocyte populations in blood, spleen and thymus... 74

Fig 3.9. Sex-dependent and organ-dependent responses in the restoration of the WT

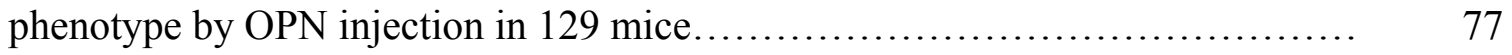

Fig. 3.10. OPN injection in Balb/c $\mathrm{OPN}^{-/-}$mice............................ 78

Fig. 3.11. Plasma corticosterone levels in Balb/c OPN ${ }^{-/ 2}$ mice subjected to CRS and OPN

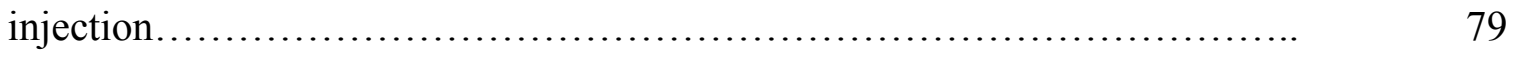

Fig. 3.12. OPN level in plasma of $129 \mathrm{OPN}^{-/}$mice after injection of OPN... $\quad 80$ Fig. 3.13 Monoclonal antibody binding sites on OPN molecule............. 82

Fig. 3.14. Effect of 4 different anti-OPN monoclonal antibodies on CRS-induced thymus

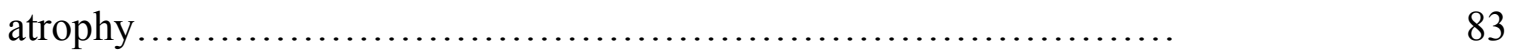

Fig 3.15. OPN level in plasma of $129 \mathrm{OPN}^{+/+}$mice after injection of anti-OPN monoclonal antibody 


\section{Chapter 4}

\section{In vitro evaluations of OPN's role in immune cell functions}

Fig 4.1 Recombinant OPN induced splenocyte migration.................... 93

Fig 4.2 Chemotaxis assay with OPN fragments.......................... 94

Fig. 4.3 Cytokine/chemokine production in LPS-stimulated peritoneal macrophages from

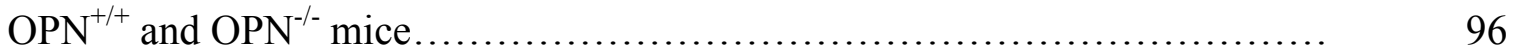

Fig 4.4 Cytokine/chemokine production in peritoneal macrophage and effect of anti-OPN

antibody ...................................................... 97 


\title{
Chapter 1
}

\section{Literature Review: OPN in immune and stress responses}

\begin{abstract}
Recent research has led to a better but as yet incomplete understanding of the complex roles osteopontin plays in mammalian physiology. A soluble protein found in all body fluids, it stimulates signal transduction pathways (via integrins and CD44 variants) similar to those stimulated by components of the extracellular matrix. This appears to promote the survival of cells exposed to potentially lethal insults such as ischemia/reperfusion or physical/chemical trauma. OPN is chemotactic for many immune cell types including macrophages, dendritic cells, and T cells; it enhances B lymphocyte immunoglobulin production and proliferation. In inflammatory situations it stimulates both pro- and anti-inflammatory processes, which on balance can be either beneficial or harmful depending on what other inputs the cell is receiving. OPN influences cell-mediated immunity and has been shown to have Th1-cytokine functions. OPN deficiency is linked to a reduced Th1 immune response in infectious diseases, autoimmunity and delayed type hypersensitivity. OPN's role in the central nervous system and in stress responses has also emerged as an important aspect related to its cytoprotective and immune functions. Evidence suggests that modulating OPN level with either OPN or anti-OPN monoclonal antibodies (depending on the circumstances) might be clinically useful in impacting on the treatment of autoimmune disease, cancer metastasis, and some forms of stress.
\end{abstract}




\subsection{Introduction}

Osteopontin (OPN) is a glycosylated phosphoprotein that is expressed in a variety of tissues and cells and secreted into body fluids. It was originally identified as a bone matrix protein and subsequently identified as a cytokine (Eta-1) produced by activated T cells and transformed cell lines (Patarca et al., 1993; Sodek et al., 2000; Denhardt et al., 2001). Receptors for OPN include certain integrins (O'Regan and Berman, 2000; Yokasaki et al., 2005; El-Tanani et al., 2006) and CD44 variants (Weber et al., 1996; Katagiri et al., 1999; Sodek et al., 2006). These receptors mediate cell adhesion, migration and cell survival in a variety of cell types. OPN's potential to interact with ubiquitously expressed multiple cell surface receptors makes it an active player in many physiological and pathological processes including wound healing, bone formation, tumorigenesis, inflammation, ischemia and immune responses.

In the immune system, OPN is expressed in many different cell types, including macrophages, neutrophils, dendritic cells, NK cells, and T and B lymphocytes as well as in epithelial cells and fibroblast cells; it is up-regulated in response to injury and inflammation or in pathological conditions in every organ examined; for example, cardiac tissue, kidney, lung, bone, brain, the gastrointestinal tract, joints, liver, adipose tissue (Gomez-Ambrosi et al., 2007) and most tumors (Sodek et al., 2006). OPN has been identified as a biomarker for various types of cancers and inflammatory diseases (Rangaswami et al., 2006; Ramaiah and Rittling, 2007). Excessive or dysregulated OPN expression has been linked to the pathogenesis of both autoimmune disorders such as multiple sclerosis (Steinman et al., 2002), systemic lupus erythematosus (Zandman-Goddard and Shoenfeld, 2003), rheumatoid arthritis (Xu et al., 2005), 
atherosclerosis (Ohsuzu, 2004) and other inflammatory diseases including cardiovascular disease (Zhao et al., 2007), chronic obstructive pulmonary disease (Woodruff et al., 2005), inflammatory bowl disease (Gassler et al., 2002), and asthma (Xanthou et al., 2007).

Although initially regarded as an RGD-containing adhesive bone matrix protein due to its presence in the extracellular matrix of mineralized tissues, considerable evidence has established that OPN is also a novel cytokine capable of stimulating signal transduction pathways in many different cell types. Recently, OPN has emerged as a key immune regulator, for example modulating the response of the immune organs (spleen, thymus) to some forms of stress. Deciphering its role in bridging immune system and stress is of great research and therapeutic interest. The purpose of this review is to summarize recent developments in our understanding of OPN's role in immune and stress responses.

\subsection{Structure and Function of Osteopontin}

The structural features and functional motifs of the OPN molecule, illustrated in Fig. 1.1, may provide clues to OPN's broad biological functions. OPN is a highly negatively charged protein that lacks extensive secondary structure. It is encoded by a single gene in a cluster of SIBLING family proteins (Small Integrin Bnding Ligand Nlinked Glycoprotein, though not all are N-linked) located on chromosome 4 in humans (Fisher et al., 2001). Its promoter is responsive to a number of different transcription factors (Denhardt et al., 2003; El-Tanani et al., 2006). With the exception of functionally important cleavage products and occasional splice variants, full-length OPN is composed of some 300 amino acids (297 in mouse; 314 in human). Although 
expressed as a 34-kDa nascent protein, extensive posttranslational modifications increase its apparent MW to about $44 \mathrm{kDa}$; in SDS-PAGE gels it migrates in the range of 50-75 kDa depending on conditions (Sodek et al., 2000). Both highly conserved sequence motifs and post-translational modifications contribute to different functional activities of OPN (Kazanecki et al., 2007a, b).

\subsubsection{Integrins}

As shown in fig. 1.1, located near the center of the OPN protein is an arginineglycine-aspartate (RGD) domain, a motif common to many extracellular matrix proteins and known to engage several integrins. OPN also contains an aspartate-rich region, two heparin-binding sites, a thrombin cleavage site and somewhere near the Cterminus a region that binds certain CD44 variants. Via the RGD sequence, OPN interacts with a variety of cell surface receptors, including the $\alpha_{v} \beta_{1}, \alpha_{v} \beta_{3}, \alpha_{v} \beta_{5}, \alpha_{v} \beta_{6}$, and $\alpha_{5} \beta_{1}$ (O'Regan and Berman, 2000; Yokosaki et al., 2005). A cryptic integrin binding site (SVVYGLR in human, SLAYGLR in mouse) is exposed only after thrombin cleavage between the $\mathrm{L}$ and $\mathrm{R}$ residues; it is important in the regulation of cell adhesion, spreading and migration by promoting the adherence of cells expressing $\alpha 4$ and $\alpha 9$ integrins $\left(\alpha_{9} \beta_{1}, \alpha_{4} \beta_{7}\right)$, which are preferentially expressed by leukocytes and lymphocytes (Helluin et al., 2000; O’Regan \& Berman, 2000; Yokoski et al., 2005). Both intact and the N-terminal fragment of OPN promote leukocyte adhesion to $\alpha_{4} \beta_{1}$. Interestingly, there are two different binding sites for $\alpha_{4} \beta_{1}$ present in a 38-aminoacid domain within the N-terminal thrombin fragment of OPN (Bayless et al., 1998). The 
interaction of OPN with the $\alpha_{8} \beta_{1}$ integrin is necessary for normal kidney morphogenesis (Offner et al., 2006).

\subsubsection{CD44}

OPN interacts with CD44 variants v6 and v7, stimulating (in a human tumor cell) transcription of the CD44 gene and also the abundance of CD44s, v6 and v9 at the cell surface (Khan et al., 2005). The interaction appears to be RGD-independent and to require the presence of $\beta 1$ integrins (Katagiri et al., 1999). The ligation of OPN and CD44 variants mediates chemotaxis and adhesion of fibroblasts, $\mathrm{T}$ cells and bone marrow cells (Weber et al., 1996; Denhardt et al., 2001; Wai and Kuo, 2004). CD44 engagement with OPN down-regulates IL-10 expression in peritoneal macrophages (Ashkar et al., 2000). Furthermore, OPN promotes proliferation and survival of IL-3dependent bone marrow cells; anti-CD44 antibody attenuates these effects (Lin et al., 2000). A C-terminal location has also been suggested as the site of CD44 interaction (Weber et al., 2002; He et al., 2006). A monoclonal antibody recognizing the Cterminal region of OPN blocked the ability of cells to attach to OPN, supporting the possibility that attachment of OPN to CD44 modulates the cells' ability to bind to the RGD binding motif via the RGD sequence (Kazanecki et al., 2007a). Kazanecki and colleagues have hypothesized that a sequence in the $\mathrm{C}$-terminal region forms a $\beta$-sheet structure with the RGDSVVYLGR domain, thereby interfering with the RGD-integrin interaction (Kazanecki et al., 2007a, b). 


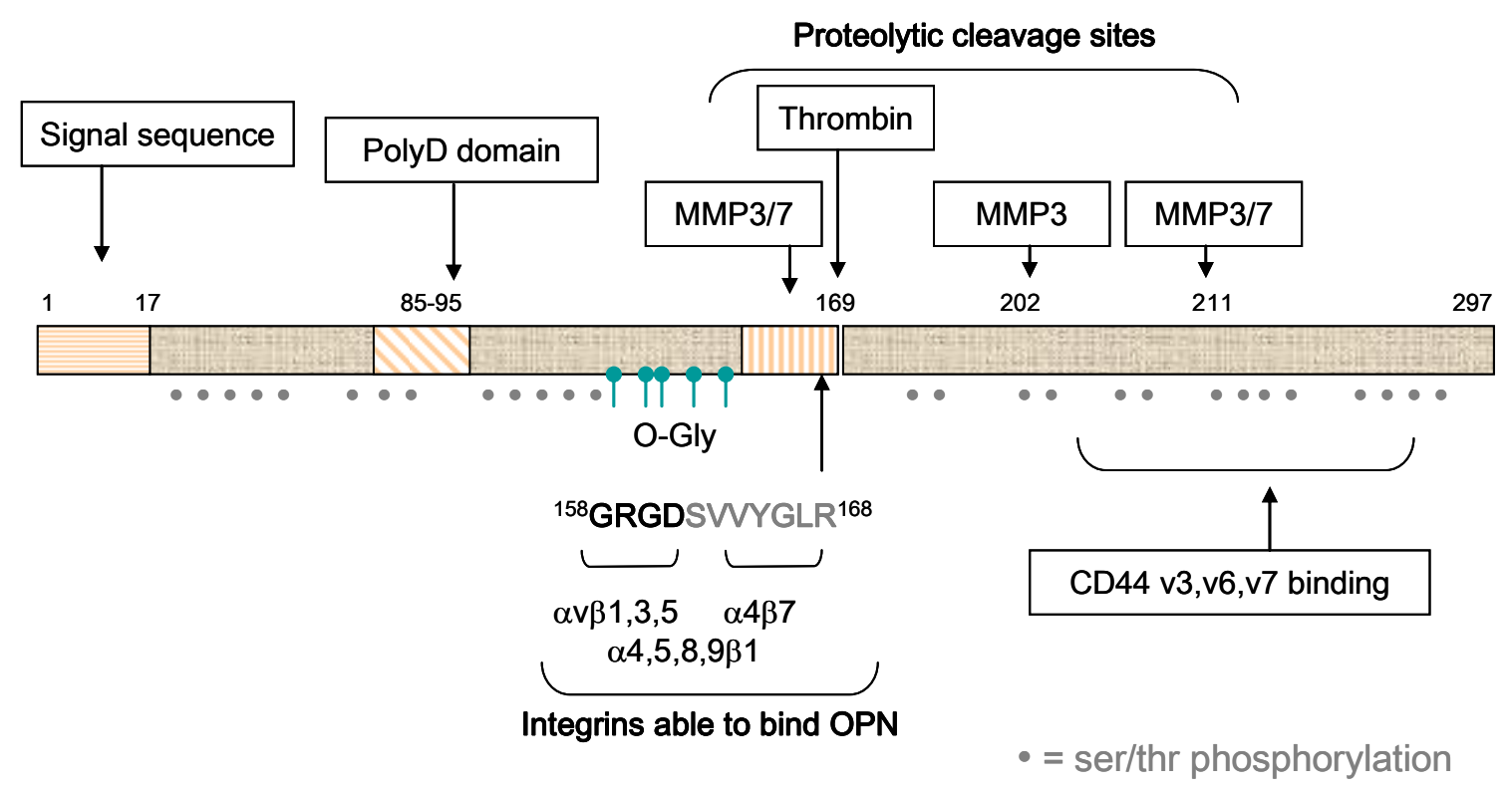

Fig. 1.1. Schematic representation of the structure features of osteopontin. From left to right are indicated: N-terminal sequence regulating OPN secretion cleaved off when the protein is secreted; region rich in aspartate residues responsible for strong binding to hydroxyapatite and makes the protein more acidic; site of O-glycosylation N-terminal to the RGD sequence responsible for integrin interactions; site of cleavage by thrombin immediately C-terminal the YGL sequence; a likely region of interaction with CD44 variants has been reported within the C-terminal portion of the protein; sites susceptible to cleavage by matrix metalloproteinases are noted; gray dots indicated potential regions of serine phosphorylation scattered throughout the protein. 


\subsubsection{Post-translational Modifications (PTM)}

PTMs of OPN influence OPN function (Kazanecki et al., 2007b). The OPN protein is highly modified, including phosphorylation, O-linked glycosylation, sulfation and sialylation. Many sites of PTMs are conserved across species; however the degree of modification of the protein varies depending on the source tissue, and cell type or differentiation stage of the cells. For example, both bovine and human milk OPN have a large number of phosphorylated serine residues (28 and 32 respectively, mostly in motifs implicating casein kinase 2). These are located in clusters of 3-5 sites and these sites are absent from the RGD region as well as from the glycosylated region (Christensen et al., 2005; 2007). In contrast, rat bone OPN (at least as isolated) contains only 10-11 phosphorylated residues (Keykhosravani et al., 2005). The sites of OPN phosphorylation are heterogeneous, and it is not known whether certain specific sites are critical. That said, phosphorylation of OPN appears necessary for various physiological functions, including migration of cancer cells (Al-Shami et al., 2005), adhesion and bone resorption by osteoclasts (Razzouk et al., 2002), inhibition of smooth muscle cell calcification (Jono et al., 2000) and regulation of mineralization (Gericke et al., 2005). Whether the PTMs play a role in immune cell function is yet to be discovered.

\subsubsection{Intracellular OPN}

An intracellular form of OPN (iOPN possibly the consequence of translation initiation downstream of the usual start site) exists as an integral component of a CD44ezrin/radixin/moesin attachment complex on the inner surface of the plasma membrane; 
it is involved in the migration of embryonic fibroblasts, activated macrophages, and metastatic cells (Zohar et al., 2000, 2004). In association with the CD44 receptor inside migratory cells, iOPN modulates cytoskeleton-related functions including cell motility, cell fusion and survival (Suzuki et al., 2002; Zohar et al., 2004). The interaction of iOPN with CD44 presumably involves a constant intracellular domain in contrast with the interaction of sOPN (secreted OPN) with extracellular variant domains of CD44v. Recent findings have revealed that iOPN also mediates IFN- $\alpha$ expression in plasmacytoid dendritic cells by selectively coupling TLR9 signaling to expression of IFN- $\alpha$ (Shinohara et al., 2006). This indicates that intracellular and secreted OPN may differentially regulate signaling pathways in different cell lineage to influence the type and intensity of immune responses.

\subsubsection{OPN and Apoptosis}

Apoptosis plays an important role in immune cell development and function. Deregulation of apoptosis in the immune system results in autoimmunity, tumorigenesis and immunodeficiency. OPN has long been regarded as a survival factor, in part by inhibiting apoptosis induced by a pathological event, growth factor deprivation for example (Khan et al., 2002). It has been demonstrated that OPN is an important anti-apoptotic factor in many circumstances; for example, OPN promotes cancer cell metastasis due to its anti-apoptotic properties that prevent programmed cell

death and allows uncontrolled proliferation of tumor cells (Hsieh et al., 2006). OPN has also been found to block the activation-induced cell death of macrophage and $\mathrm{T}$ lymphocyte as well as fibroblasts and endothelial cells exposed to harmful stimuli 
(Denhardt et al., 2001; Standal et al., 2004). OPN has been shown to suppress monocyte recirculation and apoptosis in the brain in neuroAIDS (Burdo et al., 2007). Interestingly, OPN appears to increase the survival of cardiac fibroblasts exposed to $\mathrm{H}_{2} \mathrm{O}_{2}$ and undergoing a caspase-3-independent form of necrosis (Zohar et al., 2004). OPN prevention of non-programmed cell death was also observed in inflammatory colitis (Da Silva et al., 2006). Evidently, OPN may foster cell survival in a variety of contexts; for example, cancer metastasis, immune system stress, ischemia-reperfusion, and in some brain pathologies. However, the detailed pathways and mechanisms remain to be elucidated.

\subsubsection{Signaling Pathways}

OPN signaling through the $\alpha v \beta 3$ integrin can modulate (via activation of ras and src) the phosphorylation of kinases (NIK, IKK $\beta$ ) involved in NFkB activation (Rice et al, 2006, Scatena et al., 1998); this results in the degradation of IкB, an inhibitor of NFkB (Vejda et al., 2005). NFkB regulates expression of many inflammatory cytokines. Consequently, OPN may lead to an uncontrolled immune response, and the absence of OPN may be associated with diminished cytokine functionality. One possible pathway for OPN-mediated cell survival is through the PI3k /Akt signaling cascade. OPN is a downstream effector of phosphatidylinositol 3kinase/Akt pathway identified through genetic profiling, which revealed an inverse correlation with the effect of the PI3K/Akt antagonist PTEN (Packer et al., 2006). OPN signaling through CD44 engagement also can promote cell survival by activating the PI3K/Akt pathway (Lin and Yang-Yen, 2001). Intracellular OPN is found to be 
localized together with MyD88 and TLR9 complex near the inner surface of the cytoplasmic membrane. It activates nuclear translocation of transcription factor IRF7 to induce robust IFN- $\alpha$ production. Pathways for OPN signaling are depicted in Fig. 1.2. The OPN promoter can be activated by TGF- $\beta$ through Smad signaling pathways (Hullinger et al., 2001). An activator protein-1 (AP-1) consensus site in the OPN promoter has been identified that supports OPN transcription in macrophages (Ogawa et al., 2005). Liver X receptor agonists inhibit cytokine-induced OPN expression in macrophages through interference with AP-1 signaling pathways. AP-1 regulation is further demonstrated in that OPN transcription is suppressed by PPAR- $\alpha$ agonist through repression of AP-1-dependent transactivation of the OPN promoter (Nakamachi et al., 2007). 


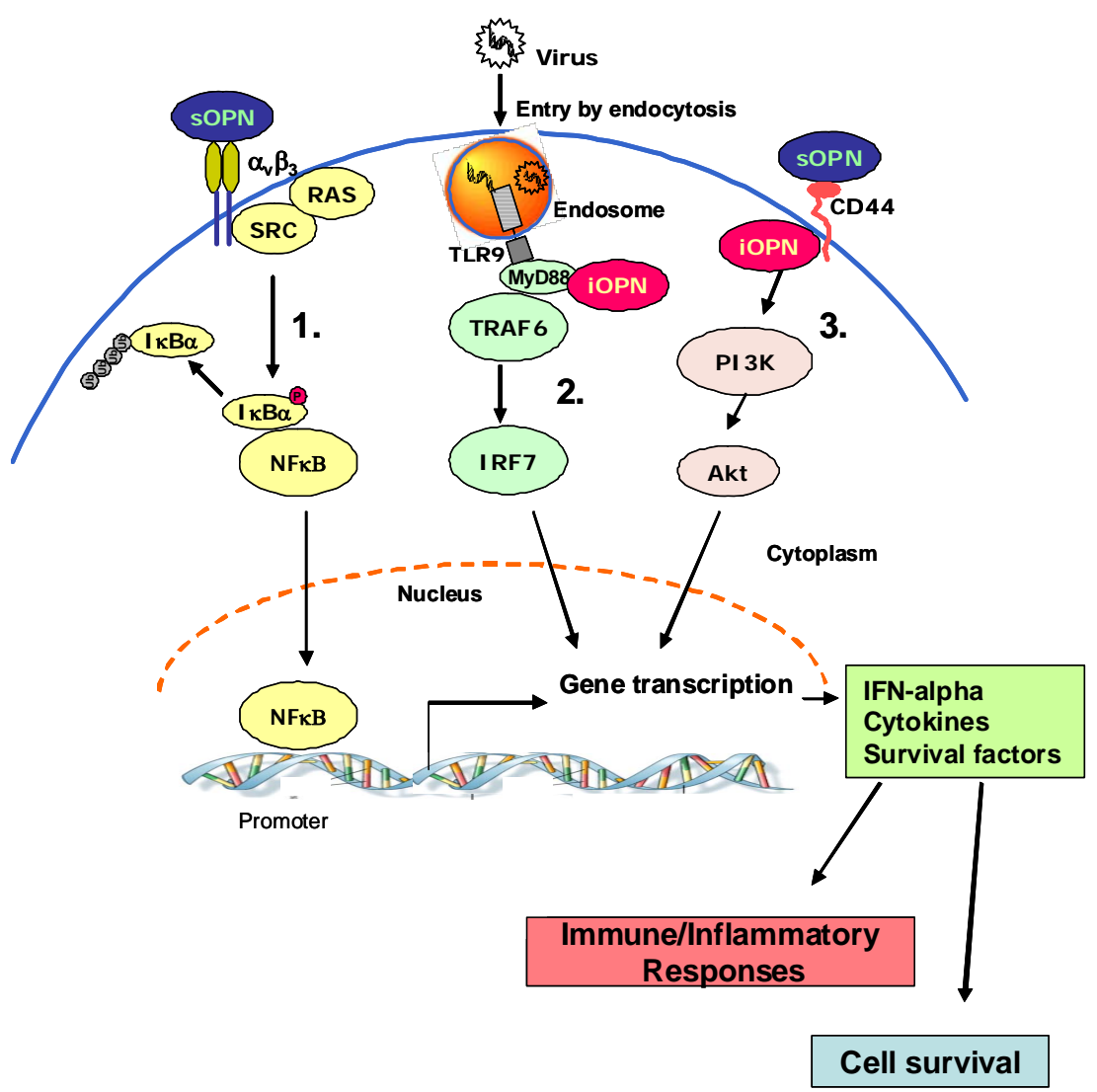

Fig. 1.2 OPN interacts with different signaling pathways to mediate immune

responses. 1. Engagement of OPN (sOPN in blue) to integrin $\alpha v \beta 3$ signal through SRC and RAS tyrosine kinase to activate transcription factor NFאB. OPN promotes

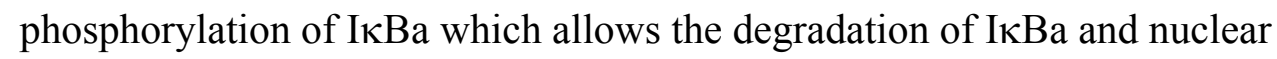
translocation of NFאB which regulates a variety of pro-inflammatory cytokines and mediators transcription. 2. In plasmacytoid DC, intracellular OPN (iOPN in red) is associated with MyD88 during TLR engagement with viral DNA in the endosome and promoting TLR9 signaling toward IRF7 rather than IRF-5/NFאB, which would allow for robust IFN- $\alpha$ production. 3. OPN interaction with CD44 activates PI3K/Akt signaling pathway which mediate cell survival. 


\subsection{OPN and Innate Immunity}

Most infectious agents induce inflammatory responses by activating innate immunity in processes often involving macrophages and neutrophils. These cells are the professional phagocytes that provide the first line of defense of the immune system. Epithelial damage causes release of the cytokines IL-1 and IL-8, which recruit macrophages and neutrophils to the site. Macrophages express toll-like receptors that recognize pathogen-associated molecular patterns (PAMPs) and engulf the pathogen, leading to the secretion of cytokines/chemokines that attract cells such as neutrophils and monocytes to sites of injury or infection. OPN's role in innate immunity is reflected in its protective function in infectious diseases. It contributes to the mucosal defense against viral pathogens. Significant up-regulation of OPN mRNA in murine intestine and epithelial cells was observed in rotavirus infection, and the disease was protracted in OPN-deficient mice (Rollo et al., 2005). Likewise, OPN-deficient mice are impaired in their ability to clear L. monocytogenes after systemic infection (Ashkar et al., 2000). Fig. 1.3 illustrates aspects of the involvement of OPN in immune phenomena. 


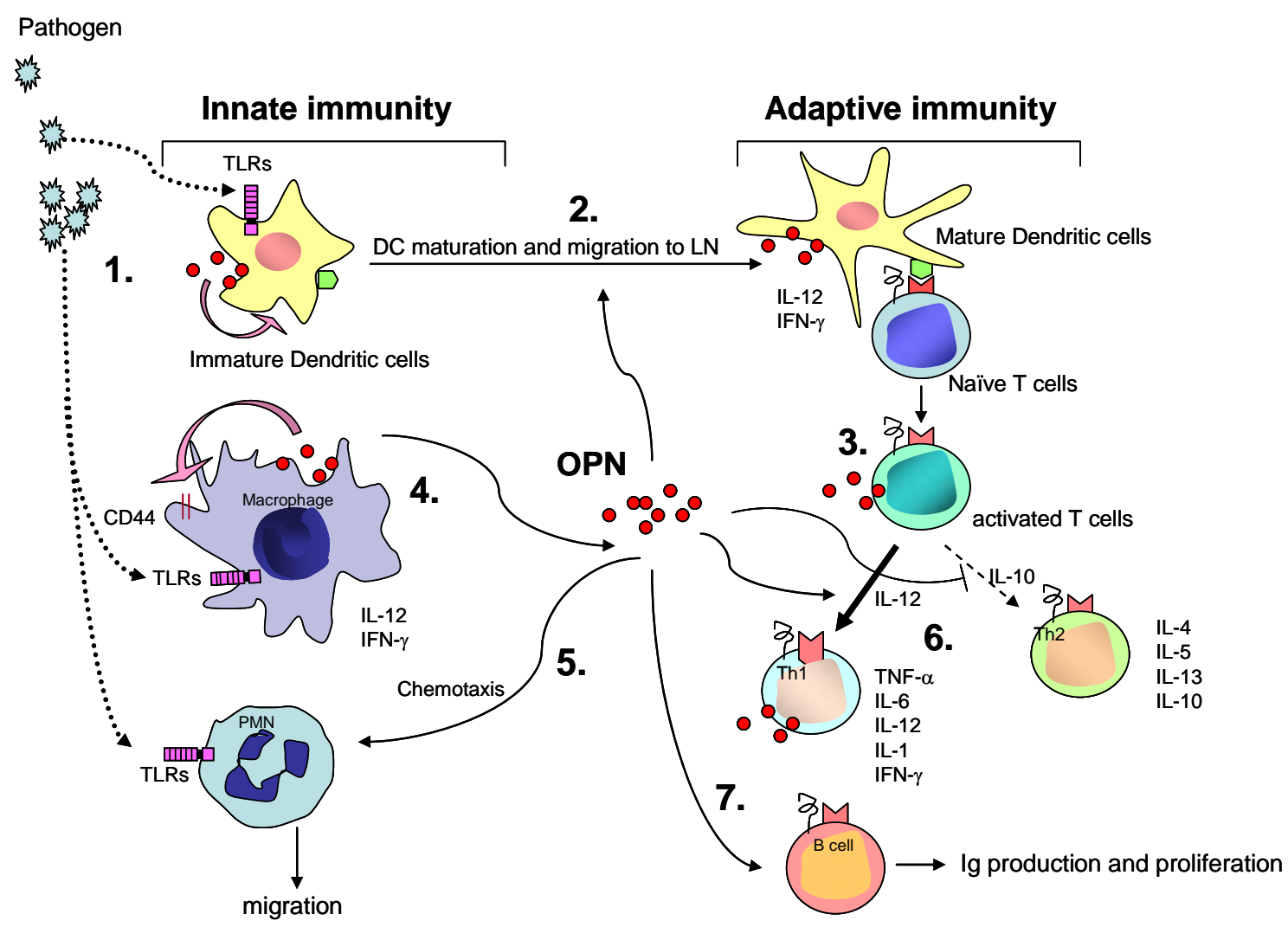

Fig. 1. 3. Regulation of innate and adaptive immunity by OPN. 1. Exogenous pathogens activate TLRs on the surface of cells, including macrophages, neutrophils and immature dendritic cells. OPN is secreted by macrophages and dendritic cells when challenged by antigens and enhances the activation and functions of these cells. OPN promotes neutrophil migration towards the site of injury, although there is no strong evidence showing production of OPN in the neutrophils. 2. Secretion of OPN promotes immature dendritic cells to mature and migrate to draining lymph nodes, where they present processed antigens through $\mathrm{MHC}$ molecules to naïve $\mathrm{T}$ cells and initiate a cellmediated immune response. 3. Signals from DCs activate naïve T cells and determine the polarization of T cells to Th1 or Th2 type cytokine responses. 4. Macrophage produce large amounts of OPN, which in an autocrine/paracrine manner contributes to 
the migration of macrophages and the expression of the pro-inflammatory cytokine IL12. 5. OPN produced by various immune cells at the inflammatory sites promotes infiltration of neutrophils. 6. Activated T cells are promoted by IL-12 to differentiate towards the Th1 type that produce Th1 cytokines. OPN inhibits Th2 cytokine IL-10 production, which leads to an enhanced Th1 response. 7. OPN promotes B lymphocyte proliferation and immunoglobulin production.

\subsubsection{Macrophages}

Monocytes express a low level of OPN, but as they differentiate into macrophages OPN expression is increased; it becomes constitutively expressed in macrophages and can be further up-regulated by LPS stimulation (Gao et al., 2004). OPN has been shown to regulate macrophage functions including migration (Zhu et al., 2004), activation (Rollo and Denhardt, 1996), phagocytosis (McKee and Nanci, 1996), pro-inflammatory cytokine production (Koguchi et al., 2002) and nitric oxide synthesis (Scott et al., 1998) in response to various inflammatory challenges. In the absence of OPN expression, macrophage migration and cytokine production are impaired (Zhu et al., 2004; Sodek et al., 2006). Zhu et al. (2004) showed that in macrophages OPN both regulates the distribution of CD44 and, as iOPN, co-localizes with CD44 at the inner surface of the plasma membrane. OPN-deficient macrophages have a more diffuse distribution of CD44, suggesting that CD44 cooperates with OPN in regulating macrophage migration. At sites of tissue injury, OPN produced by macrophages fosters cell adhesion and may act as an opsonin facilitating phagocytosis of foreign bodies (McKee and Nanci, 1996). It has been demonstrated that, in macrophages, a 
phosphorylation-dependent interaction between the amino-terminal portion of OPN and its integrin receptor stimulated IL-12 expression, whereas a phosphorylationindependent interaction with CD44 inhibited IL-10 expression (Ashkar et al., 2000). The implication is that the interaction of OPN with integrins and CD44(v) stimulates via different signal transduction pathways distinct patterns of cytokine/chemokine expression and the specific type of immune response.

\subsubsection{Neutrophils}

In contrast to macrophages, few studies have reported on OPN expression by neutrophils. Neutrophils (the majority of PMNs) are the primary responder to exogenous and endogenous stimuli and rapidly infiltrate the injured tissue to initiate an innate host defense. OPN is a chemoattractant for neutrophils (Weiss et al., 2001; Banerjee et al., 2006; Koh et al., 2007). Activated neutrophils release proteases and cytotoxic mediators in combination with phagocytosis and respiratory bursts to eliminate invading infectious agents. However, cytotoxic products released by neutrophils may also cause host tissue destruction such as observed in inflammatory bowel disease (Da Silva et al., 2006). OPN has been found to play an important role in neutrophil recruitment in alcoholic liver disease (Apte et al., 2005; Banerjee et al., 2006). The expression and localization of CD44 in neutrophils is independent of OPN, although CD44 is required for the polarization and chemotaxis of neutrophils (Alstergren et al., 2004). Koh et al. (2007) have demonstrated that OPN is important for the migration of neutrophils in vitro. They have also shown OPN-null mice are impaired in their ability to recruit PMN in vivo; however, OPN does not appear to be 
involved in neutrophil activities such as phagocytosis, superoxide release, or the production of cytokines and proteases.

\subsubsection{Dendritic Cells (DC)}

DCs are a unique immune cell population that functions as a link between innate and adaptive immunity. They function as effector cells in the innate immune system to provide the first line of defense by non-specifically recognizing invading pathogens. Through maturation and migration from the sites of infection towards secondary lymphoid organs, they turn into professional antigen-presenting cells to induce antigenspecific T cell activation. OPN is highly expressed in immature DCs but production decreases during maturation (Kawamura et al., 2005). This research demonstrated that OPN acts in an autocrine and/or paracrine manner to induce DC maturation because treatment with an anti-OPN antibody blocked LPS-induced human DC maturation. As it is for other inflammatory cells, OPN is a survival factor for dendritic cells. Blockade of OPN with anti-OPN antibody reduces co-stimulatory molecule and class II molecule expression on human monocyte-derived DCs and promotes apoptosis of mature DCs (Kawamura et al., 2005). OPN was implicated in DC migration in research demonstrating that OPN initiates Langerhans cells/dendritic cell emigration from the epidermis and attracts them to draining lymph nodes by interacting with CD44 and $\alpha_{\mathrm{v}}$ integrin (Weiss et al., 2001). OPN-deficient mice have shown a significantly reduced contact hypersensitivity reaction possibly due to an impaired ability to attract Langerhans cells/DCs to draining lymph nodes. OPN-activated DCs produce IL-12 and TNF- $\alpha$, and when incubated with naïve T cells, can induce naïve T cells into Th1- 
polarizing, IFN- $\gamma$-producing T cells (Renkl et al., 2005). OPN's presence in T cell-DC interaction may decisively influence T-cell polarization. This concept is emphasized by the deficiency of Th1 immunity in OPN-deficient mice, which leads to a compromised host defense against bacterial and viral infections (Rollo et al., 2005, Koguchi et al., 2002) and ameliorated autoimmunity (Chabas et al., 2001).

\subsection{OPN and Cell-mediated Immunity}

\subsubsection{Lymphocyte functions}

Elevated OPN expression is found in various immunological disorders. Upregulation of OPN is implicated in the formation of granulomas in tuberculosis, sarcoidosis and silicosis, all of which involve cell-mediated immune reactions (O’Regan et al., 2000, Nau et al., 1997). Studies of OPN ${ }^{-/-}$mice revealed that OPN's main immune-modulatory function is the enhancement of Th1 over Th2 immunity through two general mechanisms: regulation of cytokine production via 1) interaction with the $\alpha_{\mathrm{v}} \beta_{3}$ integrin to induce pro-inflammatory IL-12 and 2) ligation of CD44v to suppress anti-inflammatory cytokine IL-10 production (Ashkar et al., 2000). Autocrine amplification of cytokine production and cross-inhibition ensure progressive polarization of the T-helper cells towards either Th1 or Th2 cells (Abbas et al., 1996).

OPN is produced by activated T cells and is classified as a Th1 cytokine because it modulates cell-mediated immunity by promoting the Th1 response. In CD4 ${ }^{+}$ T-cells, OPN mRNA is expressed in Th1, but not Th2, polarized cells (Nagai et al., 2001). Moreover, soluble OPN may modulate the differentiation and proliferation of $\mathrm{CD}^{+}$and $\mathrm{CD}^{+} \mathrm{T}$ cells (Higuchi et al., 2004). Shinohara et al. (2005) reported that OPN gene expression in activated T cells, but not macrophages, is regulated by T-bet, a 
transcription factor that controls $\mathrm{CD} 4^{+} \mathrm{Th} 1$ cell lineage commitment. T-bet-dependent expression of OPN in $\mathrm{T}$ cells is essential for efficient skewing of $\mathrm{CD} 4^{+} \mathrm{T}$ and $\mathrm{CD} 8^{+} \mathrm{T}$ cells toward the Th1 and type $1 \mathrm{CD} 8^{+} \mathrm{T}$ cells $(\mathrm{Tc} 1)$ pathway. OPN can also stimulate human peripheral blood T cells to express IFN- $\gamma$ and CD40L, which subsequently induce IL-12 expression from monocytes; enhanced expression of CD40L by T cells may explain the ability of OPN to induce B-cell proliferation and antibody production (O'Regan et al., 2000). At low concentrations, OPN promotes chemotaxis but not chemokinesis of T cells, while activated T-cell adhesion is enhanced at high OPN concentrations, especially following cleavage of OPN by thrombin (O'Regan et al., 1999). The formation of granulation tissue and the intensity of inflammatory reactions are dramatically reduced in the absence of OPN expression (O'Regan et al., 2001). Recent evidence indicates that plasma OPN levels increase in active Crohn's disease compared with quiescent disease and decline after treatment with the anti-TNF- $\alpha$ monoclonal antibody infliximab (Agnholt et al., 2007). Furthermore, OPN regulates cell-mediated immunity by promoting $\mathrm{T}$ cell proliferation and migration as demonstrated in transgenic mice over-expressing OPN; these mice also exhibited an increase in the percentage of $\mathrm{CD}^{+} \mathrm{T}$ cells in lymph nodes (Higuchi et al., 2004). Upon stimulation with 2, 4-dinitrofluorobenzene, (DNFB, a substance that evokes delayedtype hypersensitivity in mice) increased $\mathrm{CD} 8^{+} \mathrm{T}$ cell infiltration and enhanced contact hypersensitivity were observed in the OPN transgenic mice. 


\subsubsection{Dual Eeffects}

While OPN is generally classified as a pro-inflammatory cytokine, it appears to have anti-inflammatory effects in certain pathological contexts. The multifunctional nature of OPN may reflect expression of specific isoforms, levels or timing of production and tissue distribution. On the cellular level, the increase of OPN was inversely correlated with in vitro T-cell IL-10 production. OPN's reciprocal effects on IL-12 and IL-10 expression result in a two-phase action in regulating immune responses in several immune disorders (Xanthou et al., 2007, Weber and Cantor, 2001, Hur et al., 2007). A two-phase role of OPN in immune regulation has been revealed in several studies exploring OPN's action in various immune diseases. In airway inflammatory responses, the secreted form of OPN is pro-inflammatory during primary systemic sensitization mediated by Th2-suppressing plasmacytoid DCs and antiinflammatory during secondary antigenic challenge mediated by Th2-promoting conventional DCs (Xanthou et al., 2007). Evidently, OPN can influence DCs towards either a pro-inflammatory stance or an anti-inflammatory stance through interaction with different cell surface receptors, presumably integrins and CD44(v). Both extracellular and intracellular OPN may impact on DC functions in ways that are crucial in determining the outcome of adaptive immunity.

Dual effects of OPN in colitis have been reported. Crohn's disease is characterized as a Th1-directed immune response with increased $\mathrm{CD} 4^{+} \mathrm{T}$ cell production of IFN- $\gamma$ and activation of macrophages that secrete TNF- $\alpha$ and IL-12. In contrast, ulcerative colitis is associated with an atypical Th2 response mediated by a distinct subset of NKT cells that produce IL-13 and are cytotoxic for epithelial cells. 
Compared to control mice, $\mathrm{OPN}^{-/ 2}$ mice are more susceptible to acute colitis but resistant to chronic colitis. OPN plasma concentrations correlate with the severity of Crohn's disease, consistent with a role for OPN in Th1-mediated immune responses (Sato et al., 2005). OPN is anti-inflammatory in the acute phase but pro-inflammatory in the chronic phase of colitis. The detrimental effects of OPN associated with a protracted Th1 immune response contrasts with the protective effects as shown in dextran sodium sulfate-induced colitis in $\mathrm{OPN}^{-/ 2}$ mice, which show an exacerbated disease (Da Silva et al., 2006).

\subsubsection{NKT Cells}

NKT cells are a unique subset of T cells that express both $\mathrm{T}$ cell receptor (TCR) and NK1.1 cell surface marker for NK cells. NKT cells are essential not only for defense against pathogens but also for the initiation of adaptive immune responses and in regulating autoimmune responses (Miyake et al., 2007). Diao et al. (2004) showed that OPN is secreted by NKT and augments NKT cell activation, triggering neutrophil infiltration and activation. Both OPN-null mice and NKT-deficient mice are resistant to Concanavalin A-induced hepatitis. Furthermore, a neutralizing antibody specific for a cryptic integrin-binding epitope of OPN exposed by thrombin cleavage ameliorated hepatitis, indicating that the thrombin-cleaved form of OPN is involved in inflammatory process through NKT cells and neutrophil infiltration and leads to tissue damage in Con-A-induced hepatitis. 


\subsubsection{Autoimmunity}

Many inflammatory autoimmune diseases are thought to be mediated by Th1 immune responses (Kitamura et al., 2007). Th1 immunity can lead to autoimmunity towards self-antigens. It has been suggested that OPN is an autoantigen for certain autoimmune diseases such as osteoarthritis and rheumatoid arthritis (Sakata et al., 2001; Du et al., 2005). As demonstrated in the collagen-induced arthritis model of rheumatoid arthritis documented by Yamamoto et al. (Sakata et al., 2001, Du et al., 2005), OPN recruits inflammatory cells to arthritic joints. The levels of thrombincleaved OPN are significantly increased in the plasma and synovial fluid of rheumatoid arthritis patients compared with plasma from healthy controls and from patients with osteoarthritis; this may be important in that the cleaved OPN is able to engage additional integrins (Yamamoto et al., 2007). Interestingly, splenic monocytes expressing $\alpha 4$ and $\alpha 9$ integrins from arthritic mice demonstrated enhanced migration toward thrombin-cleaved OPN compared with splenic monocytes from non-arthritic mice. Furthermore, treatment of arthritic mice with an antibody (M5 Ab) directed against the sequence SLAYGLR, exposed by thrombin cleavage of murine OPN, inhibited synovitis and inflammatory cell infiltration into the joints of treated mice compared with those of arthritic control mice.

OPN's association with multiple sclerosis has been studied intensely. OPN has been identified as the most prominent cytokine expressed within MS lesions. The plaques found in human multiple sclerosis patients have a 5-fold increase in OPN transcripts (Chabas et al., 2001). Significantly increased OPN protein levels were found in the plasma of relapsing-remitting MS patients whereas the OPN protein levels in 
primary progressive and secondary progressive MS patients were similar to healthy control levels (Vogt et al., 2003).

In the mouse experimental allergic encephalomyelitis (EAE) model, administration of OPN to $\mathrm{OPN}^{-/-}$mice induced recurrent relapses, worsening paralysis and neurological deficits. Reactive astrocytes as well as inflammatory cells are major sources of OPN in rat EAE and their effect seems to be mediated by CD44 (Kim et al., 2004). It has been suggested that the mechanism of action of OPN involves promoting the survival of activated myelin-reactive T-cells which leads to relapse and progression of MS (Hur et al., 2007). Increased levels of OPN transcripts were reported in both the brain tissue of MS patients and the spinal cords of an EAE rat model (Chabas et al., 2001). In contrast, in autoimmune myocarditis it appears that neither OPN nor CD44 play any role in the development of the disease (Vogt et al., 2003).

Highly elevated expression of OPN at the site of disease and in plasma is observed in autoimmune diseases. Importantly, the resistance to spontaneous remission (clinical relapse) and the attenuated disease phenotype in $\mathrm{OPN}^{-/-}$mice, suggests a role for OPN as a potentially critical factor in the pathogenesis of autoimmunity. OPN deficiency is linked to a reduced Th1 immune response in autoimmunity. The OPN ${ }^{-/-}$ mice are resistant to progressive EAE and had less frequent remissions (Jansson et al., 2002). Additionally, $\mathrm{OPN}^{-/-}$mice show milder progression of experimental autoimmune uveoretinitis (Kitamura et al., 2007). Polymorphisms in the gene encoding OPN have been linked to the development of systemic lupus erythematosus and multiple sclerosis (D’Alfonso et al., 2005; Niino et al., 2003). OPN plays a two-phased-role in lupus. Early in the disease, OPN mediates the pathology by inducing polyclonal B cell 
activation and isotype switching (Lampe et al., 1991, Iizuka et al., 1998) that substantially elevate $\operatorname{IgG}, \operatorname{IgM}$ and $\operatorname{Ig}$ A levels. During the late phase, lupus is characterized by Th2 cytokine-induced pathogenic autoantibody production. OPN limits the further exacerbation by inhibiting Th2-induced IL-10/IL-4 production (Weber and Cantor, 2001).

\subsubsection{Controversy about OPN’s Effects}

Although there is mounting evidence demonstrating OPN's impact on Th1 immunity against viral, bacterial and self-antigens, contradictory reports on the role of OPN have been reported. Elevation of OPN levels is believed to contribute to mononuclear cell infiltration and renal injury in murine anti-glomerular basement membrane nephritis; however it does not significantly contribute to the glomerular and tubulointerstitial mononuclear cell infiltration in an in vivo murine model of glomerulonephritis (Bonvini et al., 2000). OPN has been found to suppress bacterial antigen-specific T cell proliferation and DC migration when OPN is supplied together with heat-killed Listeria monocytogenes (Begum et al., 2007). In another study, when $\mathrm{OPN}^{-/-}$mice were analyzed after influenza infection in the lung, viral clearance, lung inflammation, and recruitment of effector $\mathrm{T}$ cells to the lung were comparable to $\mathrm{OPN}^{+/+}$mice (Abel et al., 2005). These discrepancies may be due to variations in the genetic background of knockout mice used in different studies or to the pleiotropic nature of OPN, which can interact with multiple receptors, activating different and sometimes conflicting, pathways. 


\subsection{OPN and Stress}

Depending on the duration, stress can be immuno-enhancing or immuno-suppressive. An acute stress (minutes up to hours) can enhance the immune system and tend to induce leukocyte redistribution and augment immune functions in response to the injury (Viswanathan et al., 2005) whereas chronic stress (days and months) suppresses immunity and leads to increased susceptibility to disease. This bidirectional effect is believed to be mediated by stress-induced glucocorticoid hormones that are produced by the adrenal gland (Dhabhar and McEwen, 1999). Stress hormones also influence immune response by regulating the Th1/Th2 cytokine balance and thereby affecting disease susceptibility, activity and outcome (Calcagni and Elenkov, 2006). As an important cytokine regulating Th1/Th2 in immune responses, OPN is up-regulated in various stress situations and its connection to stress hormones has recently been explored.

It is well documented that OPN plays a critical role in bone remodeling caused by mechanical stress (Denhardt and Noda, 1998, Terai et al., 1999, Nomura and Takano-Yamamoto, 2000). Mechanical stress causes the deformation of bone matrix and generates strain forces which lead to bone remodeling. Present in the bone matrix, OPN is required for stress-induced bone remodeling, at least in part because it is necessary for efficient osteoclast action; it also prevents bone marrow cell differentiation into osteoblasts and osteoclasts (Ishijima et al., 2001, 2007). Ishijima et al (2006) conducted microarray analyses that revealed, in comparison with wild type controls, that expression of $\mathrm{NF \kappa B}$ and $\mathrm{p} 53$ were reduced whereas the expression of the apoptosis-related gene BAX was enhanced in mice lacking OPN and subjected to hind- 
limb unloading. These data indicate that OPN acts to mediate mechanical stress signaling upstream to the genes encoding apoptosis-related molecules, and its action is associated with alteration of gene expression (Ishijima et al., 2006). In cardiovascular injury, OPN is up-regulated as a result of both mechanical and oxidative stress caused by reperfusion.

In recent years, the role of OPN in other forms of stress such as oxidative and physical stress has been explored as the participation of OPN in various physiological processes expanded from predominantly bone matrix-related functions to a wider area associated with immune regulation, tumorigenesis, autoimmune disease and cell survival (Itoh et al., 2005; Gross et al., 2005; Cao et al., 2007; Wang et al., 2007). That OPN expression is frequently up-regulated in response to various stressors suggests that it mediates the response of the cell or organism to the pertinent stress.

OPN expression is highly up-regulated in alveolar macrophages of chronic obstructive pulmonary disease patients that have the highest differential expression in smokers vs. nonsmokers ( $>5$ fold) (Heguy et al., 2005). Along with other inflammatory cytokines, OPN levels are increased in the bronchoalveolar lavage fluid of rats after exposure to fine particles (Cao et al., 2007). A connection between stress and immune function has been demonstrated in various experimental paradigms (Nieman and Pedersen, 1999). Stress can either enhance or impair immune system function depending on its type and duration. Stress hormones such as cortisol play a pivotal role in modulating pro/anti-inflammatory responses and the $\mathrm{TH} 1 / \mathrm{Th} 2$ cytokine balance, thereby influencing the susceptibility to and outcome of various immune-related diseases (Calcagni and Elenkov, 2006). While chronic stress is immunosuppressive and 
leads to increased vulnerability to infections and cancer, acute stress promotes immunoprotection through cell-mediated immunity (Dhabhar et al., 2000, Viswanathan et al., 2005).

Recently, using $\mathrm{OPN}^{-/-}$and $\mathrm{OPN}^{+/+}$mice to study the consequence of OPN deficiency in the response of the mice to chronic stress-induced by hind-limb unloading (HU), we reported that OPN is required for immune organ atrophy and weight loss in mice subjected to HU by modulating stress induced production of corticosteroid (Wang et al., 2007). Corticosterone levels are consistently higher in OPN-deficient mice indicating that dysregulation of corticosterone production is linked to OPN deficiency. It has been demonstrated that corticosterone enhances delayed type hypersensitivity (DTH) at low doses but suppresses DTH at high dose or chronic administration (Dhabhar and McEwen, 1999). The relationship between corticosteroid and OPN revealed by this study leads to the speculation that OPN controls corticosteroid levels and that increased OPN levels suppress production of corticosteroid, thereby enhancing cell-mediated immune functions such as DTH. In contrast, lack of OPN causes disregulated corticosteroid production, leading to a suppressed cell mediated immune response (Figure 3). These observations suggest that OPN may function as a regulator in the central nervous system to control steroid hormone production.

OPN has been found in both central nervous system and peripheral nervous system (Shin et al., 1999; Ichikawa et al., 2000). OPN expression is up-regulated in CNS injury or neuronal damage. OPN is present in the rat substantia nigra and both protein and mRNA levels are up-regulated following a pro-inflammatory insult produced by lipopolysaccharide (Iczkiewicz et al., 2006). Immunocytochemical 
localization of OPN in the cytoplasm of pyramidal neurons has been reported in the Alzheimer's disease brain (Wung et al., 2007). An increase in OPN protein and mRNA expression induced by toxic injury or mechanical stress induced nigral dopaminergic cell loss in parallel with the increase of ED1-positive macrophages in Parkinson's disease (Iczkiewicz et al., 2007). The pathogenesis of Parkinson's disease involves processes such as oxidative and nitrosative stress, apoptosis, mitochondrial dysfunction, and excitotoxicity, in all of which OPN may play a role. It was suggested that OPN is involved in Parkinson's-associated neurodegeneration because OPN is elevated in Parkinson's disease and its absence leads to reduced neurodegeneration in the MPTP model (Maetzler et al., 2007).

\subsection{Conclusions}

In the immune system, OPN is expressed by various immune cells at various differentiation stages and activation states; it modulates immune responses at several levels. First, its chemotactic property promotes cell recruitment to sites of inflammation. Second, it functions as an adhesion protein facilitating cell attachment and wound healing. Third, it mediates cell activation and cytokine production through interaction with cellular signaling pathways, and fourth, it promotes cell survival by regulation of specific programmed-cell-death pathways. OPN's involvement with these tightly regulated activities makes it very challenging to define the precise mechanism of its action. The discovery of the role OPN plays in mediating stress responses further broadens the horizon of OPN's function. The thrust of the studies summarized above lead to the hypothesis that in certain specific situations treatment of the human disease 
with OPN, or an antibody to OPN, may be clinically useful (Steinman et al., 2002; Yamamoto et al., 2007). Future work will expand on these exciting developments in our understanding of OPN and its role in orchestrating the immune system and stress responses. 


\section{Chapter 2}

\section{Osteopontin Regulates Hindlimb-unloading induced Weight Loss and Lymphoid Organ Atrophy by Modulating Corticosteroid Production}

\subsection{Introduction}

Osteopontin (OPN) is a multifunctional protein that is involved in both cell adhesion and cell signaling via its interactions with certain integrins and CD44 variants. Its ability to interact with ubiquitously expressed multiple cell surface receptors makes it an active player in many physiological and pathological processes, including tissue remodeling and cell survival (Denhardt et al., 2001; Sodek et al., 2006). OPN has been identified as a major factor in the regulation of immune responses and inflammation; its expression is up-regulated in activated T cells, macrophages and NK cells (O'Regan and Berman, 2000; Shinohara et al., 2005). It is classified as a Th1 cytokine because it enhances production of the Th1 cytokines IFN- $\gamma$ and IL-12 and inhibits production of the Th2 cytokine IL-10 by macrophages (Ashkar et al., 2000; Renkl et al., 2005). The roles that OPN plays in mammalian systems physiology are diverse. Although it is a pro-inflammatory cytokine associated with autoimmune diseases, the Th1 inflammatory response, B cell function, and NKT cell function, it also has antiinflammatory functions, such as inhibiting the induction of nitric oxide synthase and inhibiting the production of Th2 cytokines (Hwang et al., 1994; Hur et al., 2007). Its up-regulation is a hallmark for many major pathological disorders such as cardiovascular disease, cancer and lung disease (Singh et al., 2007; O'Regan, 2003). 
OPN expression is increased in response to various stressors, including mechanical and oxidative stress (Gross et al., 2005; Maetzler et al., 2007). A connection between stress and immune function has been demonstrated in various experimental paradigms (Nieman and Pedersen, 1999). Stress can either enhance or impair immune system function depending on the type and duration of the stress. Stress hormones play a pivotal role in modulating pro/anti-inflammatory responses and the TH1/Th2 cytokine balance, thereby influencing the susceptibility to and outcome of various immune-related diseases (Calcagni and Elenkov, 2006). While chronic stress is immunosuppressive and leads to increased vulnerability to infections and cancer, acute stress promotes immuno-protection through cell-mediated immunity (Dhabhar and McEwen, 1999; Viswanathan et al., 2005). To our knowledge, the role of OPN in the response of the immune organs to stress has not been examined.

$\mathrm{HU}$ is a widely used ground-based model for simulating stresses experienced by astronauts during space flight. It has been used to study the influence of limb disuse on the immune, musculoskeletal, cardiovascular, renal, neural, metabolic, and reproductive systems. As compared to chronic restraint stress, mice experiencing hind limb-unloading have free access to food and water and thus are not affected by starvation and dehydration whereas CRS is a more psychological stressor. Exposure to HU causes alterations in the immune system, including organ atrophy, similar to those observed after space flight (Sonnenfeld, 2005). Wei and colleagues (Wei et al., 2003) demonstrated that HU causes a dramatic reduction in the number of mouse splenocytes and thymocytes; the reduction in lymphocyte number resulting from stress is corticosteroid-dependent and apparently due to the induction of apoptosis. OPN has 
been found to inhibit apoptosis in various situations (Denhardt et al., 2001; Arafat et al., 2007; Hur et al., 2007). It has previously been reported that OPN is necessary for the HU-induced remodeling of bone (Denhardt et al., 2001; Yoshitake et al., 1999). Whether OPN plays a role in immune system dysfunction under HU stress is unknown. We have used $\mathrm{OPN}^{-/}$and $\mathrm{OPN}^{+/+}$mice to study the consequence of OPN deficiency on the response of the animal to HU. My research has led to the novel finding that OPN is required for immune organ atrophy in mice subjected to HU by modulating stress induced production of corticosteroid.

\subsection{Materials and Methods}

\subsubsection{Mice}

$\mathrm{OPN}^{-/}$mice were generated in the Denhardt laboratory by Rittling and colleagues (Rittling et al., 1998). Briefly, embryonic 129S7 stem cells into which the disrupted OPN gene had been engineered were inserted into C57BL/6 blastocysts. Chimeric males generated were mated to C57BL/6 females, and subsequent heterozygous F1 animals were crossed. Chimeric males that gave 100\% germ line transmission were mated to a commercially available $129 \mathrm{~S} 1$ strain to get as close to an inbred line as possible. The offspring of these matings were genotyped and crossed to generate homozygous $\mathrm{OPN}^{+/+}$and $\mathrm{OPN}^{-/ /}$lines. These constitute the $129(\mathrm{~S} 1, \mathrm{~S} 7)$ lines maintained in the Rutgers Nelson Animal Facility, which is accredited by the Association for Assessment and Accreditation of Laboratory Animal Care and is under the care of a board-certified veterinarian. The research with these mice was approved 
by the Rutgers Institutional Animal Care and Use Committee, protocol number 97:031. All animals used in the experiments were age- and sex-matched.

\subsubsection{Hindlimb Unloading}

All experimental procedures involving mice were performed in accordance with guidelines set forth by the Rutgers Institutional Animal Care and Use Committee.

Eight- to twelve-week-old male $\mathrm{OPN}^{+/+}$and $\mathrm{OPN}^{-/}$mice were weighed and randomly assigned to control and treatment groups. Each group contained 3-6 mice. Mice were caged individually in a square Plexiglas box with open top. A pulley is place on top of the box and connected to a chain by a wheel. The mouse tail was wrapped with a piece of surgical tape and a metal clip set through the tape to connect the tail to the chain. Mice were suspended at a $25^{\circ}$ angle to the floor in a head-down position with only the forelimbs touching the floor continuously for 3 days (Wei et al., 2003; Offner et al., 2006). The setup permitted the mice to move freely inside the box using their forelimbs and having access to food and water ad libitum. Control mice were housed under the same conditions except that they were not suspended. Body weights were recorded before and after suspension. Mice were euthanized with $\mathrm{CO}_{2}$ inhalation at the endpoint and spleen and thymus were collected. 


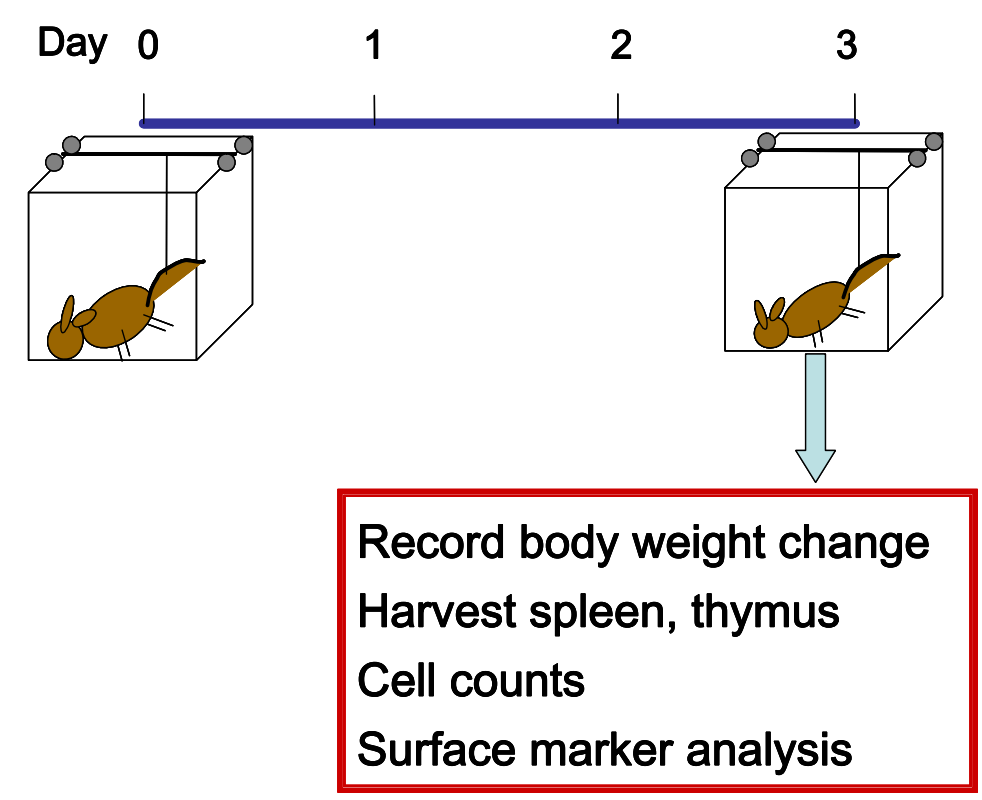

Fig. 2.1. Schematic presentation of the HU model protocol. Mice are individually caged with tail suspended by a two-dimensional pulley sitting on top of the cage. The mouse body forms a $25-30^{\circ}$ angle to the floor so that the hind limbs were not able to touch the floor. In this project, mice were suspended continuously for 3 days.

\subsubsection{Cell Counts and Surface Marker Analysis}

After 3 days of $\mathrm{HU}$, the mice were euthanized by $\mathrm{CO}_{2}$ inhalation. The thymus and spleen were excised and single cell suspensions were prepared by meshing the tissue through a 70- $\mu \mathrm{m}$ cell strainer. Red blood cells were lysed with an ACK (ammonium-calcium-potassium) buffer (Invitrogen, Cat\# 0060005DG). Remaining white cells were washed and resuspended in PBS. Total cell counts were determined with a hemocytometer. Specific lymphocyte subpopulations were identified on the basis of cell surface markers by flow cytometry: fluorescence-conjugated monoclonal 
antibodies including rat anti-mouse CD4 (clone RM4-5), CD8 (clone 53-6.7), and

CD45R/B220 (clone RA3-6B2) (all from BD Biosciences-PharMingen, San Diago CA) were used. Cells were incubated with BD Fc Block (clone 2.4G2) (BD BiosciencesPharMingen, San Diego CA) for 10 min to block non-specific binding and then incubated with specific mAbs for 20 min on ice, washed with PBS and analyzed on a multicolor flow cytometer (FACScalibur, Becton Dickinson, San Jose, CA). Data were acquired and analyzed with the CellQuest software (Becton Dickinson, San Jose, CA).

\subsubsection{Determination of Corticosterone Levels in Serum}

Blood was collected by cardiac puncture from experimental and control $\mathrm{OPN}^{+/+}$ and $\mathrm{OPN}^{-/-}$mice immediately after $\mathrm{HU}$ was terminated. After clotting at room temperature for $30 \mathrm{~min}$, serum was separated by centrifugation at $10000 \mathrm{rpm}$ for $15 \mathrm{~min}$ and stored at $-80^{\circ} \mathrm{C}$ prior to assay. The levels of corticosterone in serum samples were assessed with a corticosterone ELISA kit from IBL America (Minneapolis, MN) according to manufacturer's instructions. Briefly, in 96-well microtiter wells pre-coated with a polyclonal anti-corticosterone antibody, $20 \mu \mathrm{l}$ of serum samples or standard were mixed with $200 \mu$ l of enzyme conjugate and incubated for 1 hour at room temperature. Wells were washed and then incubated with $100 \mu$ l of substrate solution for $15 \mathrm{~min}$. The enzymatic reaction was stopped by adding $50 \mu \mathrm{l}$ of acidic stop solution. Absorbance at $450 \mathrm{~nm}$ was read with a microtiter plate reader and analysed by Softmax software (Molecular Dynamics,). 


\subsubsection{Induction of Apoptosis by Dexamethasone}

Single cell suspensions of splenocytes and thymocytes were prepared as described in 2.2.3. Cells washed with PBS were re-suspended in culture medium (RPMI 1640, 10\% heat-inactivated FBS, $55 \mu \mathrm{M} \beta$-mercaptoethanol, 2-mM L-glutamine, 50 units $/ \mathrm{ml}$ penicillin and $50 \mu \mathrm{g} / \mathrm{ml}$ streptomycin). Cells were cultured in 96-well plates at $1 \times 10^{6} /$ well in presence of dexamethasone at concentrations including $0,0.1,1,10$, $100,1000 \mu \mathrm{M})$. After a 16 -h incubation at $37^{\circ} \mathrm{C}$, the cells were washed in PBS and stained with propidium iodide $(50 \mu \mathrm{g} / \mathrm{ml})$ in the presence of $100 \mu \mathrm{g} / \mathrm{ml}$ RNAse and $0.1 \%$ saponin. The percent of apoptotic cells was determined by DNA analysis using flow cytometry.

\subsubsection{In Situ Apoptosis Detection}

Spleen and thymus tissues were fixed in Z-fix for 48 hours at room temperature (Anatech, Ltd. Battle Creek, MI 49015) immediately after excision from the mouse. Paraffin sections were processed following a standard protocol by a specialized histological lab. Nuclear DNA fragmentation in apoptotic cells was detected on paraffin sections using TACS.XL DAB in situ apoptosis detection kit by Trevigen (Gaithersburg, MD). Paraffin sections were de-paraffinized and rehydrated before labeling. Samples were first treated with proteinase K solution and then labeled with a labeling reaction mix containing BrdUTP and terminal deoxynucleotidyl transferase (TdT) for $60 \mathrm{~min}$ at $37^{\circ} \mathrm{C}$. BrdU incorporation by $\mathrm{TdT}$ at the site of DNA fragmentation was detected by a highly specific and sensitive biotinylated anti-BrdU antibody and visualized by streptavidin-horse radish peroxidase conjugate. The tissue sections were counterstained with methyl green. 


\subsubsection{T Cell Proliferation Assay}

Single cell suspensions of thymocytes and splenocytes were plated in 96-well plates, which were pre-coated with anti-CD3 at $5 \mu \mathrm{g} / \mathrm{ml}$ in PBS for $24 \mathrm{~h}$ at $4^{\circ} \mathrm{C}$. Cells were seeded at $5 \times 10^{5}$ cells per well in complete medium (RPMI 1640, 10\% heatinactivated FBS, $55 \mu \mathrm{M} \beta$-mercaptoethanol, $2 \mathrm{mM}$ L-glutamine, 50 units/ml penicillin, $50 \mu \mathrm{g} / \mathrm{ml}$ streptomycin and $5 \mu \mathrm{g} / \mathrm{ml}$ anti-CD28. (Anti-CD3 is an agonistic antibody to the $\mathrm{T}$ cell receptor (TCR) and anti-CD28 is agonistic to the co-stimulatory molecule CD28 on the T cell surface. They stimulate T cell proliferation through the initiation of signaling pathways including induction of specific protein tyrosine kinases (PTKs), breakdown of phosphatidylinositol 4,5-bisphosphate (PIP2), activation of protein kinase $\mathrm{C}(\mathrm{PKC})$ and elevation of intracellular calcium ion levels.) The cells were cultured for 72 hours at $37^{\circ} \mathrm{C}$ and $5 \% \mathrm{CO}_{2} .\left[{ }^{3} \mathrm{H}\right]$ thymidine was added to the cells for the last 16 hours of the incubation. The incorporation of $\left[{ }^{3} \mathrm{H}\right]$ thymidine was measured by $\beta$-scintillation counting.

\subsubsection{Determination of Cytokine Production}

Parallel to the proliferation assay, the supernatants of anti-CD3/anti-CD28 stimulated thymocyte or splenocyte cultures were harvested $48 \mathrm{~h}$ after treatment and stored at $-20^{\circ} \mathrm{C}$. Cytokines IL-2, IL-10 and MCP-1 were measured with DuoSet ELISA kits (R\&D Systems, Mineapolis, MN), according the manufacturer's instructions.

\subsubsection{Statistical Analysis}

Each experiment was performed at least twice with 3 or more mice in each group. Figures and tables represent experiments or compiled data from multiple experiments 
as specified in the corresponding figure legend. Data are expressed as mean \pm SEM.

Differences between groups were analyzed using student's t-test associated with Microsoft Excel software.

\subsection{Results}

\subsubsection{OPN deficiency protects mice from weight loss and lymphoid organ} atrophy

Mice subjected to certain stressors, HU for example, suffer significant reductions in their immune cell numbers in the spleen and thymus, with consequent organ atrophy (Wei et al., 2003; Dhabhar et al., 1995). To examine the role of OPN in this stress response, I exposed $\mathrm{OPN}^{-/-}$and $\mathrm{OPN}^{+/+}$mice to $\mathrm{HU}$ for 3 days. This treatment caused a significant reduction in the body weight of the $\mathrm{OPN}^{+/+}$mice; the change in body weight of $\mathrm{OPN}^{-/-}$mice was only about half as much (Fig. 2.1). 
B

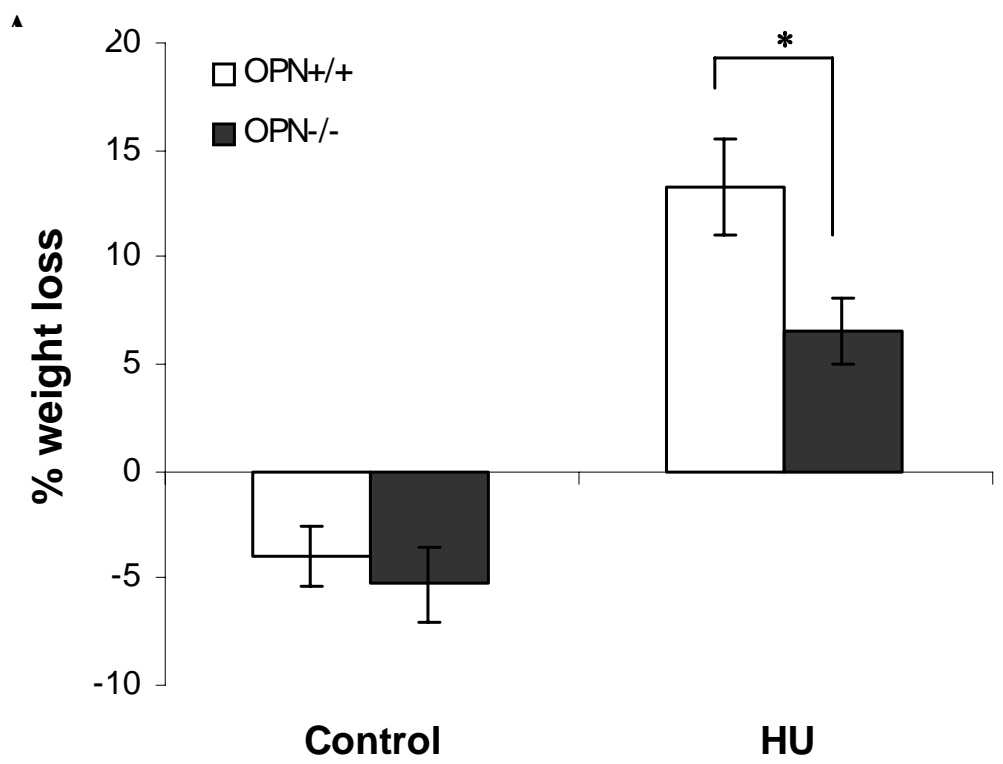

B

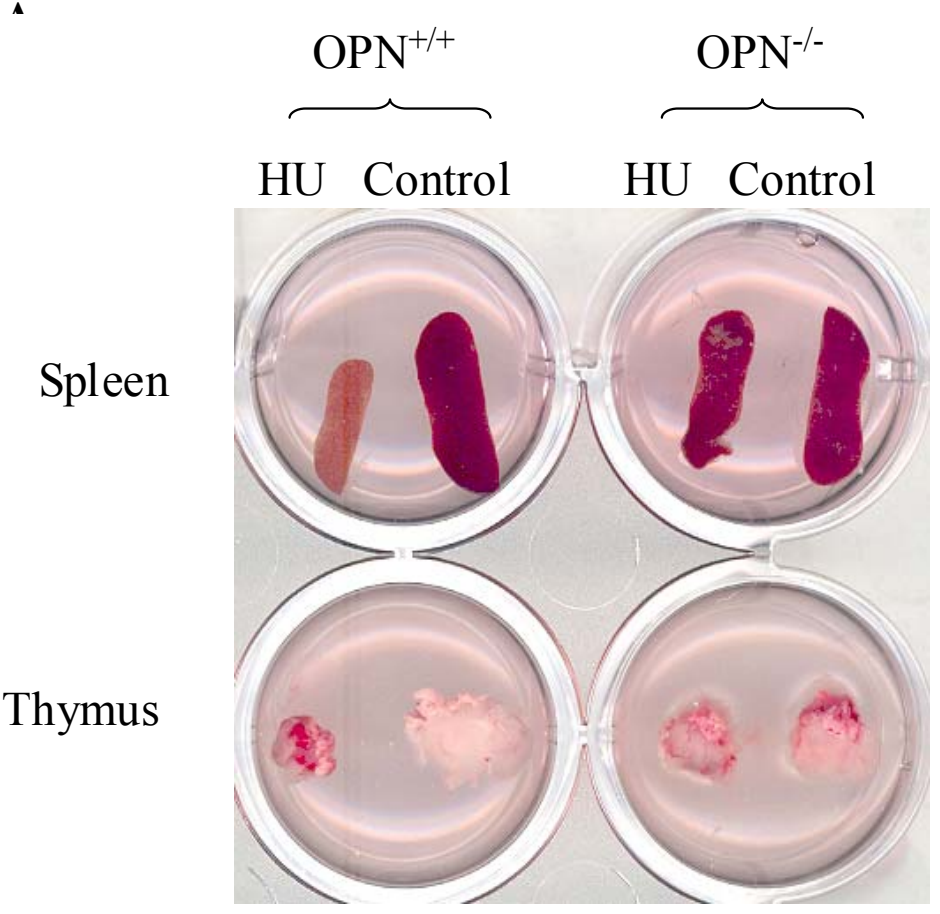


Fig. 2.2. (A) HU causes significant body weight loss. Mice were weighed before and after 3-day HU. Data are expressed as percent weight loss (mean $\pm \mathrm{SEM}$ ) relative to the body weight before HU. The asterisk denotes statistically significant difference between $\mathrm{OPN}^{+/+}$and $\mathrm{OPN}^{-/-}$mice $(\mathrm{p}<0.05$, student t-test). (B) HU causes significant lymphoid organ atrophy. The spleen and thymus were dissected from control and suspended mice. Surgically extracted whole organs were put into a cell culture dish filled with medium and scanned on a digital scanner. The spleens and thymuses of the $\mathrm{OPN}^{-/}$mice were comparable in size with or without HU.

The spleen and thymus were considerably reduced in size in the suspended wild type mice compared both to control $\mathrm{OPN}^{-/-}$mice and to the suspended $\mathrm{OPN}^{-/-}$mice $($Fig. 2.2). Much smaller differences were observed between control and suspended $\mathrm{OPN}^{-/-}$ mice. Analysis of lymphoid tissues revealed a substantial reduction in the number of splenocytes and thymocytes in the $\mathrm{OPN}^{+/+}$mice. Consequently, the suspended $\mathrm{OPN}^{-/}$ mice exhibited a much smaller, and statistically insignificant, reduction in cell number of both thymocytes and splenocytes (Fig. 2.3). 

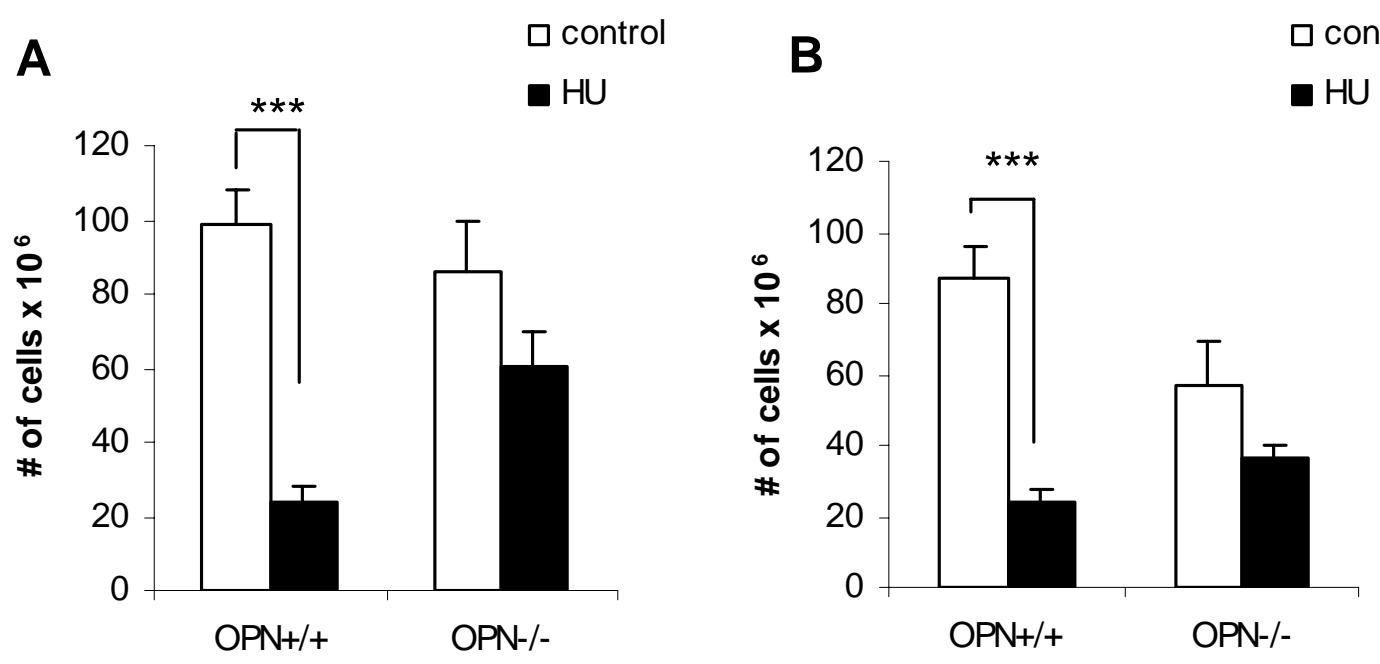

Fig. 2.3. HU leads to significant reduction in the cellularity of both thymus and spleen in $\mathrm{OPN}^{+/+}$but not $\mathbf{O P N}^{-/-}$mice. Single cell suspensions were prepared from spleens (A) and thymuses (B) of suspended and control $\mathrm{OPN}^{+/+}$and $\mathrm{OPN}^{-/-}$mice. The total cell numbers were enumerated with a hemocytometer. Data represent means \pm SEM of 6-10 animals at each data point. Statistical significance indicated by asterisk (* $\mathrm{p}<0.05, * * \mathrm{p}<0.02, * * * \mathrm{p}<0.01$ with two tailed t-test).

To determine whether the loss of cellularity in the immune organs of the $\mathrm{OPN}^{+/+}$ mice subjected to HU was due to apoptosis, we assessed the extent of apoptosis in histological sections of spleen and thymus using the TUNEL in situ staining technique. Significant numbers of apoptotic splenocytes and thymocytes were found in hindlimbunloaded $\mathrm{OPN}^{+/+}$but not in hindlimb-unloaded $\mathrm{OPN}^{-/-}$mice or control mice (Fig. 2.4). Thus it appears that OPN is necessary for immune cell apoptosis in response to the HU stress challenge. Since stress-induced elevation of glucocorticoids leads to cell apoptosis (Calcagni and Elenkov, 2006), OPN may act by increasing the sensitivity of 
lymphocytes to corticosterone-induced apoptosis or by up-regulating corticosterone levels to affect cell apoptosis in response to HU.
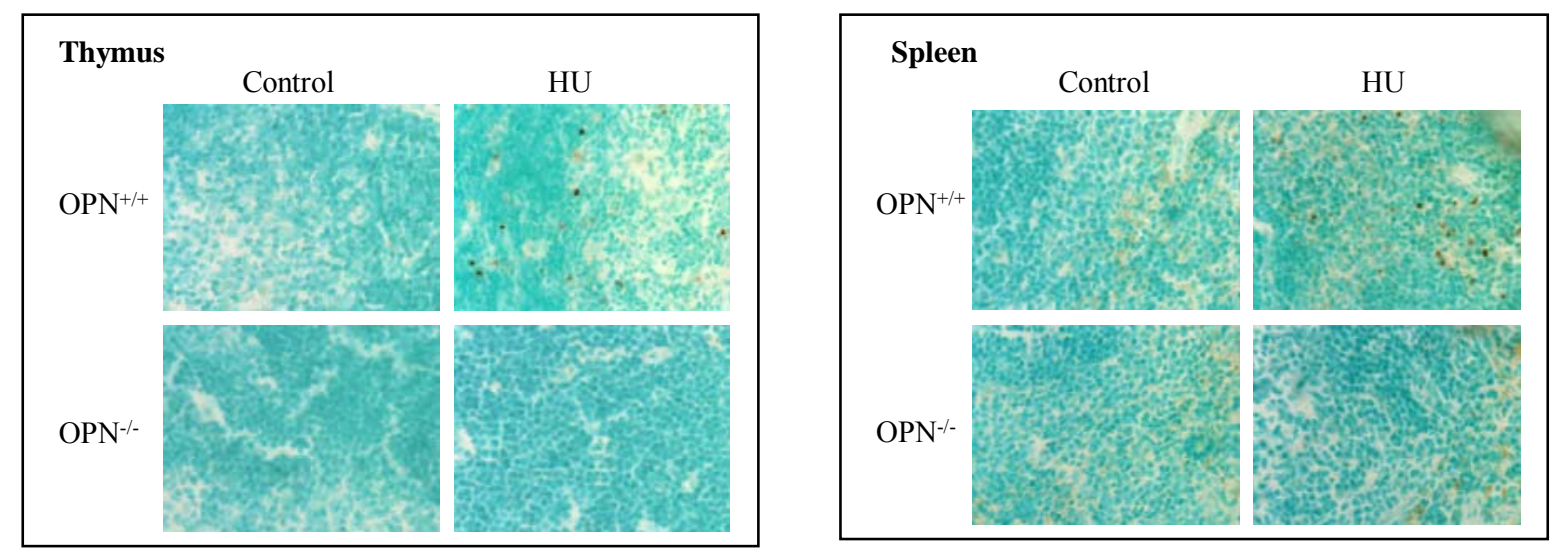

Fig. 2.4. $\mathrm{OPN}^{-/-}$mice are resistant to $\mathrm{HU}$-induced apoptotic cell death in both thymus and spleen. Wild type and $\mathrm{OPN}^{-/}$mice were subjected to hindlimb unloading for $20 \mathrm{~h}$. TUNEL-positive apoptotic cells in paraffin sections of thymus (A) and spleen (B) tissues are shown in dark brown on a methyl green counterstained background.

\subsubsection{OPN Promotes Stress-induced Loss of Splenocytes and Immature T cells in}

\section{the Thymus}

To ascertain what lymphocyte cell types were affected by HU, we examined immune cell sub-populations using flow cytometry. Analysis of untreated wild type and $\mathrm{OPN}^{-/-}$mice exhibited a normal distribution of $\mathrm{B}$ and $\mathrm{T}$ cells as well as $\mathrm{T}$ cell subpopulations; however, the total cell number was only slightly lower in $\mathrm{OPN}^{-/}$mice (Table 1). These data suggest that OPN deficiency is not causing a skewed distribution of immune cell sub-populations in mice. Splenocytes and thymocytes were harvested 
from suspended $\mathrm{OPN}^{+/+}$and $\mathrm{OPN}^{-/-}$mice and stained with fluorescence-conjugated antibodies specific for cell surface markers CD4, CD8, and B220 cell populations.

\begin{tabular}{|c|c|ccccc|}
\hline \multicolumn{2}{|c|}{} & Total cell \# & \% CD4+ & \% CD8+ & \% CD4+CD8+ & \%B220 \\
\hline \multirow{3}{*}{ Thymus } & OPN+l+ & $104.2 \pm 8.9$ & $11.2 \pm 1.2$ & $3.83 \pm 0.4$ & $83.5 \pm 1.0$ & N/A \\
& OPN-I- & $85.6 \pm 13.9$ & $13.2 \pm 3.1$ & $4.4 \pm 1.0$ & $77.4 \pm 3.6$ & N/A \\
\hline \multirow{3}{*}{ Spleen } & OPN+I+ & $84.1 \pm 9.1$ & $23.1 \pm 1.4$ & $12 \pm 0.8$ & N/A & $42.8 \pm 5.8$ \\
& OPN-I- & $56.6 \pm 13.1$ & $26.3 \pm 1.8$ & $14.1 \pm 1.1$ & N/A & $38.1 \pm 4.7$ \\
\hline
\end{tabular}

Table 2.1. Distribution of lymphocyte sub-populations in the spleen and thymus.

Single-cell suspension were generated from the spleens and thymuses of $\mathrm{OPN}^{+/+}$and $\mathrm{OPN}^{-/-}$control mice. Cells were stained with fluorochrome-conjugated cell surface marker antibodies against B220 (B cells) and CD4 (T helper cells) and CD8 (cytotoxic $\mathrm{T}$ cells) sub-populations. Data represent mean $\pm \mathrm{SEM}$ of 5-7 mice. The percentages of positively stained cells were recorded.

In the thymus, a dramatic reduction of $\mathrm{CD} 4^{+} \mathrm{CD} 8^{+}$double-positive cells (up to $80 \%$ ) was observed in suspended $\mathrm{OPN}^{+/+}$mice, whereas a much smaller reduction of this population was observed in suspended $\mathrm{OPN}^{-/}$mice compared to controls (Fig. 5A). Interestingly, the abundances of single-positive $\mathrm{CD}^{+}$and $\mathrm{CD} 8^{+}$cells in the thymus were not significantly affected by $\mathrm{HU}$ in either $\mathrm{OPN}^{+/+}$or $\mathrm{OPN}^{-/ /}$mice. In the spleen, hindlimb unloading caused a greater than $50 \%$ reduction in every subpopulation examined including $\mathrm{CD}^{+}-\mathrm{T}$ cells, $\mathrm{CD} 8^{+} \mathrm{T}$ cells and $\mathrm{B}$ cells of $\mathrm{OPN}^{+/+}$mice, but only a slight reduction of these lymphocyte types in $\mathrm{OPN}^{-/-}$mice (Fig. 5B). These results revealed that OPN is necessary for the stress-induced reduction of immature $\mathrm{T}$ cells in thymus and both $\mathrm{T}$ cells and $\mathrm{B}$ cells in spleen. 

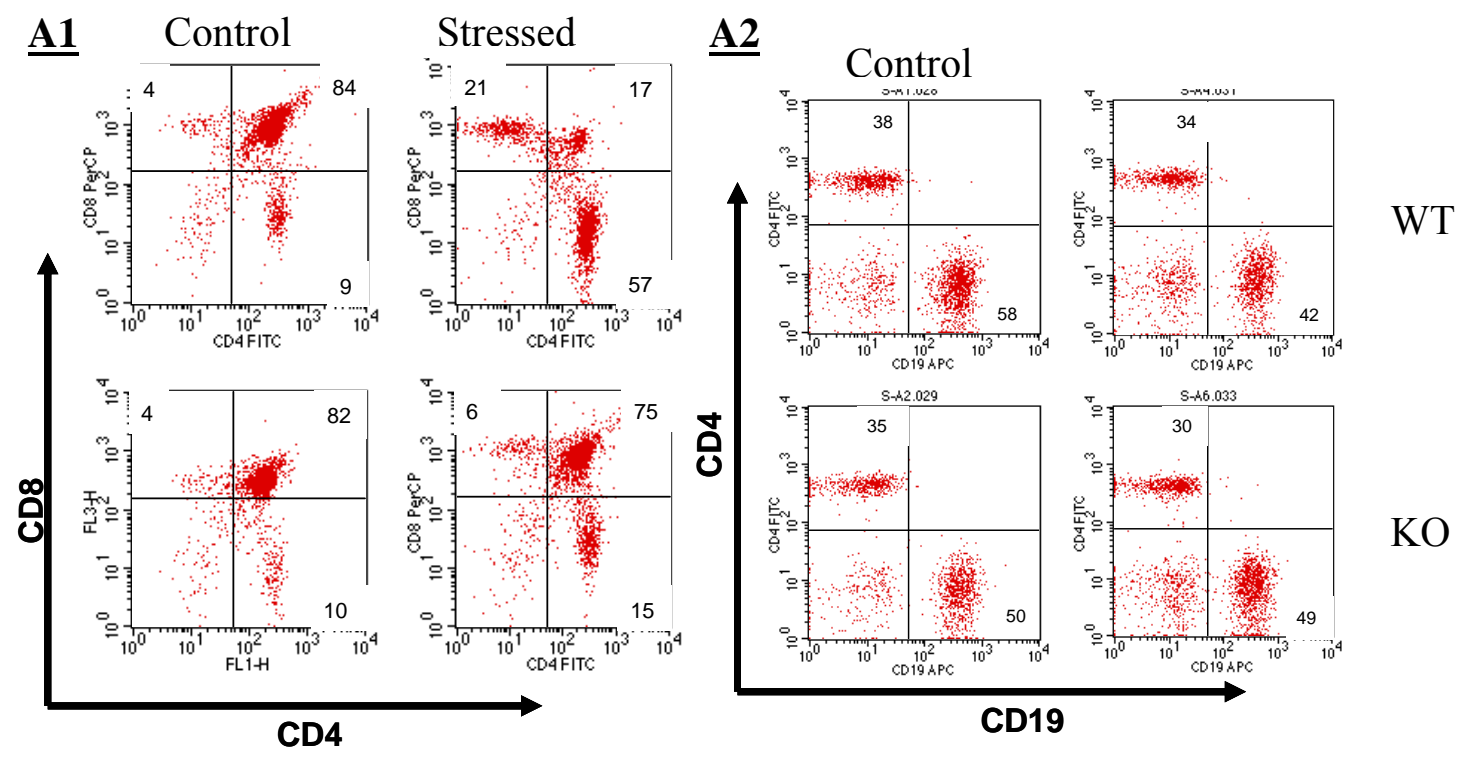

\section{B1}
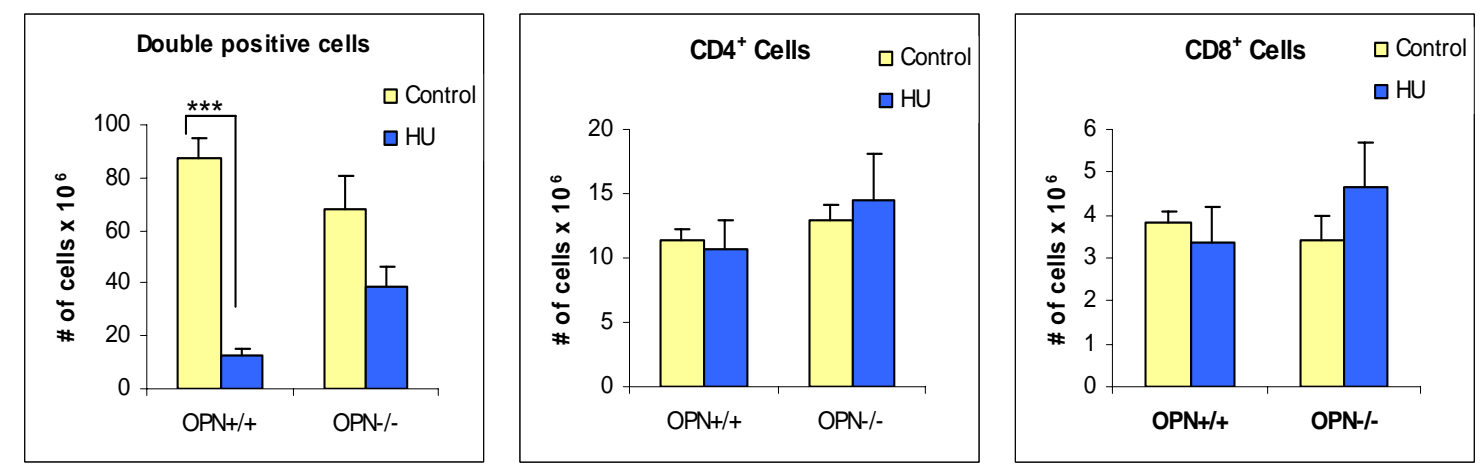

B2
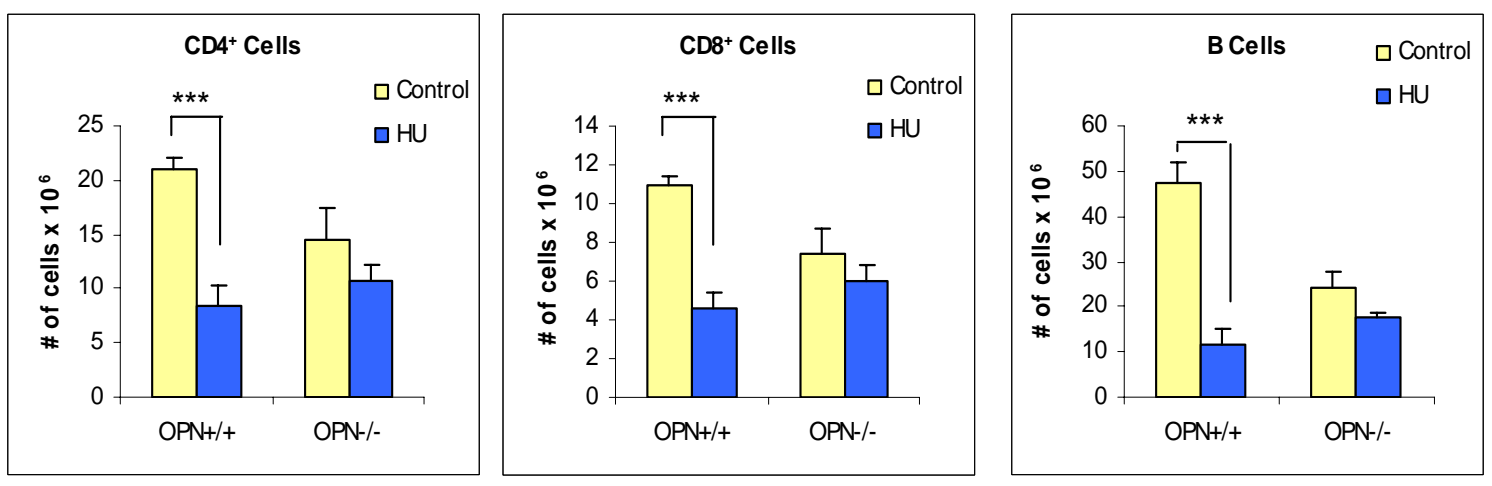
Fig 2.5. (A) Splenocytes isolated from experimental and control $\mathrm{OPN}^{+/+}$and $\mathrm{OPN}^{-/-}$ mice were stained with fluorochrome-conjugated anti-B220, anti-CD3, anti-CD8, antiCD4 antibodies and analyzed by multicolor flow cytometry. Representative dot plots show the stress-induced significant reduction in $\mathrm{CD} 4^{+} / \mathrm{CD}^{+}$double positive cells in thymus and reduction of $\mathrm{CD} 4^{+} \mathrm{T}$ cells and $\mathrm{CD} 19^{+} \mathrm{B}$ cells in spleen in WT mice but not in OPN deficient-mice. A1: Thymus, A2: Spleen. The bar graphs (B) represent summarized data from all samples of $\mathrm{OPN}^{+/+}$and $\mathrm{OPN}^{-/-}$mice. B1: thymus, B2: spleen. Data represent means \pm SEM of 4-7 animals in each data point. The statistical significances are indicated by the asterisks $(* \mathrm{p}<0.05, * * \mathrm{p}<0.02, * * * \mathrm{p}<0.01$ with two tailed t-test).

\subsubsection{Corticosterone Levels are not Elevated in $\mathrm{OPN}^{-/-}$Mice Subjected to HU.}

Corticosterone, the major stress hormone in rodents, is quickly up-regulated in response to stress, leading to the induction of substantial lymphocyte apoptosis (Calcagni and Elenkov, 2006). Interestingly, it has been shown in mice that blocking the steroid receptor could suppress the HU-induced lymphocyte reduction (Wei et al., 2003). To determine whether OPN plays a role in regulating the production of glucocorticoid after HU, we measured both corticosterone and OPN levels in the serum of the mice after HU. We found that while the OPN levels were not changed in wild type mice (data not shown), HU caused an approximate 5-fold increase in steroid level in serum of WT mice but not in OPN-deficient mice (Fig. 6). This suggests that OPN is required for upregulation of the steroid hormone in response to HU-induced stress. Also, when exogenous dexamethasone was supplied to cells isolated from $\mathrm{OPN}^{+/+}$and 
$\mathrm{OPN}^{-/-}$mice, there was no difference in the rate of induced cell death (Fig. 7B). This indicates that steroid-induced lymphoid cell death is not impaired in OPN-deficient cells. Endogenous OPN appears to act upstream of the corticosterone hormone, possibly contributing to its increased production in response to the HU-induced stress and thereby indirectly contributing to lymphoid cell death.

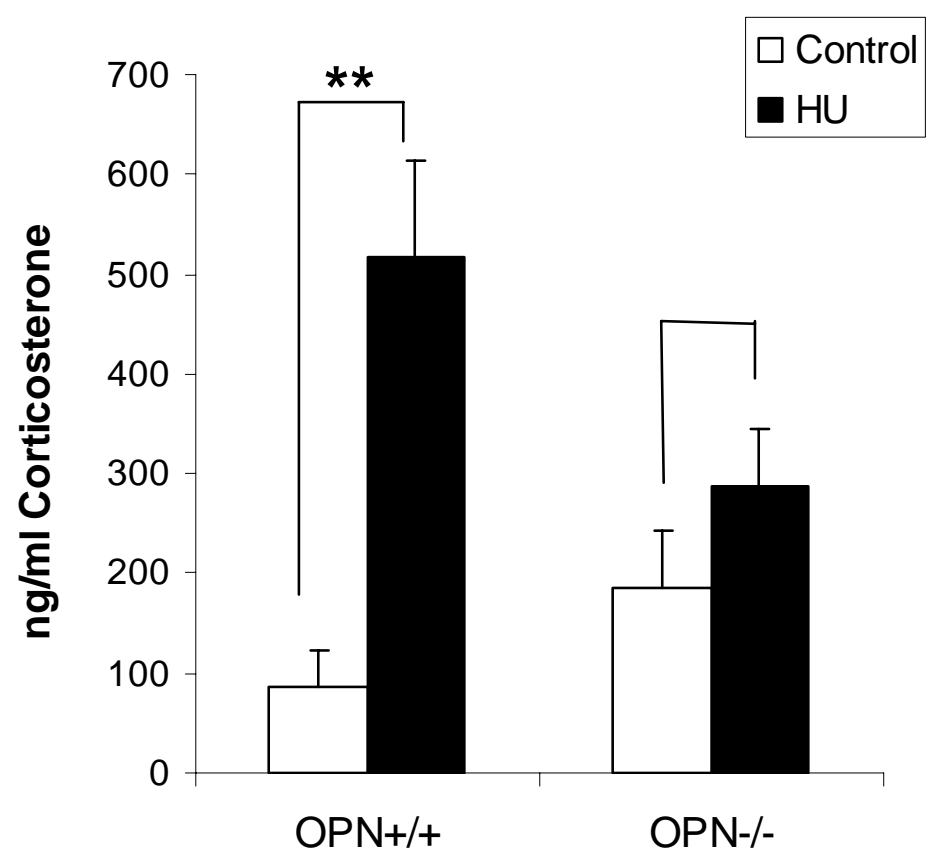

Fig. 2. 6. Serum corticosterone levels are elevated in $\mathrm{OPN}^{+/+}$mice but not in $\mathrm{OPN}^{-/-}$ mice after HU. Serum samples from suspended and control of $\mathrm{OPN}^{+/+}$or $\mathrm{OPN}^{-/-}$mice were diluted in corticosterone-free serum matrix and assayed using the corticosterone ELISA kit. Data shown represent the mean \pm SEM of 5-11 animals from several independent experiments for each data point. The statistical significances are indicated by the asterisks $(* \mathrm{p}<0.05$ with two tailed $\mathrm{t}$-test $)$. 


\subsubsection{OPN Regulates Immune Cell Proliferation and Cytokine Production in}

\section{Response to HU}

The reduction in spleen and thymus cellularity during $\mathrm{HU}$ of $\mathrm{OPN}^{+/+}$mice could be the result of decreased proliferation/maturation or increased emigration/apoptosis of the lymphocytes. Since OPN is known to promote cell proliferation in certain contexts, we investigated whether lymphocyte proliferation $\left(\left[{ }^{3} \mathrm{H}\right]\right.$ thymidine incorporation $)$ was regulated by OPN in mice subjected to $\mathrm{HU}$.

We quantified splenocyte and thymocyte $\mathrm{T}$ cell proliferation by stimulating equal numbers of these cells with anti-CD3/CD28 for $48 \mathrm{~h}$ and then labeling with $\left[{ }^{3} \mathrm{H}\right]$ thymidine for $16 \mathrm{~h}$. While there was no difference in $\left[{ }^{3} \mathrm{H}\right]$ thymidine incorporation in thymocytes from untreated $\mathrm{OPN}^{+/+}$or $\mathrm{OPN}^{-/-}$mice, a significant increase in splenocyte DNA synthesis was observed from suspended $\mathrm{OPN}^{-/-}$mice compared to suspended wild type mice (Fig. 2.7). The increased proliferative ability of the splenocytes derived from the suspended $\mathrm{OPN}^{-/-}$mice may be due to a higher percentage of activated cells in the $\mathrm{OPN}^{-/-}$mice. In contrast, the thymocytes from the suspended $\mathrm{OPN}^{+/+}$mice exhibited a dramatic increase in $\left[{ }^{3} \mathrm{H}\right]$ thymidine incorporation. This is due to the substantial loss of immature $\mathrm{CD} 4^{+} \mathrm{CD}^{+}$double-positive cells in the $\mathrm{OPN}^{+/+}$mice after $\mathrm{HU}$, resulting in a higher percentage, relative to $\mathrm{OPN}^{-/-}$mice, of single-positive $\mathrm{T}$ cells (CD4+ or CD8+) that exhibit a strong proliferative response when stimulated by anti-CD3/anti-CD28.

Parallel to the cell proliferation study, we assessed the levels of cytokine production in the supernatants of the cells activated by antiCD3/antiCD28 (Fig. 2.8). The activated $\mathrm{OPN}^{+/+}$thymocytes from the HU mice secreted substantially higher 
amounts of IL-2 than did the unstressed control at 48 hours while very low IL-2 induction in $\mathrm{OPN}^{-/-}$cells at the same time point. This indicated that OPN is required for naïve $\mathrm{T}$ cell activation during the stress response. In addition, we observed an increased production of Th-2 cytokine IL-10 in the $\mathrm{OPN}^{-/-}$cells, which is consistent with the notion that OPN promotes Th1 cytokine and inhibits Th2 cytokine expression.

Furthermore, the chemokine MCP-1 was significantly lower in activated $\mathrm{OPN}^{-/-}$ splenocytes. Decreased MCP-1 production by $\mathrm{T}$ cells in $\mathrm{OPN}^{-/-}$mice could result in a decrease in macrophage infiltration and function.

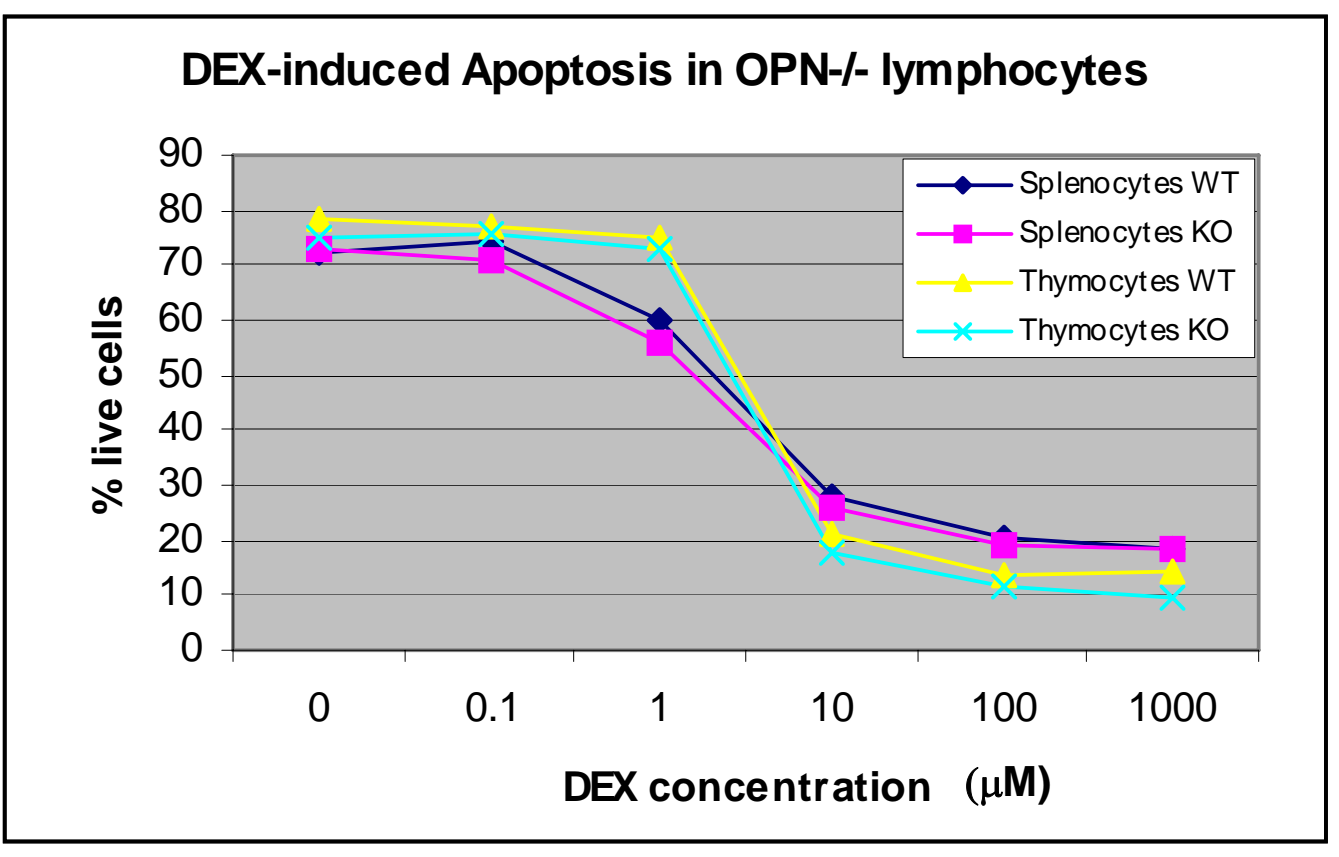

Fig. 2.7. Dexamethasone-induced cell death is not impaired in $\mathrm{OPN}^{-/}$mice. $\mathrm{OPN}^{+/+}$ and $\mathrm{OPN}^{-/-}$cells were treated with dexamethasone for $16 \mathrm{~h}$ at $37^{\circ} \mathrm{C}$ and the percentage of remaining live cells was assessed by flow cytometry with propidium iodide staining. 

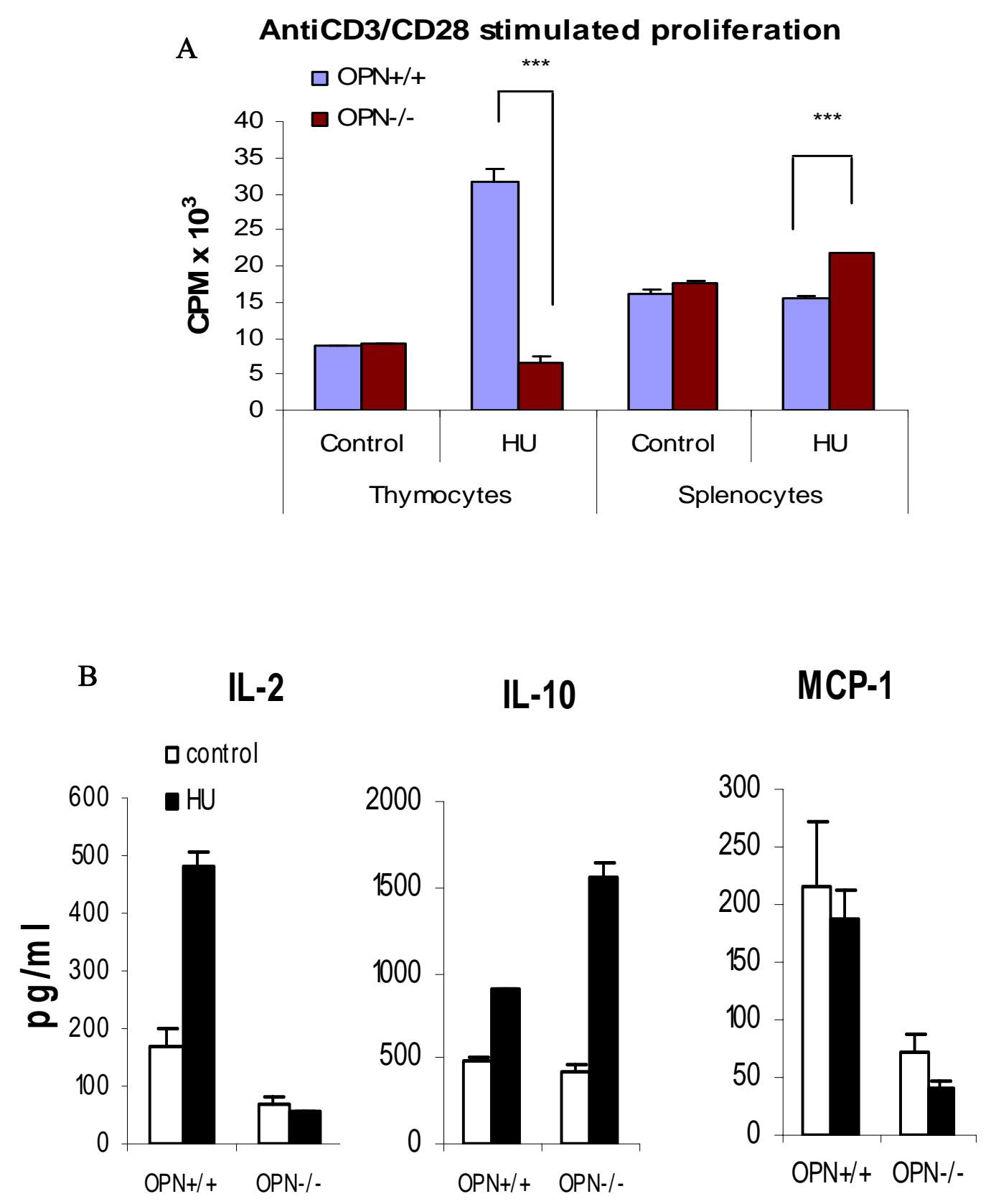

Fig. 2.8. Lymphocyte proliferation and cytokine production induced by anti-

CD3/CD28 stimulation. Total lymphocytes prepared from the spleens and thymuses of $\mathrm{OPN}^{+/+}$or $\mathrm{OPN}^{-/-}$mice were cultured in 96-well plates at $2 \times 10^{5}$ cells/well in complete RPMI without (control) and with anti-CD3 and anti-CD28. (A) After 48 h, the cells 
were pulsed with $\left[{ }^{3} \mathrm{H}\right]$ thymidine; incorporation of $\left[{ }^{3} \mathrm{H}\right]$ was quantified by scintillation counting. (B) After $48 \mathrm{~h}$, the supernatants were analyzed for cytokine production using the DuoSet ELISA kit. The results are expressed as the mean \pm SEM of triplicate wells. Statistical analysis was performed as in fig. 2.3

\subsection{Discussion}

It is well documented that various forms of physical stress (e.g. restraint, hindlimb unloading, stroke and microgravity) can cause the involution of the spleen and/or thymus, thus impairing the organism's ability to mount an immune response (Sonnenfeld, 2005; Dhabhar et al., 1995; Marcucci et al., 1980). The loss of spleen and thymus cellularity could be caused by one or a combination of factors, including increased cell death, reduced proliferation capacity in response to mitogenic stimulation, and redistribution of the lymphocytes in the body (Dhabhar et al., 1995). Depending on the specifics, stress can be immunoenhancing or immunosuppressive. Acute stress can enhance the immune response, stimulating redistribution of leukocytes and enabling their response to the injury (Dhabhar and McEwen, 1999; Viswanathan et al., 2005). Chronic stress tends to suppress the immune response and leads to lymphocyte apoptosis (Dhabhar et al., 1995) and increased susceptibility to diseases (Calcagni and Elenkov, 2006). These contrary responses are believed to be mediated in part by the stress-induced adrenal hormone glucocorticoids (Dhabhar and McEwen, 1999). There is evidence that the loss of splenocytes and thymocytes in response to HU is the result of increased glucocorticoid-dependent apoptosis (Wei et al., 2003). 
In my studies, the mice were suspended for 3 days, which is sufficient for the acute stress to become chronic. We found that after 3 days the wild-type mice had lost about $20 \%$ of their original weight compared to about $10 \%$ for the OPN-null mice; during this same 3-day period control mice gained about 5\% in weight (Fig. 2.1). Parallel to the weight loss, the reduction in the cellularity of the spleen and thymus was more than $70 \%$ in wild-type mice. However, the composition of the immune cell population in the circulation was not changed significantly (data not shown), indicating that migration/redistribution of immune cells was not a major contributing factor to the loss of cellularity in spleen and thymus. In contrast, mice lacking OPN were protected from significant spleen and thymus atrophy after HU. At three days, corticosterone levels in the plasma of the suspended wild-type mice was increased by 5-fold. Evidently, OPN is involved in the response to this stress and is necessary for augmentation of the corticosterone in response to HU. Mice subjected to physical restraint stress (immobilized in a 50-ml conical for two 12-periods separated by 12 hours of freedom) revealed that OPN was required for the immune organ atrophy similar to that induced by HU (see Chapter 3).

OPN is implicated in immune and inflammatory responses, for example recruiting macrophages to sites of injury and regulating their activities. Its expression is elevated in response to mechanical stress in bone and the vasculature (Singh et al 2007; Yoshitake et al., 1999; Denhardt and Noda, 1998). OPN levels are elevated in response to the oxidative stresses existing in tumors, after reperfusion injury, and in inflammatory diseases such as inflammatory bowel disease, chronic obstructive pulmonary disease, and Parkinson's disease (Maetzler et al., 2007; Da Silva et al., 
2006; Heguy et al., 2007). Our finding that mice lacking OPN are protected from stress-induced lymphoid organ atrophy is intriguing because this implies that OPN also functions as a stress mediator. Microarray analysis has revealed that OPN is required for the enhanced p53 gene expression in tail-suspended mice (Ishijima et al., 2006). Enhanced p53 expression can drive cells to commit apoptosis or to cease dividing in response to the harmful effects of stress; however, the role of p53 in HU-induced apoptosis in lymphocytes has not been investigated. Our results showed less cell loss in $\mathrm{OPN}^{-/}$mice after 3 days of $\mathrm{HU}$, consistent with a diminished $\mathrm{p} 53$ response in $\mathrm{OPN}^{-/-}$ mice. These data reveal that OPN acts to mediate stress signaling upstream of genes regulating apoptosis and corticosterone biosynthesis or release.

Glucocorticoid, released through activation of the HPA axis, has been suggested to play an important role in chronic stress-induced immune modulation. In fact, steroid hormones have long been associated with lymphocyte apoptosis. Interestingly, it has been reported that acute stress could enhance delayed-type hypersensitivity response (Dhabhar and McEwen, 1996) and wound healing (Dhabhar, 2003). This has been proposed to be related to the preparation of fight or flight of animals during evolution.

The parallel between the results shown here, that remodeling of stressed immune organs depends upon OPN, and the fact that remodeling of bone (osteoporosis, which does not occur in the absence of OPN, Denhardt and Noda, 1998) is intriguing. In the case of bone remodeling, it appears that this is the consequence, at least in part, of osteoclast and possibly osteocyte dysfunction. The results reported here imply an involvement of macrophages, which share the same lineage with osteoclast, in the 
remodeling of the lymphoid organs in response to HU stress. OPN has in fact been implicated in both macrophage and osteoclast function (Rittling et al., 1998; Aviles et al., 2005). OPN is produced by both cell types and facilitates their function(s), in part via interactions with CD44.

It has been reported that blockade of type II glucocorticoid receptors by RU486 (type II glucocorticoid receptor antagonist) restored cellularity and cytokine responses to immune organs in restraint-stressed, infected mice (Sheridan et al., 1998). This provided evidence that the HPA axis modulated cell trafficking and cytokine responses. Furthermore, endogenous opioids are known to be elevated by stress and play a critical role in regulating stress-induced changes in immune system (Kowalski, 1998). The opioid receptor antagonists Naltrexone and Naloxone also suppress stress-induced reduction in splenocyte number (Yin et al., 2000). OPN deficiency seems to resemble the effects of these hormone antagonists, suggesting a connection between OPN and the HPA axis.

Serum corticosterone levels were elevated in $\mathrm{OPN}^{+/+}$, but not in $\mathrm{OPN}^{-/-}$, mice after $\mathrm{HU}$, and that appears to be the proximate cause of lymphoid organ atrophy. Stress hormones regulate cytokine production and influence the balance of pro- and antiinflammatory and Th1/Th2 cytokines, for example suppressing IL-12 production from antigen presenting cells and enhancing IL-4 production by T cells (Calcagni and Elenkov, 2006). This effect in an acute response may protect the organism from excessive pro-inflammatory Th1 cytokines. In the case of acute stress, glucocorticoids cause a suppression of Th2 cytokines and inflammatory mediators, which facilitates inflammation. This is one of the mechanisms for corticosteroids to be potent anti- 
inflammatory anti-allergic drugs. OPN's role in regulating the Th1/Th2 cytokine balance has been well documented. OPN may act synergistically with corticosterone and enhance the immunosuppressive effect of stress. Indeed, the parallel actions of OPN and stress include that they both lead to exacerbation of autoimmune diseases and increase the susceptibility to infections. This study reveals for the first time the importance of OPN in stress responses and opens a new area for exploring manifold functions of OPN. 


\section{Chapter 3}

\section{Plasma OPN Affects the Response of the Immune Organs to Stress}

\subsection{Introduction}

The work in the previous chapter demonstrated that OPN is critical for hindlimb unloading $(\mathrm{HU})$ stress-induced lymphoid organ atrophy. The 3-day HU model not only mimics microgravity as experienced by astronauts in space flight but also imposes great physical challenges and chronic stress on the organism. These challenges lead to rapid systemic changes in stress hormone production, immune cell distribution, and cytokine/chemokine production; they also affect peripheral immune organs in the immune system (Sonnenfeld, 2005). Although different stress paradigms have been operationally defined as "chronic physical stress", the extent to which each of these different stressors affects the HPA (hypothalamus-pituitary-adrenal) axis and immune system remains unspecified.

Another model of stress, chronic restraint stress (CRS), has been widely used in studies of the effect of stress hormones (Nacher et al., 2004) and immune cell functions in mice (Yin et al., 2000; Zhang et al., 2008). CRS consists of a scheduled confinement and restriction of food and water during restraint. In addition to physical immobilization, psychological stress plays a significant part in this model (Bowers et al., 2008). To help us to better understand the specific effect of OPN in mediating the stress response, this model is used below to evaluate OPN-deficient mice to further 
confirm the role of OPN in the stress response and to extend the discoveries from the HU model.

This phase of my research was focused on verifying whether OPN's role in mediating the lymphoid organ responses to $\mathrm{HU}$ is reproducible in a different chronic stress model and a different mouse background. To make sure the effects observed in the knockout mice were not restricted to one strain of mouse or dependent on the genetic purity of the background, I evaluated $\mathrm{OPN}^{-/-}$mice both in a 129 mixed background and Balb/c pure background. First, I demonstrated that OPN-deficient mice in both 129 and Balb/c backgrounds showed attenuated lymphoid organ atrophy, corticosterone/cytokine production, and leukocyte trafficking in the CRS model compared to their wild type counterparts. This result confirmed that OPN was also required for CRS-induced stress responses and reinforced the role of OPN in mediating stress-induced immune responses.

To further elucidate the effect of OPN, I administered purified OPN or an antiOPN monoclonal antibody intraperitoneally into KO and WT OPN mice respectively and subjected them to the CRS treatment. I show below that purified OPN could reverse the protective effect of the OPN deficiency and cause a greater degree of organ atrophy and an increase in the level of corticosterone after stress $\mathrm{OPN}^{-/-}$mice. On the other hand, the wild type mice that received the monoclonal antibody $2 \mathrm{C} 5$ exhibited a significant protection from lymphoid organ atrophy. These results support the conclusion that plasma OPN is indeed involved in stress-induced organ atrophy and demonstrate OPN's involvement in the bidirectional communication between CNS and the immune system. 


\subsection{Materials and Methods}

\subsubsection{Animals.}

$\mathrm{OPN}^{-/-}$mice in a 129 background were generated (Rittling et al., 1998, Natasha et al., 2006) and maintained along with isogenic wild type controls in the Rutgers Nelson Animal Facility, which is accredited by the Association for Assessment and Accreditation of Laboratory Animal Care and is under the care of a board-certified veterinarian. The research with these mice was approved by the Rutgers Institutional Animal Care and Use Committee, protocol number 97:031.

$\mathrm{OPN}^{-/-}$mice on Balb/c background were kindly provided by Dr. Mari Shinohara from Dr. Harvey Cantor's lab in the Dana-Farber Cancer Institute in Boston. The breeding pairs were homozygous $\mathrm{OPN}^{-/-}$mice with more than 10 generations of backcrossing to Balb/c background therefore considered $99.99 \%$ pure Balb/c background. Breeding pairs were bred and maintained in the Rutgers Nelson Animal Facility as above. Balb/c wild type control mice were purchased from the Jackson Laboratory (Bar Harbor, ME). All animals used in the experiments were age- and sexmatched.

\subsubsection{Immuno-Affinity Purification of Osteopontin}

Mouse OPN was purified from a ras-transformed murine embryonic fibroblast line (275-3-2) (Wu et al., 2000). Conditioned medium was generated from the cells by incubating them with serum-free medium (DMEM-Mediatech Inc., Herndon, VA, 5 
$\mu \mathrm{g} / \mathrm{ml}$ penicillin, $5 \mathrm{U} / \mathrm{ml}$ streptomycin and $2 \mathrm{mM}$ glutamine) overnight after washing twice with PBS. Conditioned medium was incubated with $1 \mathrm{ml}$ of protein $\mathrm{G}$ beads coupled to $2 \mathrm{~A} 1$ monoclonal antibody at $4{ }^{\circ} \mathrm{C}$ overnight with end-over-end rotation. The beads were gently pelleted, washed two times with cold phosphate-buffered saline and packed into a 2-ml disposable columns (Pierce). OPN was eluted from the 2A1-protein G beads with $100 \mathrm{mM}$ glycine, $500 \mathrm{mM} \mathrm{NaCl}$, pH 2.5, and immediately neutralized. Fractions were analyzed by SDS-PAGE, and proteins visualized by non-ammoniacal silver staining or by western blotting. Positive fractions were pooled, desalted on PD10 columns (GE Healthcare Bio-Sciences, Piscataway, NJ), quantitated by ELISA and lyophilized.

\subsubsection{Monoclonal Anti-OPN Antibodies}

The monoclonal anti-osteopontin antibodies were created and characterized in the Denhardt laboratory by Dr. Aaron Kowalski (Kowalski, 2005). The antibodies used included mAK2A1 (2A1), mAK3D9 (3D9), mAK1G4 (1G4) and mAK2C5 (2C5). Large quantities of these antibodies were generated in mice injected with hybridoma cells and purified from the ascites fluid by Dr. Yacov Ron.

\subsubsection{Chronic Restraint Stress (CRS)}

Eight to ten-week-old mice were subject to an established CRS protocol with some modification (Yin et al., 2000). $\mathrm{OPN}^{+/+}$and $\mathrm{OPN}^{-/-}$mice were each divided into control and stress groups. Mice used in one study were randomized by evenly distributing mice from the same litter to different treatment groups so as to minimize 
the influence of litter and age variations. Mice were immobilized individually in well ventilated cylindrical wire mesh restrainers (thanks to Dr. Pat Buckendahl for generously allowing us to use her restraining devices) sized $12 \mathrm{~cm}$ (length) x $2.5 \mathrm{~cm}$ (diameter) that were clamped on both ends while ensuring that they were not squeezed or compressed. The restrained mice were held horizontally in their home cages during the restraint sessions. They were restrained for 12 hours daily followed by a 12 hourrecovery. Food and water were provided during the recovery period ad libitum.

Control animals were undisturbed in their home cages or injected with PBS parallel to the antibody or OPN injection. Six mice were used in each treatment group whenever possible or the data from parallel experiments were combined for the statistical analysis. Due to the difference in sensitivity to stress, Balb/c mice were treated for 2 cycles while 129 mice were treated for 3 cycles of physical restraint (Fig 3.1). Animal body weight was usually recorded before and after treatment. 


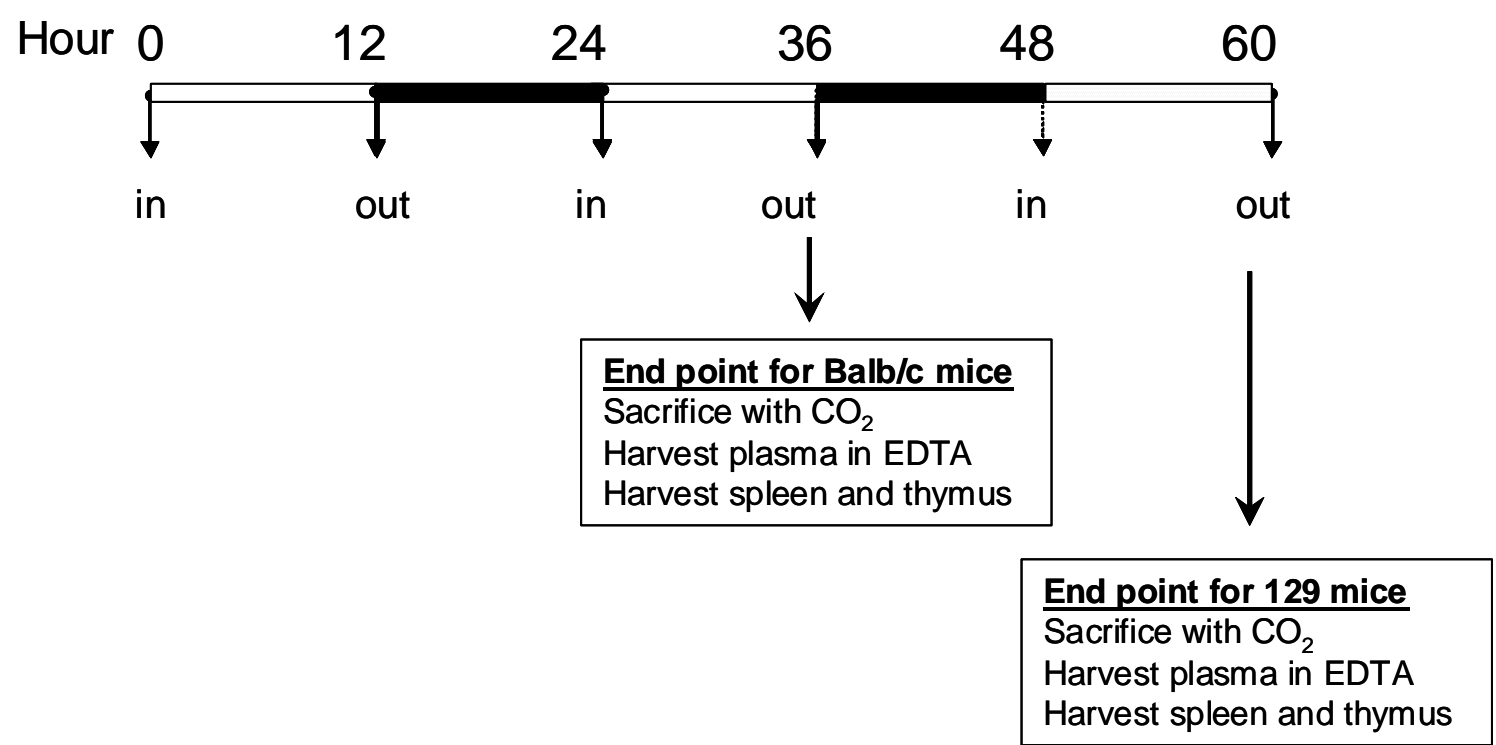

Fig 3.1. Diagram of the CRS protocol. The animal was put into the restrainer for 12 hours and released for 12 hours. The 24 hour-cycle was repeated twice for Balb/c mice and three times for 129 mice. Food and water were only available during the free session. Treatment was terminated at the end of the restraint session. The blood, spleen, thymus and adrenal glands of the mice were harvested for analysis.

\subsubsection{Endpoint harvest}

At the end of the restraint stress session, Animals were sacrificed with $\mathrm{CO}_{2}$ inhalation and the blood, spleen, thymus and adrenal glands were harvested. Blood was drawn immediately by cardiac puncture. Approximately $0.5-0.8 \mathrm{ml}$ blood was collected from each mouse and mixed with $50 \mu 1$ of $50 \mathrm{mM}$ EDTA in PBS (anticoagulant). All blood samples were kept on ice before centrifugation. Plasma samples were collected 
by centrifugation at $4^{\circ} \mathrm{C}$ for $15 \mathrm{~min}$ at $10,000 \mathrm{rpm}$ in a microcentrifuge. Supernatants were transferred to fresh tubes and stored at $-80^{\circ} \mathrm{C}$. The spleen and thymus were excised and put into $1 \mathrm{ml}$ tissue culture medium for preservation. The weight of each organ was recorded. Adrenal glands were extracted in some experiments and immediately preserved in RNA-Bee (Cat\# CS-104B, Tel-test, inc., Friendswood, TX) for mRNA extraction.

\subsubsection{Administration of Purified OPN}

Purified mouse fibroblast OPN was re-hydrated from lyophilized stock and diluted in sterile PBS before use. This OPN is phosphorylated at a few randomly located serine/threnine sites (out of some 30 potential sites) and presumably behaves as un-phosphorylated OPN (Christensen et al., 2005). $\mathrm{OPN}^{-/}$mice were divided into 3

groups: (A) control group, (B) CRS group injected with PBS (C) CRS group injected with OPN in PBS. Mice in Group (C) were injected intraperitoneally daily with $5 \mu \mathrm{g}$ of OPN in $100 \mu 1$ of PBS starting 3 days before the first restraint cycle and continuing through the restraint sessions. Mice received 25-30 $\mu \mathrm{g}$ OPN by the end of treatment depending on the number of restraint cycles. The mice in group (B) received $100 \mu$ of PBS, using the same schedule as group (C), and were similarly restrained. Mice in control group (A) were kept in their home cages undisturbed.

\subsubsection{Administration of Anti-OPN Monoclonal Antibodies}

The monoclonal antibody was diluted in sterile PBS to $0.66 \mu \mathrm{g} / \mu \mathrm{l}$. Wild type $\mathrm{OPN}^{+/+}$mice were divided into the (A) control group, (B) CRS group injected with PBS 
(C) CRS group injected with anti-OPN mAb in PBS. Mice in Group (C) were injected with $100 \mu \mathrm{g}$ of anti-OPN mAb in $150 \mu \mathrm{l}$ of PBS through an intraperitoneal (i.p.) route starting 24 hours before the first restraint cycle and then immediately before each restraint session. The total amount of anti-OPN mAb received at the end of treatment was 300-400 $\mu$ g depending on the number of restraint cycles. CRS group (B) received $150 \mu 1$ of PBS and was subjected to restraint as group (C). Control group (A) mice were kept in their home cages undisturbed.

\subsubsection{Measurement of Corticosterone, CRH and ACTH in Plasma}

The levels of corticosterone in plasma samples were assessed with a corticosterone ELISA kit from IBL America (Minneapolis, MN, Cat\# RE52211) according to the manufacturer's instructions. The levels of CRH (corticotrophinreleasing hormone) in plasma was measured by a mouse/rat CRH-HS ELISA kit from Yanaihara Institute Inc. Shizuoka, Japan (Cat\# YK131), which was developed for high specificity and sensitivity detection of mouse/rat CRH. The levels of ACTH (adrenocorticotropic hormone) were measured by an ACTH ELISA kit from MDbiosciences (St Paul, MN, Cat\# ACTH.96) according to the manufacturer's instructions.

\subsubsection{Cytokine Measurements in Plasma.}

Cytokine levels in plasma were assayed with LINCOplex mouse cytokine/chemokine kit (Linco Research, Cat\#MCYTO-70K). Luminex assays were based on a technology using multi-analyte profiling beads which enabled the detection 
and quantitation of multiple protein targets simultaneously. Undiluted plasma samples were incubated at $4^{\circ} \mathrm{C}$ for 16 hours with color-coded beads for cytokines, IL-10, IL-12, IL-6, TNF- $\alpha$, GMCSF, MIP-1 $\alpha$, MCP-1, IL-17, and IL-13. The beads were then incubated with the detection antibody and the signals were quantified by Luminex 100 . Data were analyzed with the MasterplexQT software by MiraiBio.

\subsubsection{Determination of OPN Level in Plasma}

High-binding ELISA plates were coated with purified anti-OPN Ab (R\&D Systems, AF808) at $0.8 \mu \mathrm{g} / \mathrm{ml}$ in PBS for overnight at $4^{\circ} \mathrm{C}$. Coated wells were blocked with 1\% BSA, 5\% sucrose in PBS and incubated for 1 hour before samples were applied to wells. Plasma samples were diluted 1:100 in assay diluent (PBS $+1 \%$ BSA) and $100 \mu \mathrm{l}$ of diluted samples were added to the wells. After 2 hours incubation at room temperature, the plate was washed and detection was performed by incubating the plate with $100 \mu \mathrm{l}$ of biotinylated anti-OPN mAb at $0.1 \mu \mathrm{g} / \mathrm{ml}$ (BAF808, R\&D systems) at room temperature for 2 hours. After the plate was washed, a secondary detection reagent, $100 \mu \mathrm{l}$ of streptavidin-HRP (1:200 dilution, DY998, R\&D systems) was added to the plate and incubated for $20 \mathrm{~min}$. For color development, $100 \mu \mathrm{l}$ of 3,3',5,5'tetramethylbenzidine (TMB) liquid substrate system (T8665, Sigma, St Louis, MO) was added to the washed plate and incubated for 15-20 min. When color developed to an appropriate level, $50 \mu 1$ of the stop solution was added to each well and absorbance was determined by a spectroMax microplate reader (Molecular Devices) at $450 \mathrm{~nm}$. 
Recombinant mouse OPN (441-OP, R\&D systems) was used as a protein standard in the OPN ELISA. The assays were carried out in triplicate.

\subsubsection{Analysis of Immune Cell Populations}

Blood: After removal of plasma the blood samples were mixed with $1 \mathrm{ml}$ of a red blood cell lysing buffer (Sigma, St Louis, MO) and incubated on ice for 5 min to lyse the red blood cells. The mixture was then diluted in $10 \mathrm{ml}$ of PBS and spun at $1000 \mathrm{rpm}$ for $5 \mathrm{~min}$. The white blood cell pellets were washed with $10 \mathrm{ml}$ PBS again and then resuspended in $100 \mu$ of FACS buffer (PBS $+2 \%$ FBS).

Spleen and Thymus: single cell suspensions were prepared by grinding the tissue through a $70-\mu \mathrm{m}$ cell strainer with a syringe plunger. Red blood cells were lysed by adding $1 \mathrm{ml}$ of ACK lysing buffer (Invitrogen, Cat\# 0060005DG) to the cell pellet and incubating on ice for $5 \mathrm{~min}$. Cell lysis was terminated by adding 10 volumes of PBS to the cells and centrifuging at $1000 \mathrm{rpm}$ for $5 \mathrm{~min}$. Remaining white cells were washed again and resuspended in FACS buffer.

From here, cells from the blood, spleen and thymus were processed in parallel for labeling and analysis. Specific lymphocyte subpopulations and granulocytes were identified on the basis of cell surface markers by flow cytometry: fluorescenceconjugated monoclonal antibodies including rat anti-mouse CD4 (clone RM4-5), CD8 (clone 53-6.7), and CD45R/B220 (clone RA3-6B2) (all from BD BiosciencesPharMingen, San Diago CA) were used. Cells were incubated with BD Fc Block (clone 2.4G2) (BD Biosciences-PharMingen, San Diego CA) for 10 min to block non-specific 
binding and then incubated with specific mAbs for 20 min on ice, washed with PBS and analyzed on a multicolor flow cytometer (FACScalibur, Becton Dickinson, San Jose, CA). Data were acquired and analyzed with CellQuest software (Becton Dickinson, San Jose, CA).

\subsection{Results}

\subsubsection{Comparison of the Response of WT and KO Mice to Chronic Restraint}

\section{Stress}

To verify the involvement of OPN in the stress response revealed in the HU model, I used a well established chronic stress model (CRS) (Yin et al., 2000) to evaluate $\mathrm{OPN}^{-/-}$mice. To reduce the possibility that differences in genetic background could affect the response to stress, OPN-deficient mice under Balb/c background were tested in parallel with 129 mice. The additional advantage of Balb/c mice was that they were backcrossed for more than 10 generations and therefore under a pure genetic background while the original OPN-deficient mice created in the Denhardt laboratory is under mixed background between two 129 strains (S1, S7). When subjected to CRS, an $8 \%$ body weight reduction was observed in Balb/c WT control whereas there was less than a 5\% reduction in Balb/c OPN-deficient mice, which is a statistically significant lower weight loss in $\mathrm{KO}$ mice (Fig. 3.2). In terms of thymus and spleen atrophy, CRS caused a $60 \%$ reduction in thymus weight in WT but only $30 \%$ in OPN-deficient mice. In general I observed across experiments that the reduction in spleen weight was less pronounced in the CRS model compared to the HU model. Both WT and KO mice showed a $20 \%$ reduction of spleen weight after CRS (Fig. 3.3). OPN-deficient mice in 
the 129 background were subjected to 3 cycles of restraint. Nevertheless, similar to $\mathrm{Balb} / \mathrm{c}$ mice, CRS caused a $60 \%$ reduction in thymus weight in $\mathrm{OPN}^{+/+}$mice but only a $30 \%$ in the 129 OPN-deficient mice. A 40\% reduction of spleen weight was observed in WT mice but only 10\% in OPN-deficient mice (Fig. 3.3). These results indicated that CRS caused lymphoid organ atrophy in both Balb/c and 129 wild type mice to a significantly greater extent than in $\mathrm{OPN}^{-/-}$mice. This confirms that OPN indeed plays a role in mediating stress-induced responses in immune organs.

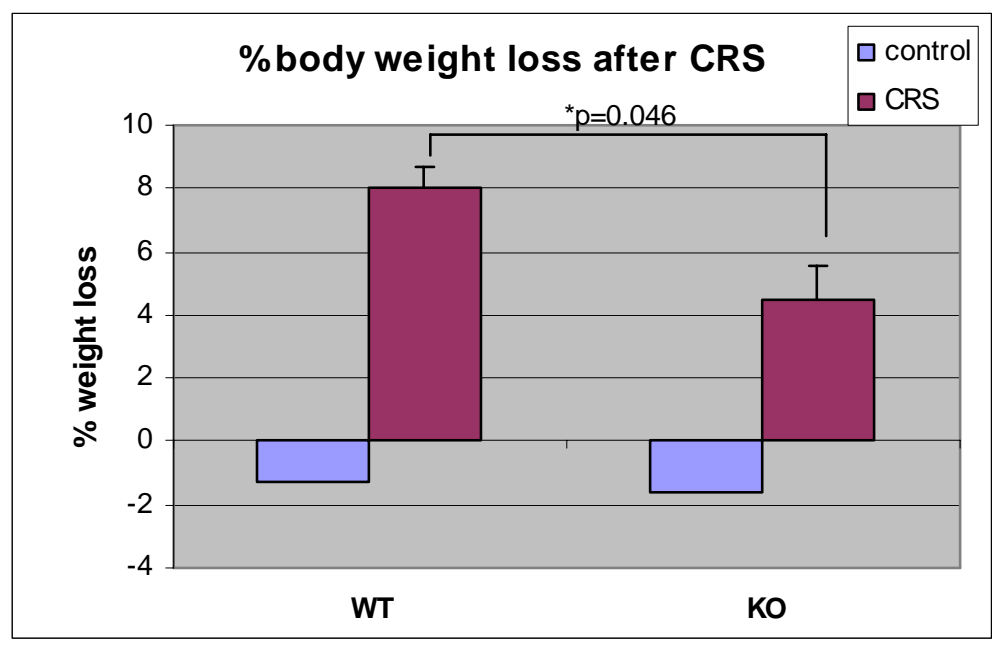

Fig. 3.2. CRS-induced body weight loss in Balb/c OPN WT and KO mice. Body weights were recorded before and after CRS. Percent of change was calculated by normalizing to pre-CRS weight. Data represent mean \pm SEM of 5- 6 animals/group. Statistical significance ( $p$-value) was generated by student $t$ test in Excel software. 

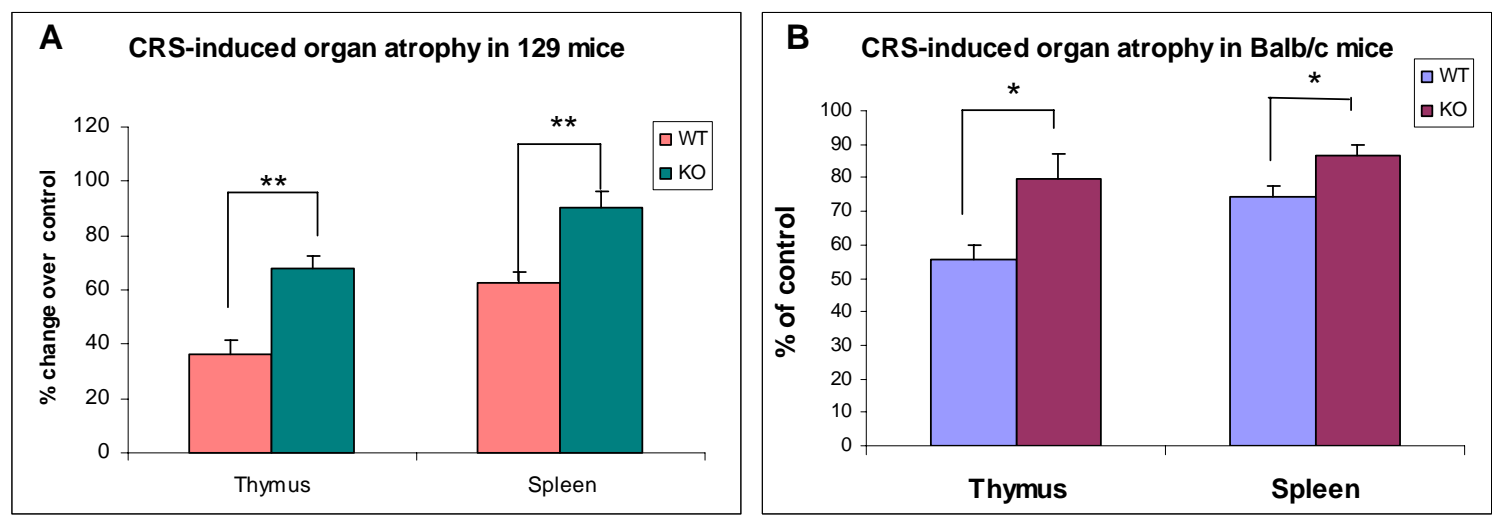

Fig. 3.3. CRS-induced organ atrophy in 129 mice and Balb/c mice. (A)

Representative data showing thymus and spleen weight change in 129 mice after 3 cycles of restraint $(n=6)$. (B) Representative data showing thymus and spleen weight reduction in Balb/c mice after 2 cycles of restraint $(n=6-9$, combined data from three independent experiments). Data represent means \pm SEM. Statistical difference between $\mathrm{OPN}^{+/+}$and $\mathrm{OPN}^{-/}$mice shown as $*=\mathrm{p}<0.05, * *=\mathrm{p}<0.01$ with student's $t$ test in Excel software.

\subsubsection{Evaluation of HPA Axis Hormones in Control and Stressed Mice}

Stress sends signals to the brain to induce the release of stress hormones. The HPA axis is a major part of the neuroendocrine system that controls reactions to stress and regulates various physiological processes including immune responses. Three major HPA hormones in mice are corticotrophin-releasing hormone (CRH), adrenocorticotropic hormone (ACTH), and corticosterone (CORT). The level of these 
hormones in the plasma changes in response to stress and each of them has been shown to interact closely with the immune system in a bi-directional manner (Chen et al., 2004). Production of cytokines can stimulate the release of glucocorticoids; in turn, HPA activation by cytokines has been found to play a critical role in restraining and shaping immune responses. Thus, cytokine-HPA interactions represent a fundamental mechanism of the maintenance of homeostasis and the development of disease during stress or infection (Calcagni and Elenkov, 2006).

Since OPN has been found to regulate corticosterone production in response to HU stress (Wang et al., 2007), I was interested to discover whether OPN directly affects corticosterone production or acts through regulating upstream hormones in the HPA axis. In addition to evaluating the corticosterone levels, two upstream hormones, $\mathrm{CRH}$ and $\mathrm{ACTH}$, of the HPA axis were also evaluated in order to identify the point where OPN interacts with this pathway (Fig. 3.4). The levels of corticosterone, CRH and $\mathrm{ACTH}$ in blood samples harvested immediately after the termination of CRS were tested with commercial ELISA kits. Results showed that the level of corticosterone was highly up-regulated in stressed WT mice. However, in KO mice, there was no significant difference in corticosterone levels between un-stressed control and stressed mice (Fig. 3.5).

Interestingly, the basal level of corticosterone was significantly higher in $\mathrm{KO}$ mice, implying that OPN plays a role in controlling the production of corticosterone; in the absence of OPN, corticosteroid production is apparently elevated leading to a persistent high level of corticosterone in circulation in the absence of applied stress. On the other hand, due to the negative feedback mechanism of CORT towards CRH and 
ACTH, upregulation of CORT leads to a reduction of CRH and ACTH. The results from the ACTH ELISA assay reflect this reciprocal relationship by showing that the levels of ACTH in WT mice were higher in control mice but largely suppressed in the stressed mice (Fig. 3.6). However, the plasma level of CRH is at the low end of the detection sensitivity of the ELISA kit; therefore, no difference was detected between each experimental group in this assay (Fig 3.7).

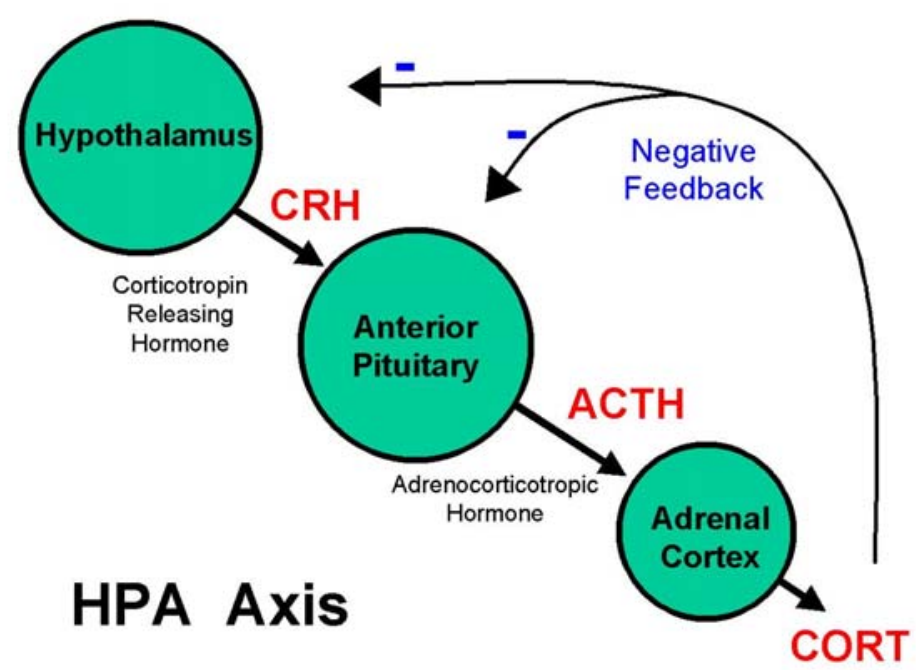

Fig. 3.4. The HPA axis. The hypothalamic-pituitary-adrenal axis is a feedback loop that includes the hypothalamus, pituitary and adrenal glands. The main hormones that constitute the HPA axis are corticotropin-releasing factor (CRF), adrenocorticotropic hormone $(\mathrm{ACTH})$ and corticosteroid (CORT). The loop is completed by the negative feedback of corticosteroid on the hypothalamus and pituitary. The release of corticosteroid into circulation has a number of effects, including elevation of blood glucose for increased metabolic demand. Corticosteroid also negatively affects the immune system and prevents the release of immuno-mediators (Jacobson 2005). 


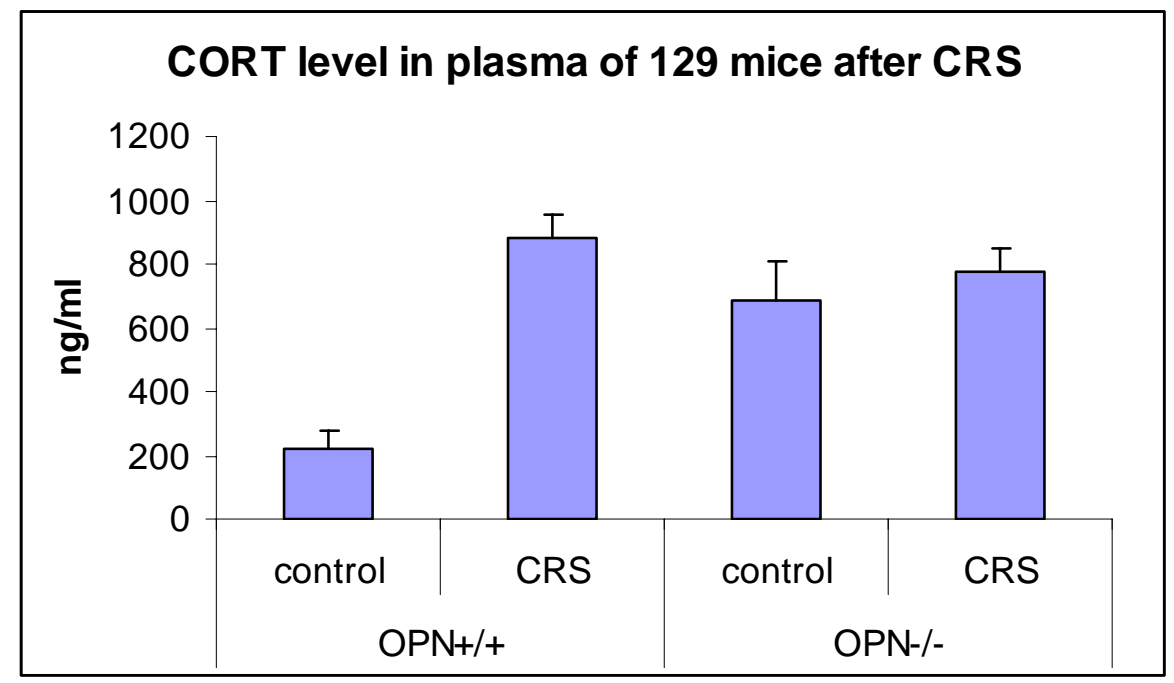

Fig. 3.5. Corticosterone levels in plasma of CRS-treated mice. Blood samples from $\mathrm{OPN}^{+/+}$and $\mathrm{OPN}^{-/-}$mice were harvested immediately after the termination of CRS and plasma samples were isolated and stored at $-80^{\circ} \mathrm{C}$ until assay. CORT assay (Corticosterone ELISA kit, IBL Inc.) was conducted with plasma samples diluted 40fold and incubated in a plate pre-coated with anti-corticosterone antibody. Data represent mean \pm SEM of 5- 7 samples. 


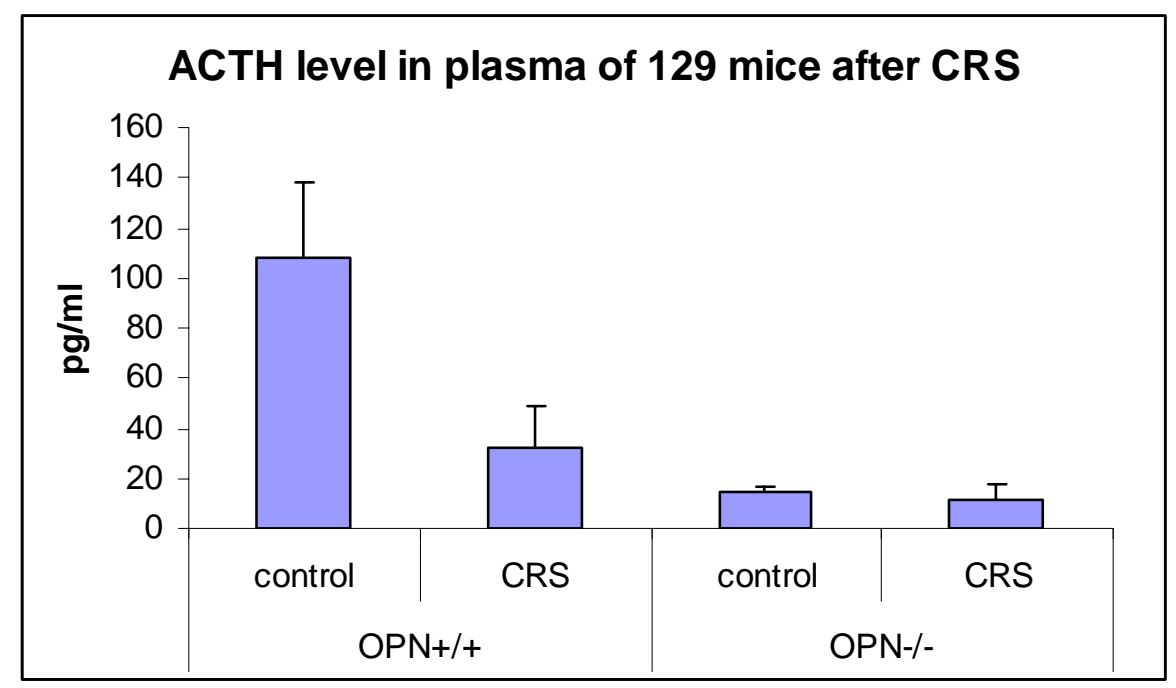

Fig. 3.6. Plasma ACTH Level in $129 \mathrm{OPN}^{-/-}$Mice. ACTH levels in plasma of WT and KO 129 mice before and after CRS were measured with an ACTH ELISA kit. Data represent mean \pm SEM of 5- 7 samples.

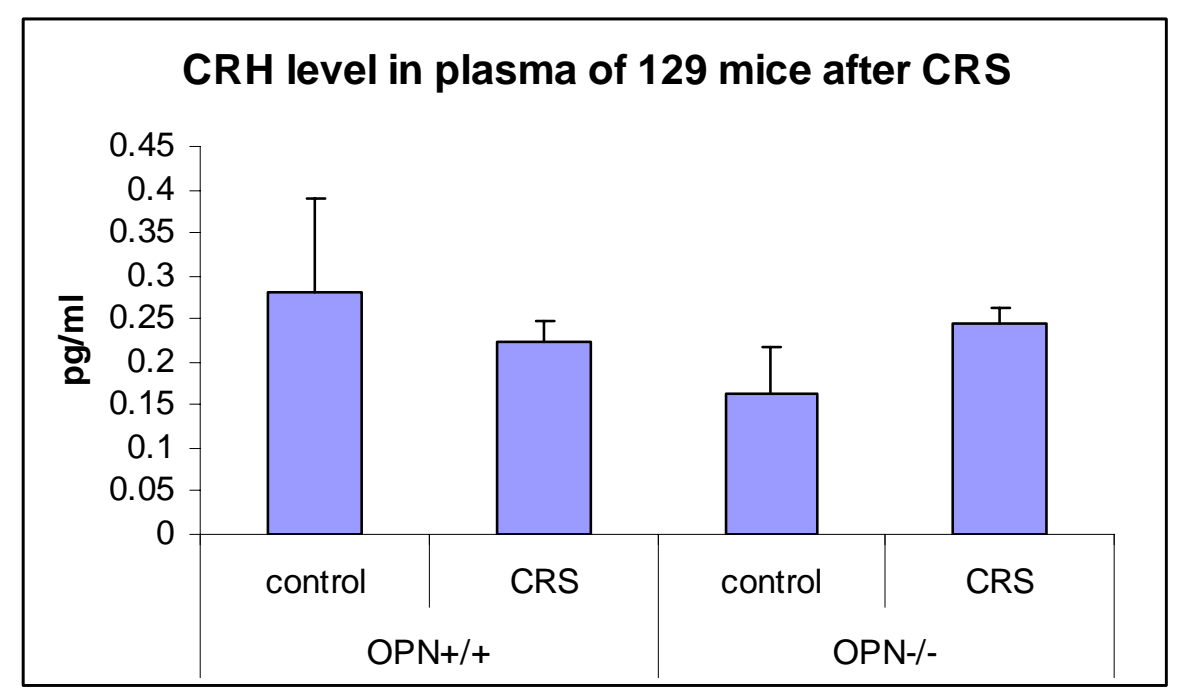

Fig. 3.7. Plasma CRH levels in $129 \mathrm{OPN}^{-/-}$mice. CRH levels in the plasma of WT and KO 129 mice before and after CRS were measured using aCRH ELISA kit. Data represent mean \pm SEM of 5- 7 replicates in each group. 


\subsubsection{Cytokine Production in the Plasma of Stressed Mice}

Stress activates the immune system and stress hormone production can lead to cytokine dysfunction. Stress seems to favor a Th2 shift and suppresses Th1 cytokines and thereby leads to increased susceptibility to inflammation and infection in a stress situation (Calcagni and Elenokov, 2006). OPN is known to regulate the balance of Th1 and Th2 cytokines and T cell polarization (Shinohara et al., 2005).

To determine the effect of OPN deficiency on the CRS-induced immune response, cytokine production in the plasma of OPN-deficient mice after stress was assessed by a multiplex Luminex mouse cytokine kit. Out of 11 cytokines tested on the multiplex panel, four cytokines, MCP-1, IL-12, IL-13, and IP-10, were detected (Fig. 3.8). These results showed that either in the baseline condition or under stress, $\mathrm{OPN}^{-/-}$ mice had reduced levels of these cytokines in the plasma compared to $\mathrm{OPN}^{+/+}$mice. A relatively high level of the chemokine IP-10 was detected in the plasma from both $\mathrm{OPN}^{+/+}$and $\mathrm{OPN}^{-/-}$mice. However, its level was not significantly changed by CRS.

OPN has been shown to be up-regulated concomitantly with MCP-1 in diseased kidney (Mezzano, et al., 2000, 2001). OPN-deficient cells exhibit a diminished response to MCP-1 induced migration (Breummer et al., 2003, Zhu et al., 2004). Although the plasma OPN levels increased with $\mathrm{CRS}$ in $\mathrm{OPN}^{+/+}$mice, the MCP-1 level did not change between control and CRS. The basal MCP-1 level in $\mathrm{OPN}^{-/}$mice was slightly lower compared to $\mathrm{OPN}^{+/+}$mice (see Fig 3.13), but it was not increased significantly after CRS. This result implies that OPN affects stress and immune cell function through different mechanisms. 
Data for IL-12 showed a dramatic reduction of IL-12 production in $\mathrm{OPN}^{-/}$mice which is consistent with the known fact that OPN is required for IL-12 production. IL13 is a cytokine secreted by many cells especially Th2 cells and it is a mediator of allergic inflammation. It's not clear what effect OPN has on IL-13 production, but the data here suggest that since OPN inhibits Th2 cytokine production, it may have a direct or indirect inhibitory effect on IL-13.
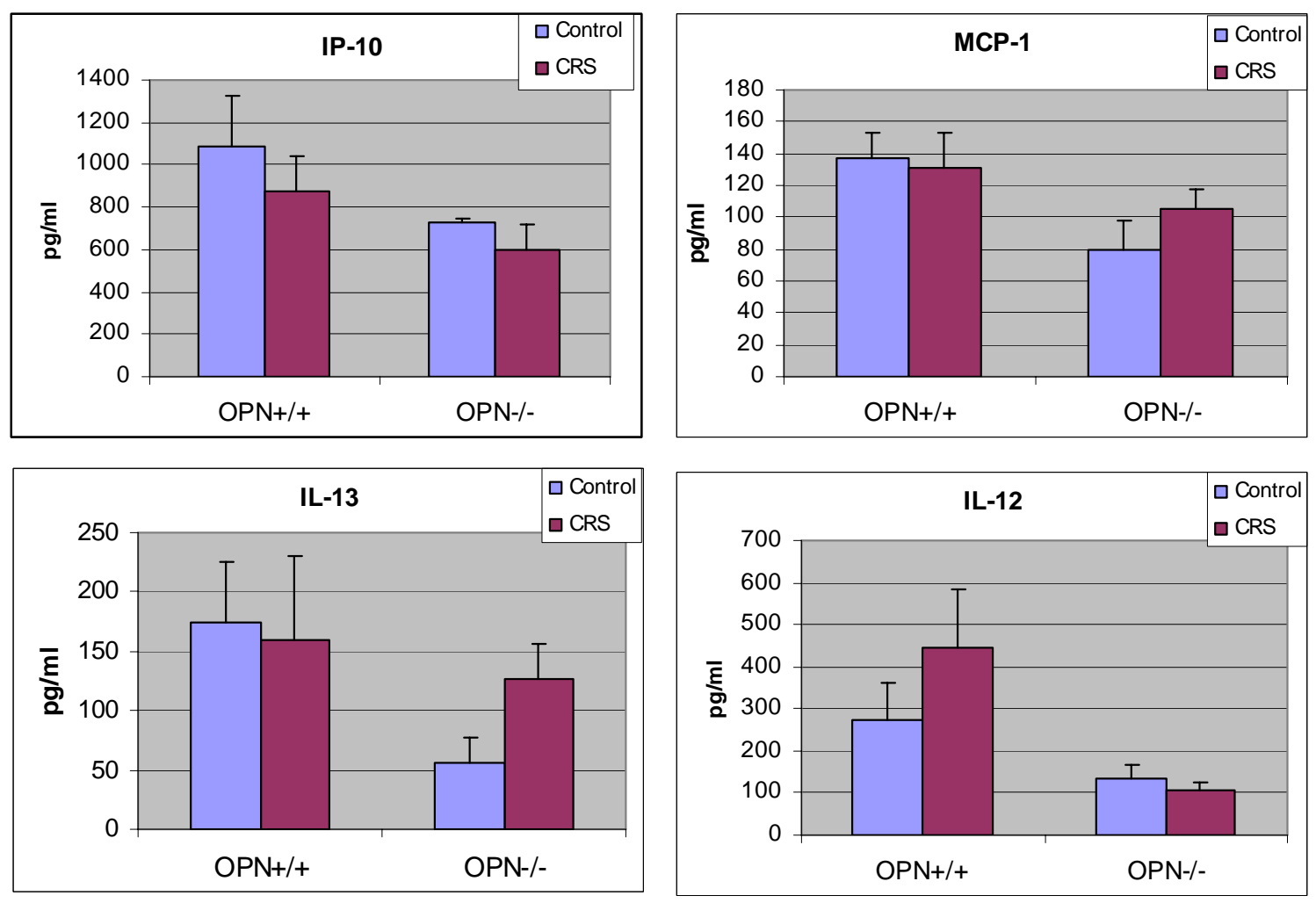

Fig. 3.8 Production of certain cytokines in control and stressed 129 mice. Cytokine

levels in plasma samples were measured using the Lincoplex mouse cytokine/chemokine kit. Four cytokines were measured simultaneously based on flow cytometry technology on a Luminex 100 System. Data represents the mean \pm SEM (n $=6$ ). 


\subsubsection{Immune Cell Copulations in Different Immune Compartments}

To determine whether OPN contributes to stress-induced immune cell redistribution, lymphocyte populations in the blood, spleen, and thymus were examined by flow cytometry. As shown in Fig. 3.9 A and B, CD4+ T cells were significantly decreased in the blood and spleen of WT mice after CRS, indicating that stress led to a reduction in $\mathrm{CD} 4+\mathrm{T}$ cells possibly due to apoptosis in the periphery and secondary lymphoid organs. However in the $\mathrm{OPN}^{-/-}$mice, the loss of $\mathrm{CD}^{+} \mathrm{T}$ cells in both of these compartments was not significant. Interestingly, the B cell population exhibited an opposite trend in response to stress in $\mathrm{OPN}^{+/+}$and $\mathrm{OPN}^{-/-}$mice. While B cells increased in blood of WT mice after CRS, they decreased in the $\mathrm{OPN}^{-/-}$mice (Fig. 3.9A). Although in mice subjected to HU (see fig 2.5 in chapter 2), all 3 major lymphocyte populations were significantly reduced in spleen, resulting in a dramatic reduction in the mass of the spleen; in mice subjected to CRS, only CD4+T cells were affected significantly. This may explain why I often observed weak or insignificant spleen atrophy in CRS experiments. Furthermore, all three lymphocyte populations were not affected by CRS in $\mathrm{OPN}^{-/-}$mice (Fig. 3.9B).

As determined before by the weight, the thymus is the organ most affected by stress showing a dramatic reduction of mass after CRS. The data from cell type profiling are consistent and confirmed this result. CRS caused a statistically significant reduction in lymphocytes numbers in both $\mathrm{OPN}^{+/+}$and $\mathrm{OPN}^{-/-}$mice, but the degree of reduction was more dramatic in $\mathrm{WT}$ mice than in $\mathrm{OPN}^{-/}$mice (Fig. 3.9C). Thymus tissue consists of $80 \%$ double positive (DP) T cells $\left(\mathrm{CD}^{+} / \mathrm{CD}^{+}\right)$, therefore the reduction in the DP population has the greatest impact on the total mass of the organ. 
These data correlate with the organ weight results and identify the cell types contributing to the organ atrophy.
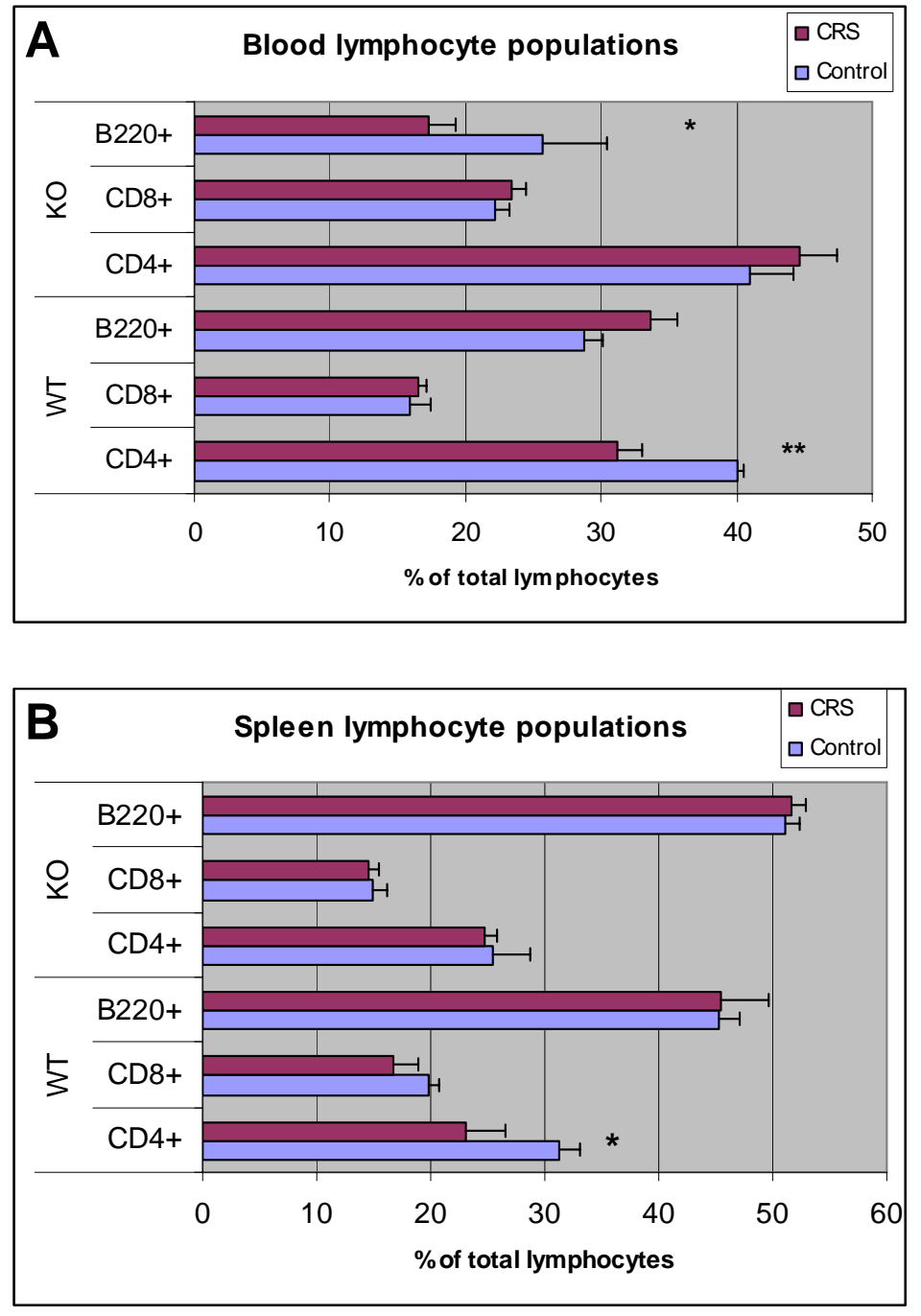


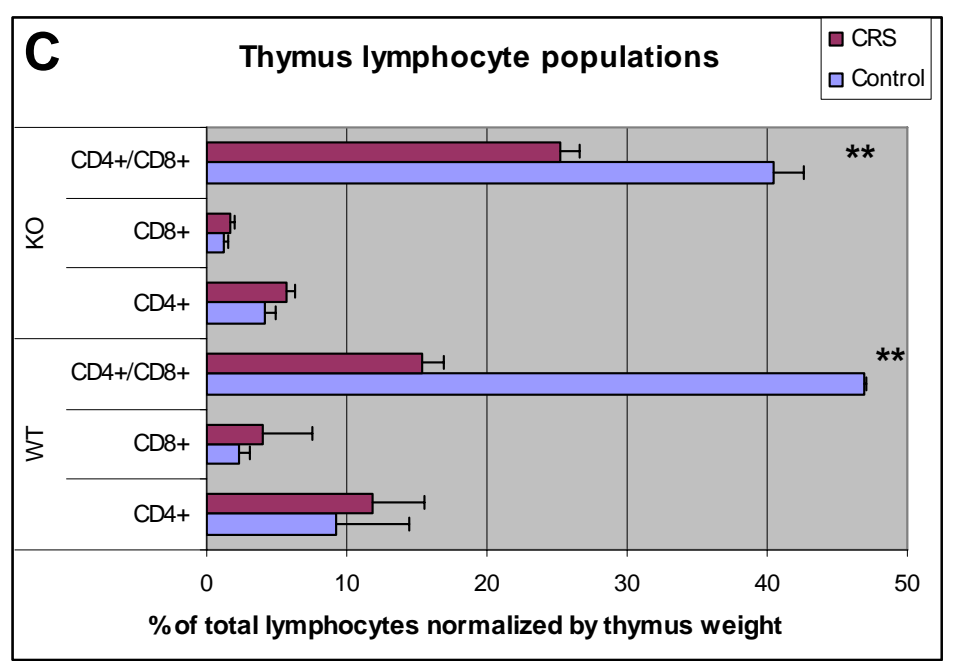

\section{Fig. 3.9. Effect of CRS on lymphocyte populations in blood, spleen and thymus.}

Immune cells harvested from blood, spleen and thymus were stained with antibodies for CD4, CD8 and B220 conjugated with fluoro-cytochromes. Percentages of each cell population were quantified by flow cytometry. Data represent mean $\pm \mathrm{SEM}$ of 4-5 animals. *, Statistical significance at $\mathrm{p}<0.05 ; * *$, statistical significance at $\mathrm{p}<0.01$. (A) lymphocyte populations in blood; (B) lymphocyte populations in spleen; (C) lymphocyte populations in thymus normalized by thymus weight.

\subsubsection{OPN Injection in OPN-deficient mice}

To directly demonstrate that stress-induced organ atrophy is promoted by the presence of OPN, I injected purified mouse fibroblast OPN into OPN-deficient mice prior to and during $\mathrm{CRS}$. $\mathrm{OPN}^{-/-}$mice were injected intraperitoneally with $5 \mu \mathrm{g}$ of OPN daily for three days prior to starting the restraint. The injections continued at the beginning of each 24-h restraint cycle to maintain a constant presence of the exogenous OPN in the circulation. I found that when both male and female mice were used in CRS 
experiments, male mice responded to OPN better than female mice and that the thymus was more sensitive to CRS than spleen (Fig. 3.10). When this experiment was repeated in $\mathrm{Balb} / \mathrm{c} \mathrm{OPN}^{-/}$male mice, CRS led to a mild reduction of thymus weight of $27 \%$ whereas injection of OPN caused a $51 \%$ reduction of thymus weight (Fig. 3.11). These results have been closely reproduced in several other experiments using $\mathrm{OPN}^{-/}$mice in the 129 background. Furthermore, OPN also promoted the further increase of corticosterone in plasma of $\mathrm{OPN}^{-/}$mice after CRS (Fig. 3.12) but the results from different experiments were not as consistent as organ atrophy. These results indicated that exogenous OPN supplied to OPN-deficient mice partly restored the wild type phenotype; the presence of OPN in the circulation may modulate stress hormones and other unknown factors to cause the increased organ atrophy.

To confirm the presence of OPN circulating in the blood during the experiment, plasma samples harvested at the end of the experiments were assayed for OPN levels. First, the OPN ELISA assay revealed that OPN was indeed up-regulated by CRS by about $25 \%$ in wild type mice. In OPN knockout mice, as expected, OPN was undetectable.

In studies where I supplied $\mathrm{OPN}^{-/}$mice with exogenous OPN, mice were injected with OPN from several sources: specifically preparations of OPN from RAStransformed mouse fibroblast cultures purified by Chris Kazanecki (Kazanecki, 2007) and a commercial mouse recombinant OPN expressed in a mouse myeloma cell line NS0 (R\&D Systems, 441-OP). OPN was detectable in the plasma of all samples from these experiments and the amount of OPN correlated to the number of injections each animal received. Animals receiving a total of 5 injections $(25 \mu \mathrm{g})$ had twice as much 
OPN in the plasma compared to animals receiving 3 injections (Fig • 3.13). However, even with up to 6 injections, the OPN level in the plasma reached only $30 \%$ of the wild type level. Nevertheless, these results clearly demonstrated that OPN in the plasma is essential for promoting stress-induced lymphoid organ atrophy.
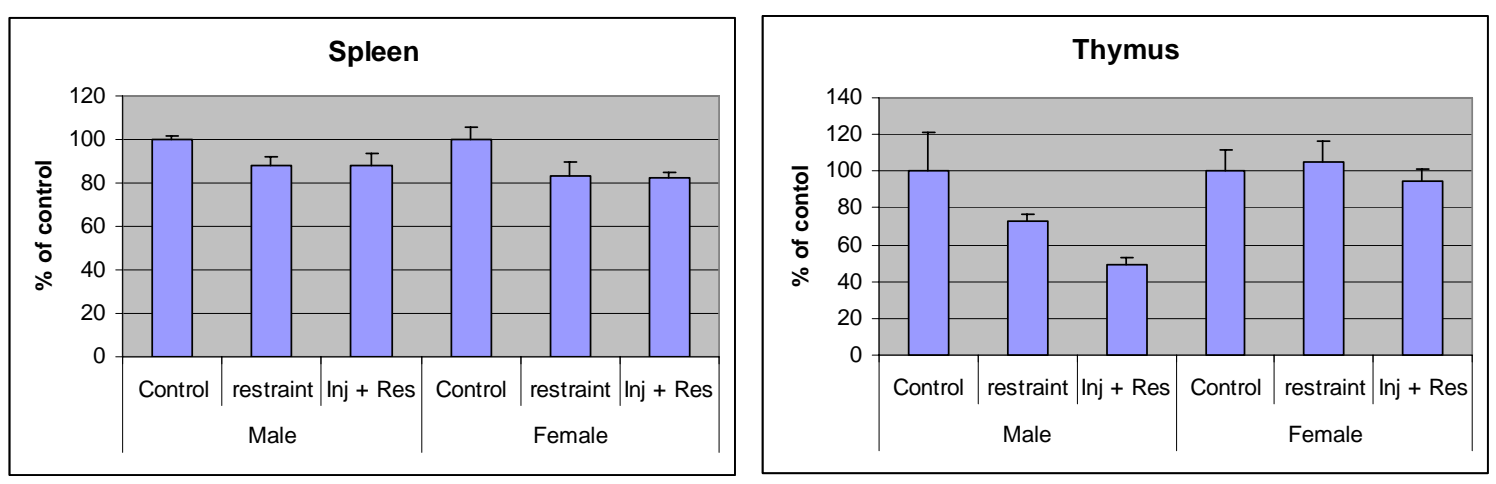

Fig 3.10. Sex-dependent and organ-dependent responses in the restoration of the wild type phenotype by OPN injection in strain 129 mice. OPN-deficient 129 mice were divided into 3 groups. Control group was untreated ( $\mathrm{n}=2$ for each gender); the second group was subjected to CRS for 3 cycles $(n=3-5)$; and the third group were injected with purified mouse fibroblast OPN $(n=3-5)$. Each mouse received $5 \mu \mathrm{g}$ of OPN daily for 3 days before and 3 days during the CRS. 


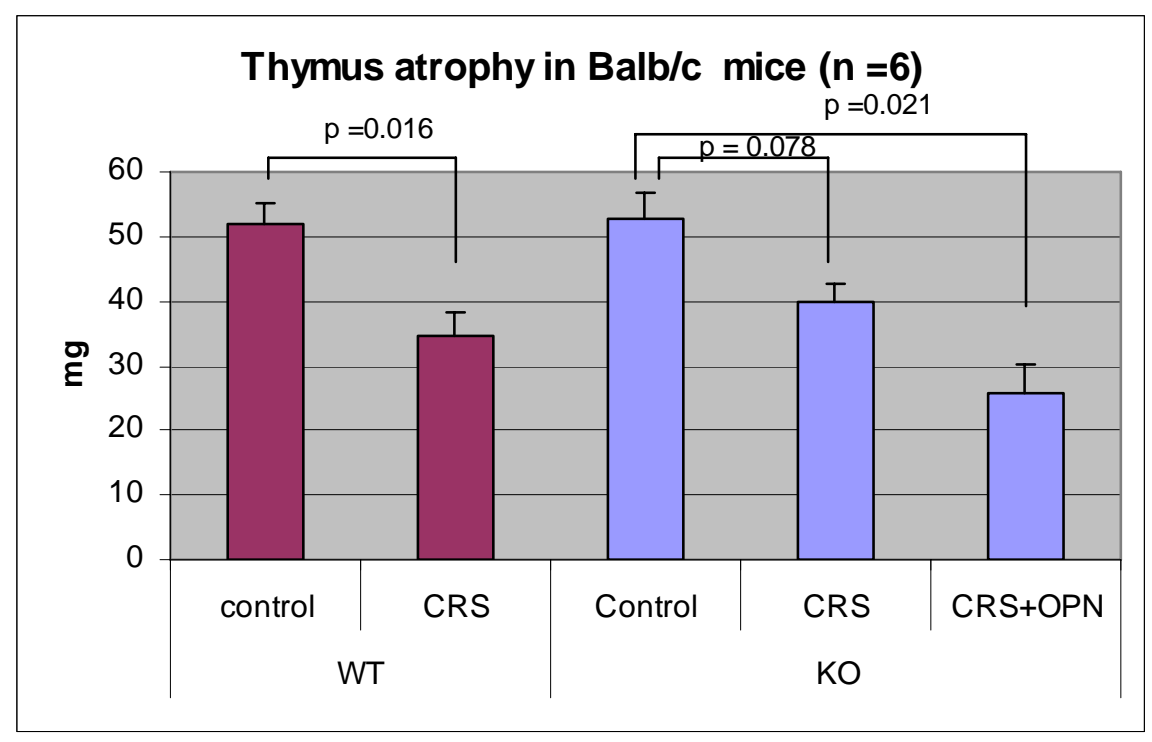

Fig. 3.11. OPN injection in Balb/c $\mathrm{OPN}^{-/-}$mice. $\mathrm{OPN}^{-/-}$mice in the Balb/c background were injected with purified OPN ( $5 \mu \mathrm{g} /$ day) 3 days before and 2 days during CRS.

Animals were divided into three groups (right, in blue): Control group $(n=6)$, untreated; CRS group $(n=6)$ was injected with PBS and restrained; CRS + OPN group $(n=6)$ was injected with OPN in PBS and restrained. Wild type littermates were treated in parallel for comparison (left, in red) with 3 animals in control group and 5 animals in CRS group. Data represent mean \pm SEM. Statistical significance indicated as $\mathrm{p}$ value generated by student $\mathrm{t}$ test in Excel software. 


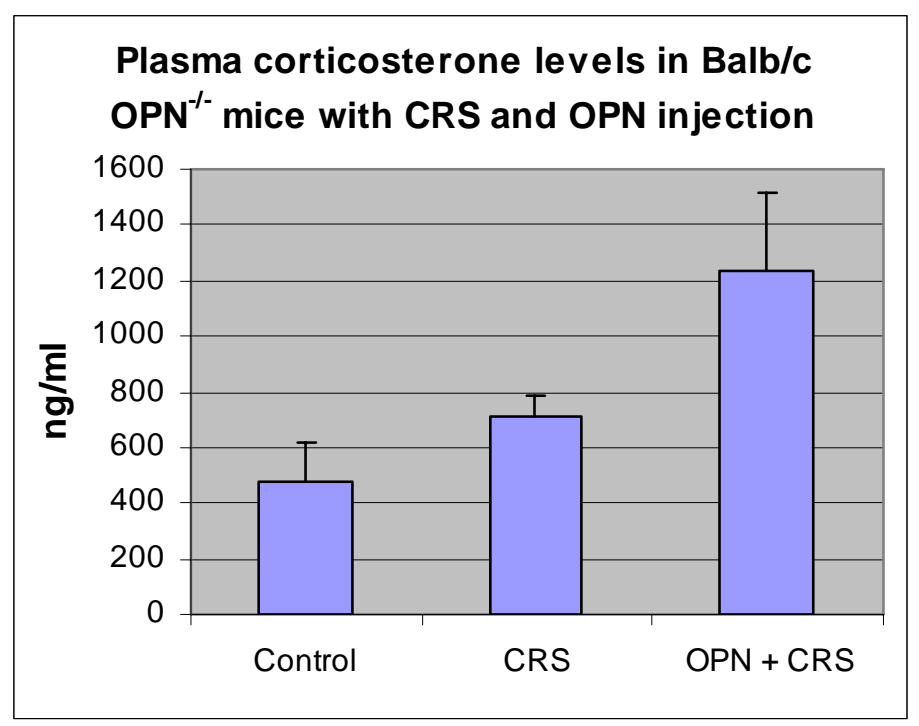

Fig. 3.12. Plasma corticosterone levels in Balb/c $\mathrm{OPN}^{-/-}$mice subjected to CRS and OPN injection. Plasma harvested immediately after termination of CRS was assayed using a CORT ELISA. The assay was conducted with plasma samples diluted 10-fold and incubated in a plate pre-coated with anti-corticosterone antibody. Data represent mean \pm SEM of 5 replicates in each group. 


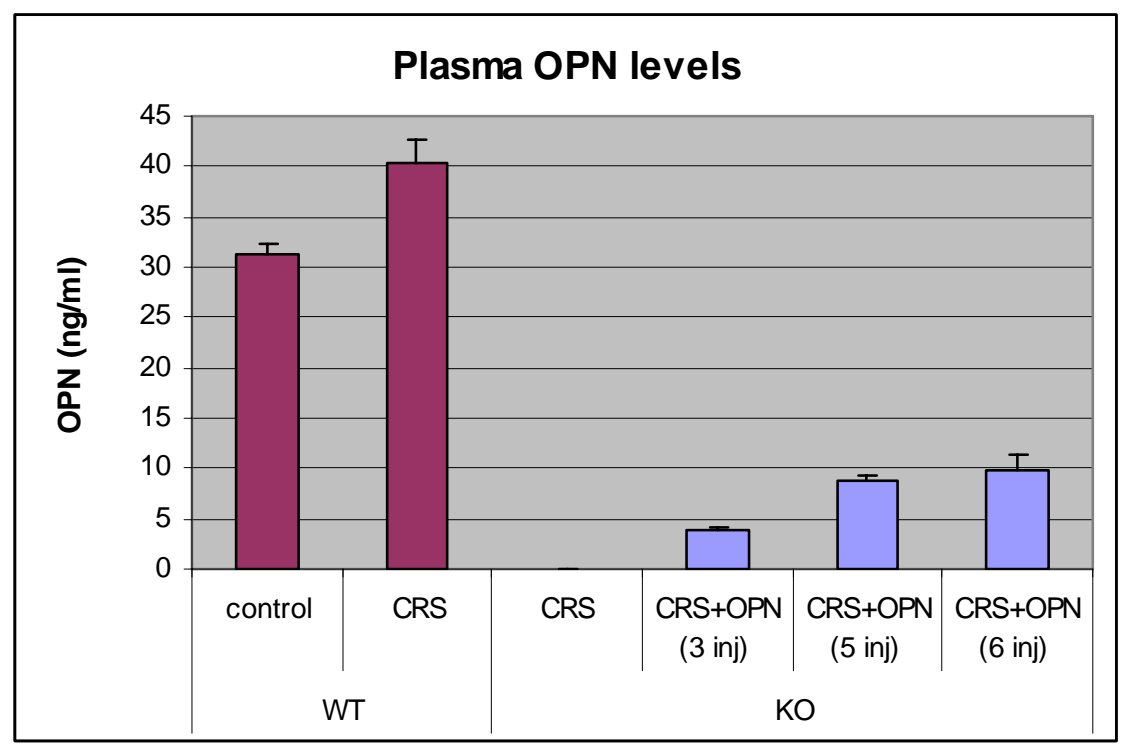

Fig. 3.13. OPN level in plasma of $129 \mathrm{OPN}^{-/-}$mice after injection of OPN. Plasma samples were harvested from 129 mice after CRS. OPN levels were assayed by ELISA using OPN antibodies from R\&D Systems. OPN concentrations were calculated with mouse recombinant OPN from R\&D Systems as a standard. Assay was conducted on samples from multiple experiments stored at $-80^{\circ} \mathrm{C}$. Data represent mean $\pm \operatorname{SEM}(\mathrm{n}=4$ 7). P-value was generated with student $t$ test in Excel software. 


\subsubsection{Anti-OPN monoclonal antibody injection in WT mice}

It was encouraging to discover that OPN can restore partially the WT phenotype of stress-induced organ atrophy in $\mathrm{OPN}^{-/-}$mice. But the other side of the coin is whether sequestering of OPN in WT mice would protect the lymphoid organs from stress-induced organ atrophy. Taking advantage of the wide variety of monoclonal antibodies generated in the Denhardt laboratory, I injected 4 different monoclonal antibodies $(2 \mathrm{~A} 1,3 \mathrm{D} 9,2 \mathrm{C} 5,1 \mathrm{G} 4)$ into $\mathrm{WT}$ mice. Each $\mathrm{mAb}$ recognizes a distinct epitope in the OPN molecule as indicated in Fig. 3.14. Naïve Balb/c mice or WT littermates of 129 OPN mice were injected with $100 \mu \mathrm{g}$ of mAb 24 hours before starting the CRS cycle and continued simultaneously with the beginning of each restraint cycle. Of the four monoclonal antibodies tested, only $2 \mathrm{C} 5$ caused a statistically significant change in thymus weight compared to CRS only group (Fig. 3.15).

Injection of 2C5 resulted in an increase in thymus weight to the level of that in the $\mathrm{OPN}^{-/-}$mice after CRS. This result has been confirmed in a second experiment. Some evidence suggests that $2 \mathrm{C} 5$ recognizes the region close to the RGD integrin binding site and may block the interaction of OPN with integrins, though this remains to be confirmed. Since mAbs recognizing other epitopes on the OPN molecule tested were not as effective in this model, the result suggests that integrin interaction is important for OPN function in mediating the stress response.

When OPN levels in mice injected with an anti-OPN mAb were measured, an increase of OPN was detected (Fig.3.16). One possible explanation is that the antibody binding to the target protein can inhibit the turnover of the protein. Nevertheless, administration of 2C5 moderately reversed severe thymus atrophy caused by stress. 
The effect of mAb $2 \mathrm{C} 5$ on preventing organ atrophy encouraged me to believe that administration of certain anti-OPN monoclonal antibodies may ameliorate stressinduced immune responses and help in impeding stress-related diseases.

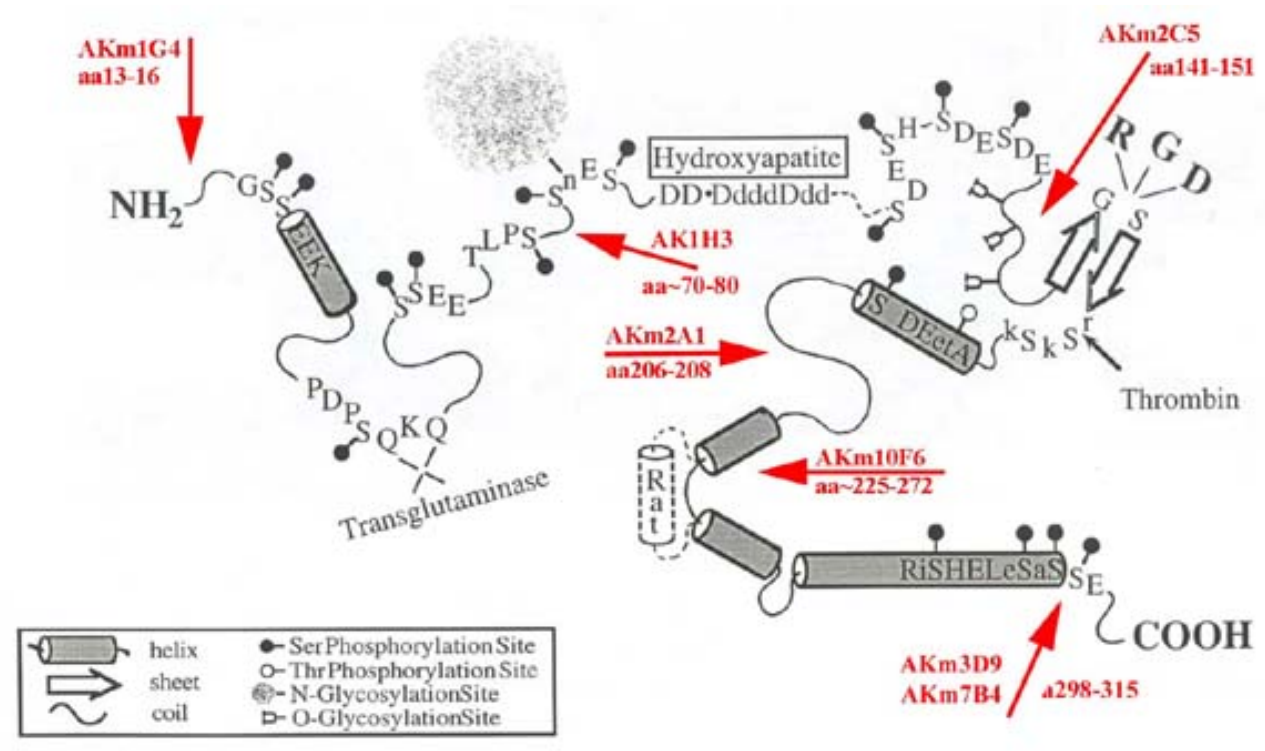

Fig. 3.14 Monoclonal antibodies binding sites on OPN molecule. Schematic of the structure of the osteopontin protein with mAb binding sites indicated by red arrow (Kowalski, 2005). Clone 1G4 and 3D9 recognize N- and C- terminal regions respectively; $2 \mathrm{~A} 1$ recognizes a region in the middle of the $\mathrm{C}$ terminal half of OPN and 2C5 may recognize a region near RGD motif which is important for integrin interaction. 

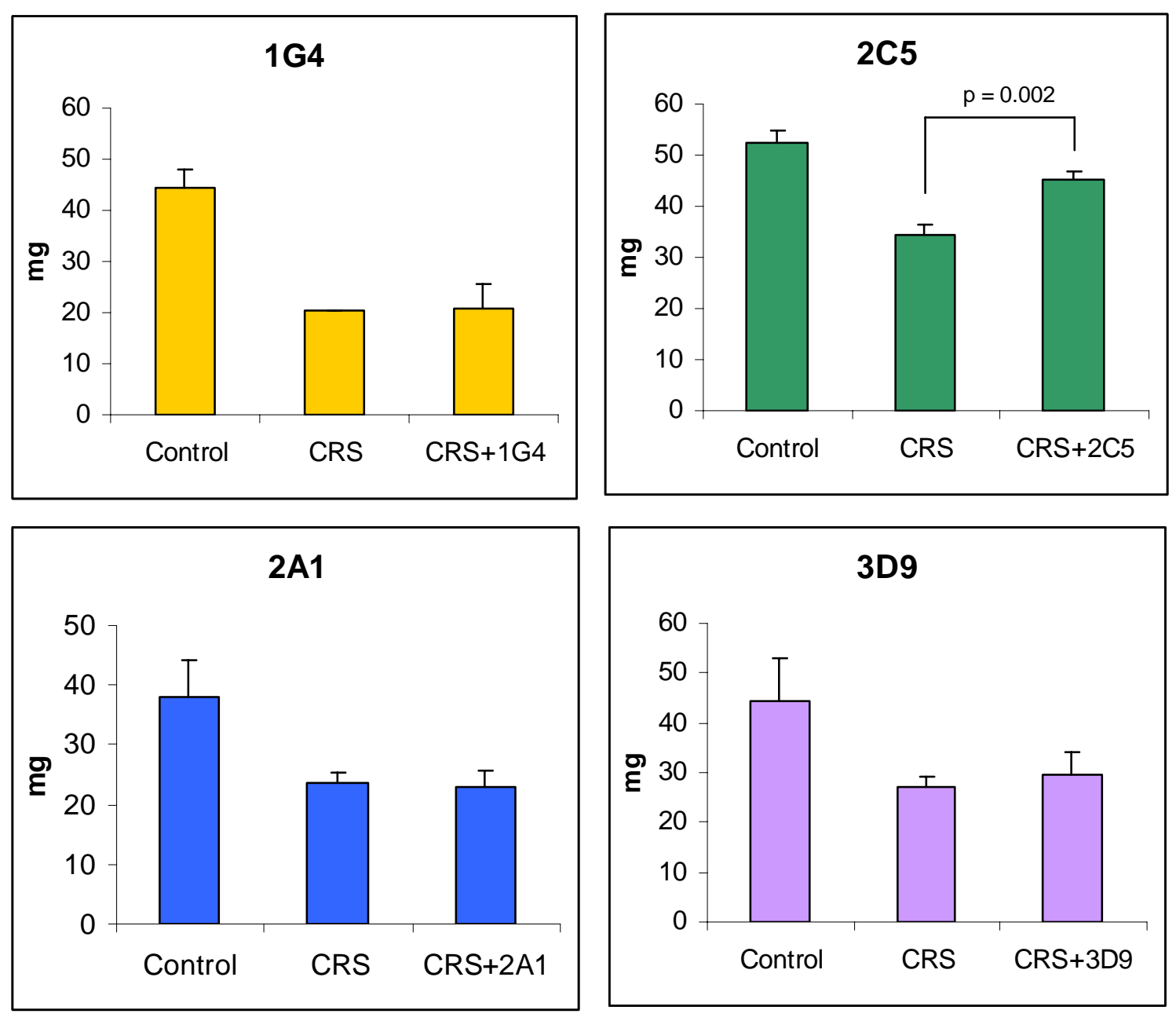

Fig. 3.15. Effect of 4 different anti-OPN monoclonal antibodies on CRS-induced thymus atrophy. In 4 independent experiments, $\mathrm{OPN}^{+/+}$mice in a Balb/c or 129 background were injected with 4 different anti-OPN mAbs (100 $\mu \mathrm{g}) 24$ hours before CRS and immediately prior to each cycle of restraint. Animals were divided into three groups: Control group $(n=2-4)$, untreated; CRS group $(n=5-6)$, injected with PBS and restrained; CRS + mAb group $(n=5-7)$ was injected with OPN in PBS and restrained. At the end of the CRS session (two 24h-cycle for Balb/c mice, three 24h-cycle for 129 mice), the spleen and thymus were evaluated for loss of weight compared to the control 
group. Spleen data are not shown here because CRS caused insignificant changes in spleen weight in all 4 experiments. Data represent mean \pm SEM. The statistical significance indicated by the $p$ value was generated by the Student $t$ test in Excel software.

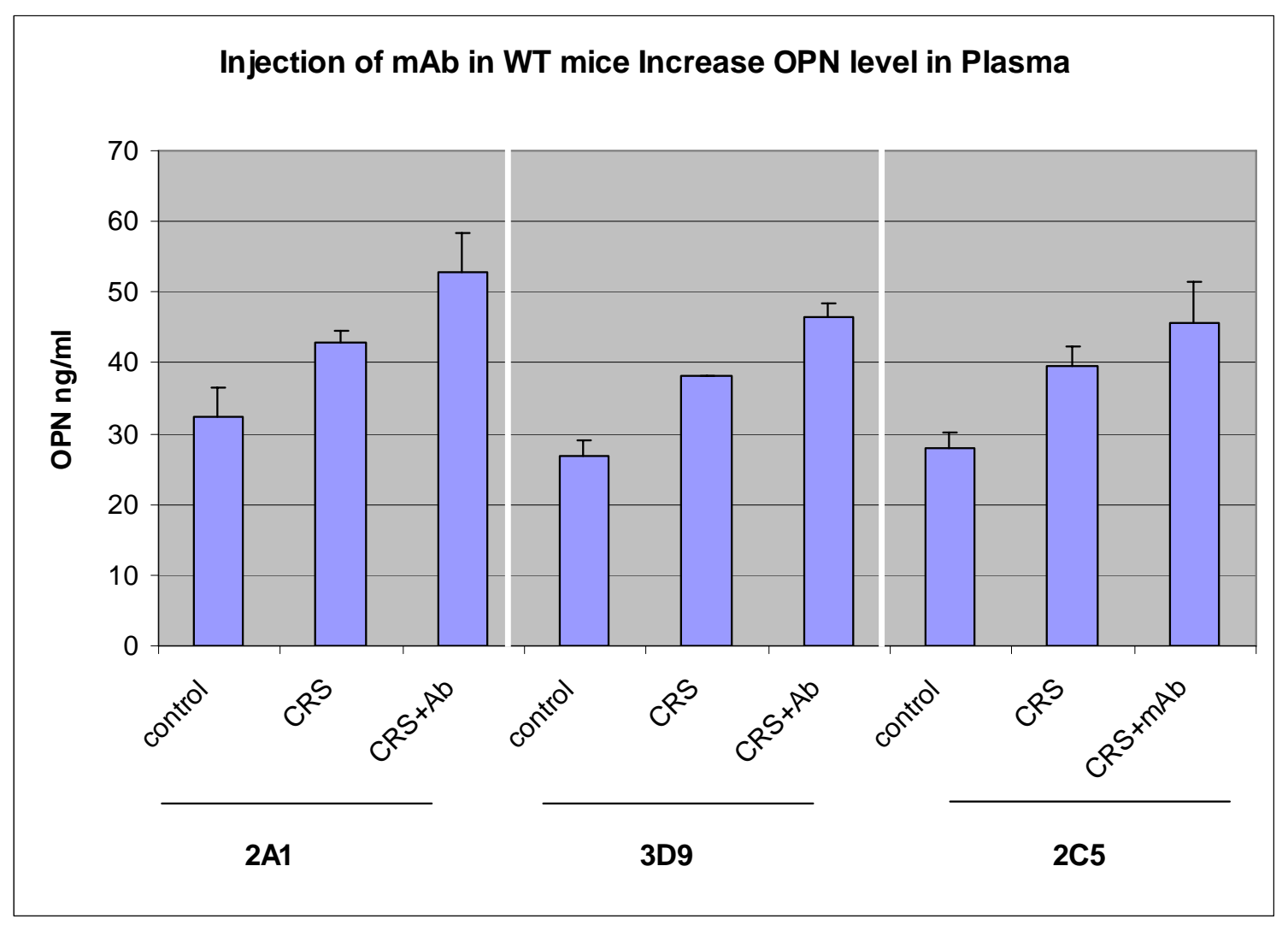

Fig 3.16. OPN level in plasma of $129 \mathrm{OPN}^{+/+}$mice after injection of anti-OPN monoclonal antibody. Plasma samples were harvested from wild type 129 mice after CRS. OPN level was assayed by ELISA using a kit from R\&D Systems. OPN concentrations were calculated with mouse recombinant OPN from R\&D Systems as a standard. Assays were conducted on samples from multiple experiments stored at $-80^{\circ} \mathrm{C}$. Data represent mean \pm SEM ( $\mathrm{n}=4-7)$. P-value was generated with student $t$ test in Excel software. 


\subsection{Discussion}

Osteopontin is both a pluripotent soluble protein modulating various cellular activities and an immobilized ECM protein in mineralized matrices. It is difficult to determine the molecular mechanism of a specific effect of OPN due to the interplay of various factors including its ability to engage multiple integrins and CD44 variants; its posttranslational modifications; its proteolytic status; and its expression in both secreted and intracellular forms. OPN is up-regulated in response to physiological/pathological or environmental challenges and exerts its functions on cell survival, immune responses, wound healing and bone/tissue remodeling (Denhardt et al., 2001, Sodek et al., 2006). Many of these physiological and pathological processes are stress related and intertwine with the CNS. OPN has also been described as a stress mediator that is involved in various stress situations such as mechanical stress, oxidative stress and cellular stress (see chapter 1). For example, OPN has been found necessary for mechanical stress-induced bone loss by regulating the ability of osteocytes to respond to mechanical stress (Morinobu et al., 2003; Ishijima et al., 2007). However, the role of OPN in other physical and psychological stress responses has remained un-explored. Both HU and CRS are physical stress models containing a significant psychological component that activates neural transmitters and stress hormones (Aviles et al., 2005; Dhabhar et al., 2000). Until now, the role of OPN in the stress response of immune organs has not been examined.

I have demonstrated that OPN-deficient mice are resistant to CRS-induced lymphoid organ atrophy. The stress-induced up-regulation of corticosterone production was significantly reduced in $\mathrm{OPN}^{-/-}$mice. However body weight loss was comparable 
between WT and KO mice in the CRS model possibly due to the food water deprivation during the restraint period. Furthermore, spleen weight loss was sometimes insignificant in the CRS model possibly because the stress level had not reached the threshold to cause spleen atrophy. In general, the length of the restraint sessions and the degree of physical wasting was less severe in CRS than in HU. Nevertheless, the reduction of the thymus and spleen weights were usually measureable and were correlated with other stress-related parameters such as corticosterone production.

Glucocorticoid hormones are end products of the HPA axis, a highly conserved vertebrate endocrine system that is integral to energy balance during predictable circadian changes in activity as well as during periods of stress (Jacobson, 2005). Glucocorticoid release from the adrenal cortex is modulated in part by the hypothalamus and the anterior pituitary, which either secrete corticotrophin-releasing hormone and adrenocorticotropic hormone, respectively, when an energetic need is perceived or decrease production of the stimulating hormones when energetic needs are perceived as stable (Sapolsky, 2002). Circulating glucocorticoid concentrations rise dramatically above baseline levels in response to psychological and physical stressors. Psychological stressors can be characterized as stimuli that evoke such emotional responses as fear or anxiety. On the other hand, a physical stressor, including internal or external noxious stimuli, such as extreme temperatures, injury, increased or decreased physical activity, triggers a release of adrenocorticotropic hormone and corticosterone (Reeder and Kramer, 2005). Typically, both psychological and physical stressors are associated with increased energetic needs, and it is generally presumed that the stress response is adaptive and has evolved to help meet these needs. However, 
long-term exposure to stressors and elevated circulating CORT concentrations may be associated with multiple deleterious effects, including immune suppression and cell death (Sapolsky, 2002).

Data from my research demonstrated both that injection of purified OPN into OPN-deficient mice enhances the CRS-induced lymphoid organ atrophy and corticosterone production and that injection of a specific anti-OPN monoclonal antibody (2C5) into wild type mice ameliorates stress-induced lymphoid organ atrophy. These findings suggest that circulating OPN mediates stress responses in the immune system possibly through regulating corticosterone production.

It has been well documented that mice subjected to chronic physical stress exhibit an increased rate of lymphocyte apoptosis, redistribution of immune cells to the periphery and atrophy in the thymus and the spleen (Yin et al., 2000; Offner et al., 2006). Based on these observations, lymphoid organ atrophy is a convenient marker for monitoring stress-induced changes in the immune system. The thymus is a primary lymphoid organ that manifests dynamic physiological changes and is exquisitely sensitive to stress and toxic insult. It is the first lymphoid tissue to respond to chemical and physical challenges, consequently leading to loss of cortical lymphocytes by apoptosis followed by organ atrophy (Pearse, 2006). The spleen is the largest secondary lymphoid organ and it is an immune cell reservoir and the site of activation and interaction for B and T lymphocytes. Due to the presence of B and T lymphocytes, the chemical and physical stress effects on these cell populations may be reflected in the spleen. Therefore evaluation of changes in size and cellularity of this organ reflect the changes in the immune system. By determining the role of lymphocyte death in a 
stressed immune system and the factors contributing to this process, we may be able to develop therapies to maintain a healthy immune system, which can help prevent malignancy and infections and treat stress-related illnesses. My study reveals for the first time that OPN is one of the factors contributing to the process of stress-induced organ atrophy and that it plays a significant role in immune cell survival/redistribution following chronic physical stress.

This discovery suggests that perhaps modulating OPN levels in the body can be an effective therapeutic approach to counteract cell death in immune organs and keep humans healthier during times of prolonged physical stress, e.g. space flight. Additionally, since OPN expression is highly perturbed in cancer and inflammatory diseases, the benefit of controlling OPN production may have a wide impact on the overall health outcome. 


\section{Chapter 4}

\section{Effect of OPN on Immune Cell Functions}

\subsection{Introduction}

OPN is a chemoattractant for many immune cells, including neutrophils (Koh et al., 2007), dendritic cells (Weiss et al., 2001), macrophages and T cells (O’Regan et al., 1999). It has been demonstrated both in vitro and in vivo that OPN directly induces chemotaxis and also indirectly facilitates migration of these cells to other chemoattractants (Giachelli et al., 1998). OPN's functions are mediated by RGDdependent integrins to facilitate adhesive activities which can be enhanced by thrombin cleavage or mediated by RGD-independent integrins and CD44 variants to facilitate cell migration (Zhu et al., 2004). However, the location of the CD44-binding motifs remains poorly defined.

OPN enhances Th1 and inhibits Th2 cytokine expression. It induces murine macrophages to produce IL-12, and inhibits IL-10 expression by LPS-stimulated macrophages. Many in vitro studies also emphasize the importance of an autocrine function for OPN in macrophages, suggesting that macrophages are both a source and a target of OPN (Zhu et al., 2004). Indeed, macrophages from OPN-null mice were susceptible to programmed cell death and showed impaired macrophage accumulation and migration in response to MCP-1(Bruemmer et al., 2003). In addition, suppression of OPN production in RAW 264.7 macrophage-like cells impairs their migration, sensitizes them to serum withdrawal-induced cell death, and reduces their secretion of IL-12 (Morimoto et al., 2004). Constitutive osteopontin production is involved in 
maintaining macrophages in a differentiated phenotype because the cells with suppressed osteopontin expression had an altered phenotype with monocyte-like characteristics (Nystrom et al., 2007).

Besides a clear role in macrophage biology, OPN also affects the lymphocyte phenotype. OPN was cloned from activated CD4+ T cells, where it is highly expressed (Patarcha et al., 1989; Weber and Cantor, 1996). Subsequently, OPN was found to be expressed by lymphocytes associated with sarcoidosis, and its expression correlated with granuloma maturity (Meada et al., 2001). Osteopontin induced T cell chemotaxis, supported T cell adhesion, and costimulated T cell proliferation (O’Regan, et al., 1999). OPN also induced CD40 ligand (CD40L) and IFN- $\gamma$ expression on human T cells, resulting in CD40L- and IFN- $\gamma$-dependent IL-12 production concomitantly with CD-3 stimulation. These findings suggest a functional role for osteopontin in the early Th1 responses, namely regulation of T cell dependent IL-12 production (O'Regan et al., 2000). More recently, OPN has also been implicated in regulating the survival of CD4+ and CD8+ T cells in experimental autoimmune encephalomyelitis, a model of multiple sclerosis, suggesting that OPN contributes to the progression of this autoimmune disease (Hur et al., 2007).

In efforts to develop a robust in vitro assay to facilitate functional characterization of monoclonal antibodies to OPN, I explored various aspects of OPN's immune functional activities using in vitro approaches. In the process of developing these assays, the involvement of OPN in regulating immune cell activation has been reexamined and confirmed. 


\subsection{Materials and Methods}

\subsubsection{Lymphocyte Chemotaxis Assay with OPN}

The migration of the splenocytes was measured using transwell inserts (membrane pore size $5 \mu \mathrm{m}$, Becton Dickinson and Co, Franklin Lakes, NJ, USA) preequilibrated in culture medium (RPMI-1640) overnight at $4^{\circ} \mathrm{C}$. Splenocytes were seeded in transwells at 1 X $10^{6}$ cells per $100 \mu$ per well. The bottom wells were loaded with $600 \mu$ of assay medium or $600 \mu$ of OPN or an OPN fragment at the indicated concentration diluted in the same medium. A well-known T cell chemoattractant, MIP$3 \beta$, was used as a positive control. Transwells containing splenocytes were immersed in a chemoattractant-containing medium and incubated in a $37^{\circ} \mathrm{C}, 5 \% \mathrm{CO}_{2}$ incubator for 3 hours. Cells that migrated through the membrane to the bottom wells were collected and counted with a FACS Calibur (Becton Dickinson) for $30 \mathrm{sec}$.

Full-length OPN tested:

Recombinant OPN (R\&D Systems, 441-OP)

F275-3-2, ras-transformed mouse fibroblast derived OPN, purified by antiOPN-conjugated immuno-affinity column OPN fragments provided by Dr Esben Sørensen:

"SKK" (Thrombin OPN, AA's 148-204)

"AKDK" (Thrombin OPN, AA's 205-262)

“C18” (N-term OPN, AA's 1-145/147 + 4 O-glycosyl residues)

"SP200" (N-term OPN, two N-term variants and a few minor contaminants of OPN origin) 
The first three fragments were highly purified (99\%) by Vydac -18 RP-HPLC. "SP200" was purified by superdex 200 and was not as pure as the others.

\subsubsection{Peritoneal Macrophage Collection and Activation}

Peritoneal macrophages were collected from naïve animals without thioglycolate elicitation. $\mathrm{OPN}{ }^{+/+}$and $\mathrm{OPN}^{-/-}$mice were sacrificed by $\mathrm{CO}_{2}$ inhalation. Peritoneal macrophages were collected by injection of $4 \mathrm{ml}$ of sterile PBS into the peritoneal cavity and gently rubbing the belly before withdrawing approximately $3 \mathrm{ml}$ of lavage fluid. Greater than $90 \%$ of the cells collected were macrophages. Cells were washed and plated in 96-well plates in DMEM $+10 \% \mathrm{FBS}$. After incubating at $37^{\circ} \mathrm{C}$ for 2 hours, the macrophage attached to the plastic surface of the wells; unattached cells were gently rinsed off. Cells were treated with fresh medium only, medium containing LPS or medium containing LPS and various concentrations of OPN mAb (R\&D systems) and incubated for 48 hours. Culture supernatants were harvested and assayed for cytokine production with Luminex multiplex mouse cytokine kit.

\subsection{Results}

\subsubsection{OPN Mediates Splenocyte Chemotaxis Through the N-terminal Half of the}

\section{Molecule.}

In order to determine the chemotaxis function of osteopontin, recombinant OPN was first used to establish a dose-dependent cell migration response. As shown in fig 4.1, recombinant OPN has been tested ranging from $0.64 \mu \mathrm{g} / \mathrm{ml}$ to $10 \mu \mathrm{g} / \mathrm{ml}$. A steady increase in the number of cells migrating into the lower chamber was correlated with the increase in the concentration of OPN. This result confirmed that full length 
recombinant OPN can induce splenocyte migration. Next, I used several bovine OPN fragments generated by cleavage of full-length OPN with thrombin or endoproteinase Lys-C and provided by Dr. Esben Sørensen (Aarhus University, Denmark) to test their effect on inducing splenocyte chemotaxis. As described in materials and methods, these fragments represent various regions of the protein including either $\mathrm{C}$ - or $\mathrm{N}$-terminal portions or the middle section. Data in fig 4.2 indicate that only one of the 4 fragments induced splenocyte migration, specifically the highly purified post-translationally modified N-terminal fragment. This result suggests that the chemotaxis function of OPN is conveyed by the N-terminal half of the molecule.

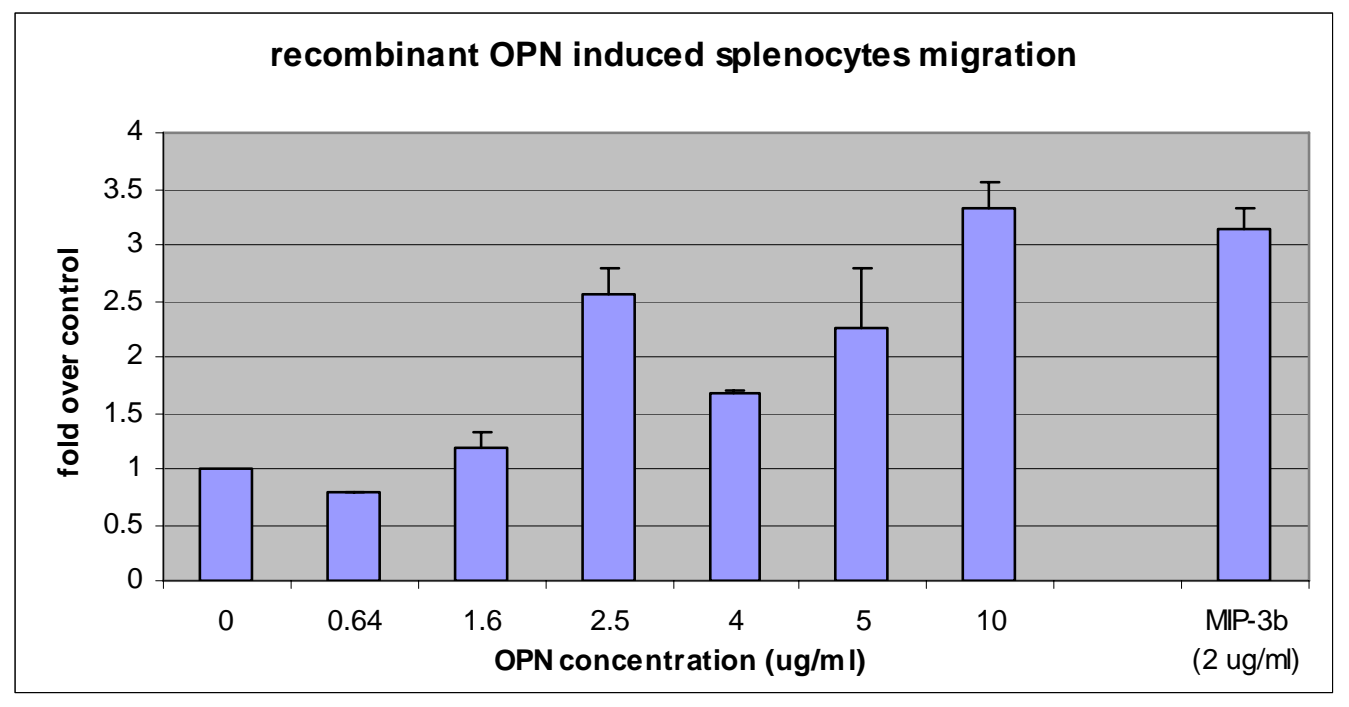

Fig 4.1. Recombinant OPN induced splenocyte migration. Splenocytes seeded in the transwells were incubated with recombinant mouse OPN (R\&D Systems) at various concentrations in the lower chambers for 3 hours. MIP-3 $\beta$ was used as a positive control at $2 \mu \mathrm{g} / \mathrm{ml}$. Cells that migrated to the lower chambers were harvested and 
enumerated on a FACSCalibur for 30 sec. All measurements were conducted in duplicate.

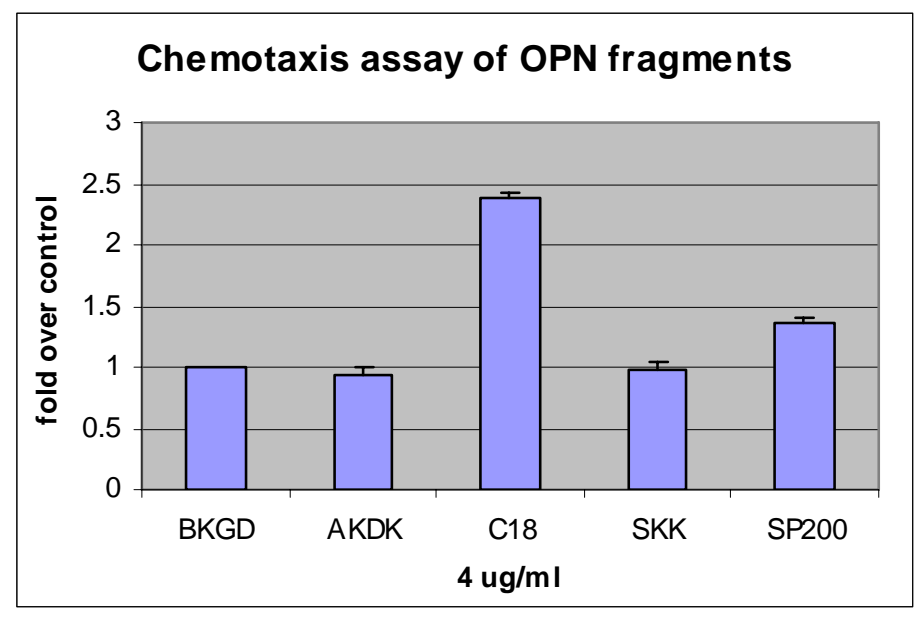

Fig 4.2 Chemotaxis assay with OPN fragments. Splenocytes seeded in transwells were incubated for 3 hours with OPN fragments including "AKDK”: AA 205-262, “C18”:AA 1-145/147, “SKK": AA 148-204, “SP200”: mixture of two N-terminal variants. All fragments were used at $4 \mu \mathrm{g} / \mathrm{ml}$ in the lower chambers. Cells migrated to the lower chambers were harvested and enumerated on FACSCalibur for $30 \mathrm{sec}$. All measurements were conducted in duplicates.

\subsubsection{OPN Mediates Macrophage Activation}

To determine OPN's role in regulating cytokine production in macrophages, peritoneal macrophages were isolated from wild type and OPN-deficient mice and stimulated with $100 \mathrm{ng} / \mathrm{ml}$ LPS for 48 hours. Cytokine/chemokine production in the culture supernatant was measured using multiplex Luminex mouse cytokine/chemokine 
kit. Several chemokines including MIP-1 $\alpha$, MCP-1 GMCSF, GCSF, TNF- $\alpha$, IL-9 and IP-10 were down regulated in the absence of OPN (Fig. 4.3). It has been reported that OPN deficiency reduces the recruitment of macrophages, neutrophils and dendritic cells (Zhu et al., 2004; Koh et al., 2007; Weiss et al., 2001). These results imply that OPN allows the expression of chemokines that may crucially influence cell recruitment during an inflammatory challenge.

To determine whether an anti-OPN antibody can reproduce the cytokine deficiency observed in $\mathrm{OPN}^{-/-}$mice, commercially available OPN antibody (R\&D Systems) was added to $\mathrm{OPN}^{+/+}$macrophage cultures while stimulating them with LPS. Clearly from two independent experiments, LPS-induced IP-10 production and IL-17 production was inhibited by the anti-OPN antibody (Fig. 4.5). Unfortunately, the multiplex kit did not detect the signature OPN-regulated cytokines IL-12 and IL-10, while IL-6 was highly produced and maxed out of the detection range. One of the possible reasons is that different cytokines were released and peaked at different time point and some are less stable than others so it's hard to capture certain cytokines. Another possibility was that the sensitivity for each cytokines in a multiplex kit is different especially when some cytokines are produced at low level; the kit is not optimized to detect weak cytokines. It is necessary to fine tune this assay towards detection of one or a few specific cytokines. I am confident that with further effort in optimization, this can be a reliable assay for in vitro characterization of OPN monoclonal antibodies. 


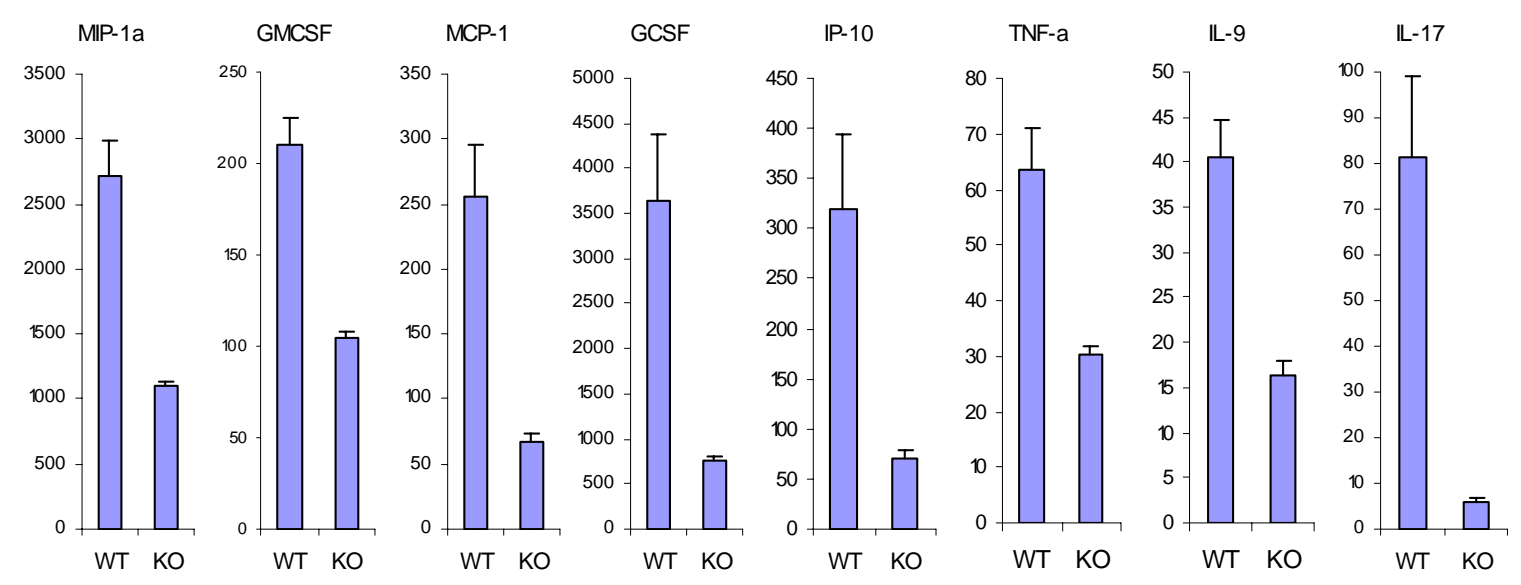

Fig. 4.3 Cytokine/chemokine production in LPS-stimulated peritoneal macrophages from $\mathrm{OPN}^{+/+}$and $\mathrm{OPN}^{-/-}$mice. Peritoneal macrophages were harvested from $\mathrm{OPN}^{+/+}$ and $\mathrm{OPN}^{-/-}$mice and cultured in DMEM $+10 \%$ FBS. LPS was added at $100 \mathrm{ng} / \mathrm{ml}$ and incubated for 48 hours. Cytokine production in the supernatant were measured with Luminex multiplex mouse cytokine kit. Here are the representative data from one of two experiments. 

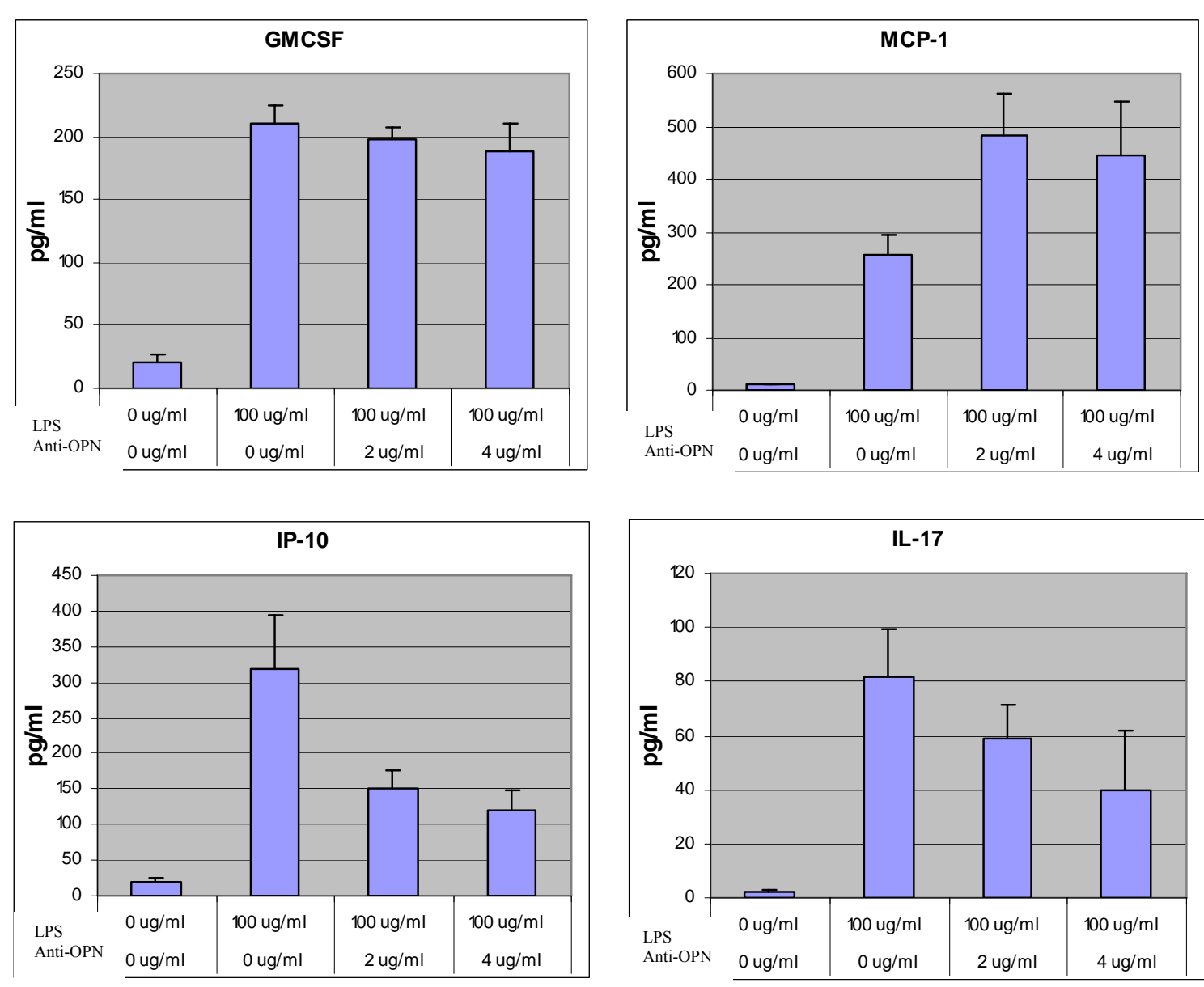

Fig 4.4 Cytokine/chemokine production in peritoneal macrophage and effect of anti-OPN antibody. Peritoneal macrophages isolated from $\mathrm{OPN}^{+/+}$mice were cultured in DMEM $+10 \%$ FBS. LPS was added at $100 \mathrm{ng} / \mathrm{ml}$ and anti-OPN (R\&D Systems) was added at 2 or $4 \mu \mathrm{g} / \mathrm{ml}$ as indicated in the plots and incubated for 48 hours. Cytokine productions in the supernatant was measured with the Luminex multiplex mouse cytokine kit. Only representative cytokines are shown here. This is the result of one of two reproducible experiments. 


\subsection{Discussion}

There are many possible ways to examine OPN's effect in immune regulation based on well-known OPN functions. For example, OPN mediates both cytokine production in macrophage and/or T lymphocytes (Scatena et al., 2007), and the chemotaxis of macrophage and/or lymphocytes (O'Regan and Berman, 2000). OPN also promotes survival of various cell types and regulates the production of nitric oxide in macrophages (Standal et al., 2004). However, on some occasions, marginal effects of OPN were observed or the results of a certain role of OPN by one laboratory were not reproducible by another or even in the same laboratory (Denhardt) at a different times due to the variation in the experimental conditions or other unknown reasons. It has proven to be difficult to establish a reproducible and robust assay for characterization of the properties of anti-OPN monoclonal antibodies. It may take extensive optimization and standardization of the assay procedures and the careful choice of the assay reagents and cell types to establish a reliable in vitro assay of OPN.

I have experienced the same frustration in developing these assays. In the chemotaxis assay, I choose to use splenocytes because these cells are a mixture of different lymphocyte cell types in suspension that are known to respond to chemotaxis by OPN. This way the cell migration can be readily quantified by flow cytometry. The assays I conducted have demonstrated a dose-response induction of cell migration by recombinant OPN although the window of activation is relatively small and variable. Compared to the positive control MIP-3 $\beta$, a potent $\mathrm{T}$ cell chemoattractant, OPN was at least 5 times less effective. I have been able to show that one N-terminal OPN fragment was effective in activating splenocytes migration. It has been suggested that OPN- 
mediated chemotaxis is largely dependent on its interaction with CD44 receptors (Weber et al., 1996). Therefore, this result suggests that the chemotaxis function of OPN is conveyed by the $\mathrm{N}$-terminal half of the molecule though a CD44 binding site is not known to be located in this region. However, further optimization of the assay to increase the window of activation would be necessary to determine the feasibility of this as a functional assay for anti-OPN monoclonal antibodies characterization and to confirm the migratory effect of $\mathrm{N}$-terminal fragment.

In the macrophage cytokine production assay, I have used resident peritoneal macrophages to avoid possible pre-activation of the cells by thioglycolate. LPS induces robust production of many cytokines and chemokines from macrophages. These chemokines and cytokines are the messengers for attracting and activating other immune cells to the site of the infection. OPN has been indicated to facilitate the inflammatory response in bacterial infection in vivo (Nau et al., 2000). The experiment using macrophages isolated from $\mathrm{OPN}^{-/}$mice revealed that $\mathrm{OPN}$ deficiency led to reduced expression of several chemokines and cytokines (Fig 4.3), but it is a challenge to demonstrate in vitro using an anti-OPN antibody to block LPS-induced cytokine production on wild type cells because OPN may concomitantly be expressed with other cytokines during the stimulation. The presence of antibody may not sufficient to sequester newly expressed OPN. 


\section{Chapter 5}

\section{Conclusions and Future Directions}

As a soluble protein ubiquitously present in all body fluids and hyper-produced by various cell types during pathological and environmental challenges, OPN fulfills multiple roles in regulating cell signaling and coordinating the interaction among different physiological systems and cellular functions. Due to its flexibility, variability in posttranslational modification, proteolytic modification and being a ligand for multiple receptors, it is a challenge to figure out the molecular and cellular mechanisms in each of OPN's actions. It is important to explore the areas that OPN may involve with different physiological and pathological processes to gain a better understanding of the scope of its functions and bring us closer to elucidating OPN's physiological importance.

My studies were designed to investigate the role of OPN, as an immune mediator, in changes in immunological and endocrinological status during stress (HU or CRS). The key point of this research is that it revealed OPN to be a critical factor in bridging the interaction between the immune system and the CNS (Central Nervous System). My research demonstrated that OPN is involved in stress responses by promoting corticosteroid-induced immune cell death and consequently causing severe immune organ atrophy under chronic stress as tested in both HU and CRS mouse models. OPN is probably regulating either or both corticosterone and $\mathrm{ACTH}$ production in the hypothalamic-pituitary-adrenal (HPA) axis of the central nervous system because OPN-deficiency leads to dis-regulation of corticosterone by showing a high basal level of corticosterone; also, ACTH production was substantially suppressed 
in $\mathrm{OPN}^{-/-}$mice. This discovery supports the role of OPN in mediating physical and psychological stress and increases our understanding of the complex interactions of OPN with the immune system and CNS.

It is well known that stress causes activation of the HPA axis and also the sympathetic nervous system (Leonard, 2006; Elenkov et al., 2000). There is growing evidence showing that neurohormones can modulate the immune system and vice versa (Besedivsky et al., 1996; Del Rey et al., 2003; Venihaki et al, 2003). It has been reported that the HPA axis modulates cell trafficking and T-cell cytokine responses because blockade of type II glucocorticoid receptors (by RU486) restores cellularity and cytokine responses to lymphoid organs in restraint-stressed, infected mice (Sheridan et al., 1998). Furthermore, endogenous opioids are known to be elevated by stress and to play a critical role in regulating stress-induced changes in the immune system (Kowalski, 1998). Opioid receptor antagonists Naltrexone and Naloxone also suppressed stress-induced reduction of splenocytes (Yin et al., 2000). The studies presented in this dissertation showed that OPN deficiency caused the same effects as these antagonists. Furthermore, administration of an anti-OPN mAb helped reverse the thymus atrophy caused by CRS. I have examined hormones involved in HPA axis but not those involved in SNS(Sympathetic Nervous System). It is conceivable that OPN may affect the SNS hormones and mediators, but proof of this requires additional experimentation. The understanding of the interaction of OPN with these neurohormones is critical to determine the molecular basis of OPN's interaction with CNS. It will also facilitate the development of countermeasures to alleviate the stressrelated detrimental effects on human health. 


\section{References}

Abbas, AK, Murphy KM, Sher A., (1996) Functional diversity of helper T lymphocytes. Nature 383,787-793.

Abel B, Freigang S, Bachmann MF, Boschert U, Kopf M. (2005) Osteopontin is not required for the development of Th1 responses and viral immunity. $\mathrm{J}$ Immunol.

175:6006-13.

Agnholt J, Kelsen J, Schack L, Hvas CL, Dahlerup JF, Sørensen ES. (2007)

Osteopontin, a protein with cytokine like properties, is associated with inflammation in Crohn's disease. Scand J Immunol. 65:453 60.

Al-Shami R, Sørensen ES, Ek-Rylander B, Andersson G, Carson DD, Farach-Carson MC. (2005) Phosphorylated osteopontin promotes migration of human choriocarcinoma cells via a p70 S6 kinase-dependent pathway. J Cell Biochem. 94:1218-33.

Alstergren P, Zhu B, Glogauer M, Mak TW, Ellen RP, Sodek J. (2004) Polarization and directed migration of murine neutrophils is dependent on cell surface expression of CD44. Cell Immunol. 231:146-57.

Apte UM, Banerjee A, McRee R, Wellberg E, Ramaiah SK. (2005) Role of osteopontin in hepatic neutrophil infiltration during alcoholic steatohepatitis. Toxicol Appl Pharmacol. 207:25-38.

Arafat HA, Katakam AK, Chipitsyna G, Gong Q, Vancha AR, Gabbeta J, Dafoe DC. (2007) Osteopontin protects the islets and beta-cells from interleukin-1 beta-mediated cytotoxicity through negative feedback regulation of nitric oxide. Endocrinology 148:575-84.

Ashkar S, Weber GF, Panoutsakopoulou V, Sanchirico ME, Jansson M, Zawaideh S, Rittling SR, Denhardt DT, Glimcher MJ, Cantor H. (2000) Eta-1 (osteopontin): an early component of type-1 (cell-mediated) immunity. Science 287:860-4.

Aviles H, Belay T, Vance M, Sonnenfeld G. (2005) Effects of space flight conditions on the function of the immune system and catecholamine production simulated in a rodent model of hindlimb unloading. Neuroimmunomodulation 12:173-81.

Banerjee A, Apte UM, Smith R, Ramaiah SK. (2006) Higher neutrophil infiltration mediated by osteopontin is a likely contributing factor to the increased susceptibility of females to alcoholic liver disease. J. Pathol 208:473-485

Bayless KJ, Meininger GA, Scholtz JM, Davis GE (1998) Osteopontin is a ligand for the alpha4beta1 integrin. J Cell Sci. 1111:1165-74. 
Begum MD, Umemura M, Kon S, Yahagi A, Hamada S, Oshiro K, Gotoh K, Nishizono A, Uede T, Matsuzaki G. (2007) Suppression of the bacterial antigenspecific $\mathrm{T}$ cell response and the dendritic cell migration to the lymph nodes by osteopontin. Microbiol Immunol. 51:135-47.

Besedovsky HO, del Rey A. Brenner D, Labreuche J, Touboul PJ, Schmidt-Petersen K, Poirier O, Perret C,Schönfelder J, Combadière C, Lathrop M, Cambien F, BrandHerrmann SM, Amarenco P; GENIC Investigators. (2006) Cytokine polymorphisms associated with carotid intima-media thickness in stroke patients. Stroke 37:1691-6

Besedovsky HO, del Rey A. (1996) Immune-neuro-endocrine interactions: facts and hypotheses. Endocr Rev. 17:64-102.

Bonvini JM, Schatzmann U, Beck-Schimmer B, Sun LK, Rittling SR, Denhardt DT, Le Hir M, Wuthrich RP. (2000) Lack of in vivo function of osteopontin in experimental anti-GBM nephritis. J Am Soc Nephrol. 11:1647-55.

Bruemmer D, Collins AR, Noh G, Wang W, Territo M, Arias-Magallona S, Fishbein MC, Blaschke F, Kintscher U, Graf K, Law RE, Hsueh WA. (2003) Angiotensin IIaccelerated atherosclerosis and aneurysm formation is attenuated in osteopontindeficient mice. J Clin Invest.112:1318-1331

Burdo TH, Wood MR, Fox HS. (2007) Osteopontin prevents monocyte recirculation and apoptosis. J Leukoc Biol. 81:1504-11

Calcagni E, Elenkov I. (2006) Stress system activity, innate and T helper cytokines, and susceptibility to immune-related diseases. Ann N Y Acad Sci. 1069:62-76.

Cao Q, Zhang S, Dong C, Song W. (2007) Pulmonary responses to fine particles: differences between the spontaneously hypertensive rats and wistar kyoto rats. Toxicol Lett. 171:126-37

Chabas D, Baranzini SE, Mitchell D, Bernard CC, Rittling SR, Denhardt DT, Sobel RA, Lock C, Karpuj M, Pedotti R, Heller R, Oksenberg JR, Steinman L. (2001). The influence of the pro-inflammatory cytokine, osteopontin, on autoimmune demyelinating disease. Science. 294:1731-5.

Chellaiah MA, Kizer N, Biswas R, Alvarez U, Strauss-Schoenberger J, Rifas L, Rittling SR, Denhardt DT, Hruska KA (2003) Osteopontin deficiency produces osteoclast dysfunction due to reduced CD44 surface expression. Mol Biol Cell 14:17389.

Chen CC, Parker CR Jr. Adrenal androgens and the immune system. (2004) Semin Reprod Med. 22:369-77 
Christensen B, Kazanecki CC, Petersen TE, Rittling SR, Denhardt DT, Sørensen ES. (2007) Cell type-specific post-translational modifications of mouse osteopontin are associated with different adhesive properties. J Biol Chem. 282:19463-72.

Christensen B, Nielsen MS, Haselmann KF, Petersen TE, Sørensen ES. (2005) Posttranslationally modified residues of native human osteopontin are located in clusters: identification of 36 phosphorylation and five O-glycosylation sites and their biological implications. Biochem J. 390:285-92.

Da Silva AP, Pollett A, Rittling SR, Denhardt DT, Sodek J, Zohar R. (2006) Exacerbated tissue destruction in DSS-induced acute colitis of OPN-null mice is associated with downregulation of TNF-alpha expression and non-programmed cell death. J Cell Physiol. 208:629-39.

D'Alfonso S, Barizzone N, Giordano M, Chiocchetti A, Magnani C, Castelli L, Indelicato M, Giacopelli F, Marchini M, Scorza R, Danieli MG, Cappelli M, Migliaresi S, Bigliardo B, Sabbadini MG, Baldissera E, Galeazzi M, Sebastiani GD, Minisola G, Ravazzolo R, Dianzani U, Momigliano-Richiardi P. (2005) Two single-nucleotide polymorphisms in the $5^{\prime}$ and $3^{\prime}$ ends of the osteopontin gene contribute to susceptibility to systemic lupus erythematosus. Arthritis Rheum. 52:539-47.

Del Rey A, Kabiersch A, Petzoldt S, Besedovsky HO. (2003) Sympathetic abnormalities during autoimmune processes: potential relevance of $\beta$-noradrenalineinduced apoptosis. Ann N Y Acad Sci. 992:158-67.

Denhardt DT, Mistretta D, Chambers AF, Krishna S, Porter JF, Raghuram S, Rittling SR. (2003) Transcriptional regulation of osteopontin and the metastatic phenotype: evidence for a Ras-activated enhancer in the human OPN promoter. Clin Exp Metastasis. 20:77-84.

Denhardt DT, Noda M, O'Regan AW, Pavlin D, Berman JS (2001) J. Clin. Invest. 107:1055-1061.

Denhardt DT, Noda M, O'Regan AW, Pavlin D, Berman JS. (2001) Osteopontin as a means to cope with environmental insults: regulation of inflammation, tissue remodeling, and cell survival. J Clin Invest. 107:1055-61.

Denhardt DT, Noda M. (1998) Osteopontin expression and function: role in bone remodeling. J Cell Biochem Suppl. 30-31:92-102.

Dhabhar FS, Satoskar AR, Bluethmann H, David JR, and McEwen BS (2000). Stressinduced enhancement of skin immune function: A role for $\gamma$ interferon . Proc Natl Acad Sci USA. 97:2846-2851

Dhabhar FS, McEwen BS (1999) Enhancing versus suppressive effects of stress hormones on skin immune function. Proc Natl Acad Sci USA. 96:1059-64. 
Dhabhar FS, McEwen BS. (1996). Stress-induced enhancement of antigen-specific cell-mediated immunity. J Immunol. 156:2608-15

Dhabhar FS, Miller AH, McEwen BS, Spencer RL (1995) Dynamics and hormonal mechanisms. J Immunol 154:5511-27.

Dhabhar FS. (2003) Stress, leukocyte trafficking, and the augmentation of skin immune function. Ann N Y Acad Sci. 992:205-17.

Diao H, Kon S, Iwabuchi K, Kimura C, Morimoto J, Ito D, Segawa T, Maeda M, Hamuro J, Nakayama T, Taniguchi M, Yagita H, Van Kaer L, Onoe K, Denhardt D, Rittling S, Uede T. (2004) Osteopontin as a mediator of NKT cell function in T cellmediated liver diseases. Immunity 21:539-50.

Du H, Masuko-Hongo K, Nakamura H, Xiang Y, Bao CD, Wang XD, Chen SL, Nishioka K, Kato T. (2005) The prevalence of autoantibodies against cartilage intermediate layer protein, YKL-39, osteopontin, and cyclic citrullinated peptide in patients with early-stage knee osteoarthritis: evidence of a variety of autoimmune processes. Rheumatol Int. 26:35-41.

El-Tanani MK, Campbell FC, Kurisetty V, Jin D, McCann M, Rudland PS. (2006) The regulation and role of osteopontin in malignant transformation and cancer. Cytokine Growth Factor Rev. 17:463-74.

Fisher LW, Torchia DA, Fohr B, Young MF, Fedarko NS. (2001) Flexible structures of SIBLING proteins, bone sialoprotein, and osteopontin. Biochem Biophys Res Commun. 280:460-5.

Gao C, Guo H, Wei J, Mi Z, Wai P, Kuo PC. (2004) S-nitrosylation of heterogeneous nuclear ribonucleoprotein $\mathrm{A} / \mathrm{B}$ regulates osteopontin transcription in endotoxinstimulated murine macrophages. J Biol Chem. 279:11236-43.

Gassler N, Autschbach F, Gauer S, Bohn J, Sido B, Otto HF, Geiger H, Obermuller N. (2002) Expression of osteopontin (Eta-1) in Crohn disease of the terminal ileum. Scand J Gastroenterol. 37:1286-95.

Gericke A, Qin C, Spevak L, Fujimoto Y, Butler WT, SÃ,rensen ES, Boskey AL. (2005) Importance of phosphorylation for osteopontin regulation of biomineralization. Calcif Tissue Int. 77:45-54.

Giachelli CM, Lombardi D, Johnson RJ, Murry CE, Almeida M. (1998) Evidence for a role of osteopontin in macrophage infiltration in response to pathological stimuli in vivo. Am J Pathol. 152:353-358.

Gomez-Ambrosi J, Catalan V, Ramirez B, Rodriguez A, Colina I, Silva C, Rotellar F, Mugueta C, Gil MJ, Cienfuegos JA, Salvador J, Fruhbeck G. (2007) Plasma 
osteopontin levels and expression in adipose tissue are increased in obesity. J Clin Endocrinol Metab. 92:3719-27

Goppelt-Struebe M, Wiedemann T, Heusinger-Ribeiro J, Vucadinovic M, Rehm M, Pröls F. (2000) Cox-2 and osteopontin in cocultured platelets and mesangial cells: role of glucocorticoids. Kidney Int. 57:2229-38,

Gross TS, King KA, Rabaia NA, Pathare P, Srinivasan S (2005) Upregulation of osteopontin by osteocytes deprived of mechanical loading or oxygen. J Bone Miner Res. 20:250-6.

Guo H, Cai CQ, Schroeder RA, Kuo PC (2001) Osteopontin is a negative feedback regulator of nitric oxide synthesis in murine macrophages. J Immunol 166:1079-86.

He B, Mirza M, Weber GF. (2006) An osteopontin splice variant induces anchorage independence in human breast cancer cells. Oncogene. 25:2192-202.

Heguy A, O'Connor TP, Luettich K. Worgall S, Cieciuch A, Harvey BG, Hackett NR, Crystal RG (2006) Gene expression profiling of human alveolar macrophages ofphenotypically normal smokers and nonsmokers reveals a previously unrecognized subset of genes modulated by cigarette smoking J Mol Med. 84:318-28.

Helluin O, Chan C, Vilaire G, Mousa S, DeGrado WF, Bennett JS. (2000) The activation state of alphavbeta 3 regulates platelet and lymphocyte adhesion to intact and thrombin-cleaved osteopontin. J Biol Chem. 275:18337-43.

Higuchi Y, Tamura Y, Uchida T, Matsuura K, Hijiya N, Yamamoto S.(2004) The roles of soluble osteopontin using osteopontin-transgenic mice in vivo: proliferation of CD4+ T lymphocytes and the enhancement of cell-mediated immune responses. Pathobiology. 71:1-11.

Hsieh YH, Juliana MM, Hicks PH, Feng G, Elmets C, Liaw L, Chang PL. (2006) Papilloma development is delayed in osteopontin-null mice: implicating an antiapoptosis role for osteopontin Cancer Res. 66:7119-27.

Hullinger TG, Pan Q, Viswanathan HL, Somerman MJ. (2001). TGF-beta and BMP-2 activation of the OPN promoter: roles of smad- and hox-binding elements. Exp Cell Res. 262:69-74

Hur EM, Youssef S, Haws ME, Zhang SY, Sobel RA, Steinman L (2007) Osteopontininduced relapse and progression of autoimmune brain disease through enhanced survival of activated T cells. Nat Immunol. 8:74-83.

Hwang SM, Lopez CA, Heck DE, Gardner CR, Laskin DL, Laskin JD, Denhardt DT (1994) Osteopontin inhibits induction of nitric oxide synthase gene expression by inflammatory mediators in mouse kidney epithelial cells. J Biol Chem. 269:711-5. 
Ichikawa H, Itota T, Nishitani Y, Torii Y, Inoue K, Sugimoto T. (2000) Osteopontinimmunoreactive primary sensory neurons in the rat spinal and trigeminal nervous systems. Brain Res. 863:276-81.

Iczkiewicz J, Jackson MJ, Smith LA, Rose S, Jenner P. (2006). Osteopontin expression in substantia nigra in MPTP treated primates and in Parkinson's disease. Brain Res. 1118:239-50.

Iczkiewicz J, Rose S, Jenner P. (2007). Osteopontin expression in activated glial cells following mechanical- or toxin-induced nigral dopaminergic cell loss. Exp Neurol. 207:95-106

Iizuka J, Katagiri Y, Tada N, et al. (1998) Introduction of an osteopontin gene confers the increase in B1 cell population and the production of anti-DNA autoantibodies. Lab Invest. 78:1523-33

Ishijima M, Ezura Y, Tsuji K, Rittling SR, Kurosawa H, Denhardt DT, Emi M, Nifuji A, Noda M. (2006) Osteopontin is associated with nuclear factor kappaB gene expression during tail-suspension-induced bone loss. Exp Cell Res. 312:3075-83

Ishijima M, Rittling SR, Yamashita T, Tsuji K, Kurosawa H, Nifuji A, Denhardt DT, Noda M. (2001) Enhancement of osteoclastic bone resorption and suppression of osteoblastic bone formation in response to reduced mechanical stress do not occur in the absence of osteopontin. J Exp Med. 193:399-404.

Ishijima M, Tsuji K, Rittling SR, Yamashita T, Kurosawa H, Denhardt DT, Nifuji A, Noda M. (2002) Resistance to unloading-induced three-dimensional bone loss in osteopontin-deficient mice. J Bone Miner Res. 17:661-7.

Ishijima M, Tsuji K, Rittling SR, Yamashita T, Kurosawa H, Denhardt DT, Nifuji A, Ezura Y, Noda M. (2007) Osteopontin is required for mechanical stress-dependent signals to bone marrow cells. J Endocrinol. 193:235-43.

Itoh Y, Yasui T, Okada A, Tozawa K, Hayashi Y, Kohri K (2005) Examination of the anti-oxidative effect in renal tubular cells and apoptosis by oxidative stress. Urol Res. $33: 261-6$.

Jansson, M., V. Panoutsakopoulou, J. Baker, L. Klein, and H. Cantor. (2002) Cutting edge: attenuated experimental autoimmune encephalomyelitis in eta-1/ osteopontindeficient mice. J. Immunol. 168: 2096-2099.

Jono S, Peinado C, Giachelli CM, (2000) Phosphorylation of osteopontin is required for inhibition of vascular smooth muscle cell calcification. J Biol. Chem. 275, 20197203 
Katagiri YU, Sleeman J, Fujii H, Herrlich P, Hotta H, Tanaka K, Chikuma S, Yagita H, Okumura K, Murakami M, Saiki I, Chambers AF, Uede T. (1999) CD44 variants but not CD44s cooperate with beta1-containing integrins to permit cells to bind to osteopontin independently of arginine-glycine-aspartic acid, thereby stimulating cell motility and chemotaxis. Cancer Res. 59:219-26.

Kawai T, Sato S, Ishii KJ, Coban C, Hemmi H, Yamamoto M, Terai K, Matsuda M, Inoue J, Uematsu S, Takeuchi O, Akira S. (2004) Interferon-alpha induction through Toll-like receptors involves a direct interaction of IRF7 with MyD88 and TRAF6. Nat Immunol. 5:1061-8.

Kawamura K, Iyonaga K, Ichiyasu H, Nagano J, Suga M, Sasaki Y. (2005)

Differentiation, maturation, and survival of dendritic cells by osteopontin regulation. Clin Diagn Lab Immunol. 12:206-12.

Kazanecki CC, Kowalski AJ, Ding T, Rittling SR, Denhardt DT. (2007a) Characterization of anti-osteopontin monoclonal antibodies: Binding sensitivity to posttranslational modifications. J Cell Biochem. 102:925-935

Kazanecki CC, Uzwiak DJ, Denhardt DT. (2007b) Control of osteopontin signaling and function by post-translational phosphorylation and protein folding. J Cell Biochem. 102:912-924

Keykhosravani M, Doherty-Kirby A, Zhang C, Brewer D, Goldberg HA, Hunter GK, Lajoie G. (2005) Comprehensive identification of post-translational modifications of rat bone osteopontin by mass spectrometry. Biochemistry. 44:6990-7003.

Khan SA, Cook AC, Kappil M, Gunthert U, Chambers AF, Tuck AB, Denhardt DT. (2005) Enhanced cell surface CD44 variant (v6, v9) expression by osteopontin in breast cancer epithelial cells facilitates tumor cell migration: novel post-transcriptional, posttranslational regulation. Clin Exp Metastasis. 22:663-73.

Khan SA, Lopez-Chua CA, Zhang J, Fisher LW, Sørensen ES, Denhardt DT. (2002) Soluble osteopontin inhibits apoptosis of adherent endothelial cells deprived of growth factors. J Cell Biochem. 85:728-36

Kikuchi Y, Imakiire T, Yamada M, Saigusa T, Hyodo T, Hyodo N, Suzuki S, Miura S. (2005) Mizoribine reduces renal injury and macrophage infiltration in non-insulindependent diabetic rats. Nephrol Dial Transplant. 20:1573-81,

Kim MD, Cho HJ, Shin T. (2004) Expression of osteopontin and its ligand, CD44, in the spinal cords of Lewis rats with experimental autoimmune encephalomyelitis. J Neuroimmunol. 151:78-84 
Kitamura M, Iwabuchi K, Kitaichi N, Kon S, Kitamei H, Namba K, Yoshida K, Denhardt DT, Rittling SR, Ohno S, Uede T, Onoe K. (2007) Osteopontin aggravates experimental autoimmune uveoretinitis in mice. J Immunol. 178:6567-72.

Koguchi Y, Kawakami K, Kon S, Segawa T, Maeda M, Uede T, Saito A. (2002) Penicillium marneffei causes osteopontin-mediated production of interleukin-12 by peripheral blood mononuclear cells. Infect Immun. 70:1042-8.

Koh A, da Silva AP, Bansal AK, Bansal M, Sun C, Lee H, Glogauer M, Sodek J, Zohar R. (2007) Role of osteopontin in neutrophil function. Immunology, 122(4):466-75

Kowalski, J. (1998) Immunomodulatory action of class mu- delta- and kappa-opioid receptor agonists in mice. Neuropeptides. 32:301-306

Lampe MA, Patarca R, Iregui MV, Cantor H. (1991) Polyclonal B cell activation by the Eta-1 cytokine and the development of systemic autoimmune disease. J Immunol. 147:2902-6.

Leonard BE.(2006) HPA and immune axes in stress: involvement of the serotonergic system. Neuroimmunomodulation. 13(5-6):268-76

Lin YH and Yang-Yen HF. (2001) The osteopontin-CD44 survival signal involves activation of the phosphatidylinositol 3-kinase/Akt signaling pathway. J. Biol. Chem. $276,46024-46030$

Lin YH, Huang CJ, Chao JR, Chen ST, Lee SF, Yen JJ, Yang-Yen HF. (2000) Coupling of osteopontin and its cell surface receptor CD44 to the cell survival response elicited by interleukin-3 or granulocyte-macrophage colony-stimulating factor. Mol Cell Biol. 20:2734-42.

Maeda K, Takahashi K, Takahashi F, Tamura N, Maeda M, Kon S, Uede T, Fukuchi Y. (2001) Distinct roles of osteopontin fragments in the development of the pulmonary involvement in sarcoidosis. Lung 179:279-91.

Maetzler W, Berg D, Schalamberidze N, Melms A, Schott K, Mueller JC, Liaw L, Gasser T, Nitsch C. (2007) Osteopontin is elevated in Parkinson's disease and its absence leads to reduced neurodegeneration in the MPTP model. Neurobiol Dis. 25:473-82

McKee MD, Nanci A. (1996) Secretion of osteopontin by macrophages and its accumulation at tissue surfaces during wound healing in mineralized tissues: a potential requirement for macrophage adhesion and phagocytosis. Anar Rec. 245:394-409

Mezzano SA, Droguett MA, Burgos ME, Ardiles LG, Aros CA, Caorsi I, Egido J. (2000) Overexpression of chemokines, fibrogenic cytokines, and myofibroblasts in human membranous nephropathy. Kidney Int. 57:147-58 
Miyake S, Yamamura T. (2007) NKT cells and autoimmune diseases: unraveling the complexity. Curr Top Microbiol Immunol. 314:251-67.

Morinobu M, Ishijima M, Rittling SR, Tsuji K, Yamamoto H, Nifuji A, Denhardt DT, Noda M. (2003) Osteopontin expression in osteoblasts and osteocytes during bone formation under mechanical stress in the calvarial suture in vivo. J Bone Miner Res. 18:1706-15.

Nagai S, Hashimoto S, Yamashita T, Toyoda N, Satoh T, Suzuki T, Matsushima K. (2001) Comprehensive gene expression profile of human activated T(h)1- and T(h)2polarized cells. Int Immunol. 13:367-76.

Nakamachi T, Nomiyama T, Gizard F, Heywood EB, Jones KL, Zhao Y, Fuentes L, Takebayashi K, Aso Y, Staels B, Inukai T, Bruemmer D. (2007) PPARalpha agonists suppress osteopontin expression in macrophages and decrease plasma levels in patients with type 2 diabetes. Diabetes. 56:1662-70.

Nau GJ, Guilfoile P, Chupp GL, Berman JS, Kim SJ, Kornfeld H, Young RA. (1997) A chemoattractant cytokine associated with granulomas in tuberculosis and silicosis. Proc Natl Acad Sci U S A. 94:6414-9.

Nieman DC, Pedersen BK (1999) Exercise and immune function. Recent developments Sports Med. 27:73-80.

Niino M, Kikuchi S, Fukazawa T, Yabe I, Tashiro K. (2003) Genetic polymorphisms of osteopontin in association with multiple sclerosis in Japanese patients. J Neuroimmunol. 136:125-9.

Nomura S, Takano-Yamamoto T. (2000) Molecular events caused by mechanical stress in bone. Matrix Biol. 19:91-6

Nystrom T, Duner P, Hultgardh-Nilsson A. (2007) A constitutive endogenous osteopontin production is important for macrophage function and differentiation. Exp Cell Res. 313:1149-1160

O’Regan A, Hayden JM, Berman JS. (2000) Osteopontin augments CD3-mediated interferon-g and CD40 ligand expression by Tcells which results in IL-12 production from peripheral blood mononuclear cells. J Leukoc Biol 68:495-502

O’Regan AW, Chupp GL, Lowry JA, Goetschkes M, Mulligan N, Berman JS. (1999) Osteopontin is associated with $\mathrm{T}$ cells in sarcoid granulomas and has $\mathrm{T}$ cell adhesive and cytokine-like properties in vitro. J Immunol.162:1024-1031

Offner H, Subramanian S, Parker SM, Wang C, Afentoulis ME, Lewis A, Vandenbark AA, Hurn PD (2006) Splenic atrophy in experimental stroke is accompanied by increased regulatory $\mathrm{T}$ cells and circulating macrophages. J Immunol 176:6523-31. 
Ogawa D, Stone JF, Takata Y, Blaschke F, Chu VH, Towler DA, Law RE, Hsueh WA, Bruemmer D. (2005) Liver x receptor agonists inhibit cytokine-induced osteopontin expression in macrophages through interference with activator protein-1 signaling pathways. Circ Res. 96:e59-67.

Ohshima S, Kobayashi H, Yamaguchi N, Nishioka K, Umeshita-Sasai M, Mima T, Nomura S, Kon S, Inobe M, Uede T, Saeki Y. (2002) Expression of osteopontin at sites of bone erosion in a murine experimental arthritis model of collagen-induced arthritis: possible involvement of osteopontin in bone destruction in arthritis. Arthritis Rheum. 46:1094-101.

Ohsuzu F. (2004) The roles of cytokines, inflammation and immunity in vascular diseases. J. Atheroscler. Thromb. 11, 313-321

O'Regan A, Berman JS. (2000) Osteopontin: a key cytokine in cell-mediated and granulomatous inflammation. Int J Exp Pathol. 81:373-90.

O'Regan A. (2003) The role of osteopontin in lung disease. Cytokine Growth Factor Rev. 14:479-88.

O'Regan AW, Chupp GL, Lowry JA, Goetschkes M, Mulligan N, Berman JS. (1999) Osteopontin is associated with $\mathrm{T}$ cells in sarcoid granulomas and has $\mathrm{T}$ cell adhesive and cytokine-like properties in vitro. J Immunol. 162:1024-31.

O'Regan AW, Hayden JM, Body S, Liaw L, Mulligan N, Goetschkes M, Berman JS. (2001) Abnormal pulmonary granuloma formation in osteopontin-deficient mice. Am J Respir Crit Care Med. 164:2243-7.

Packer L, Pavey S, Parker A, Stark M, Johansson P, Clarke B, Pollock P, Ringner M, Hayward N. (2006) Osteopontin is a downstream effector of the PI3-kinase pathway in melanomas that is inversely correlated with functional PTEN. Carcinogenesis. 27:177886

Patarca R, Saavedra RA, Cantor H. (1993) Molecular and cellular basis of genetic resistance to bacterial infection: the role of the early T-lymphocyte activation1/osteopontin gene. Crit Rev Immunol. 13:225-46.

Ramaiah SK, Rittling S. (2007) Pathophysiological Role of Osteopontin in Hepatic Inflammation, Toxicity and Cancer. Toxicol Sci. 2007 Sep 22;

Rangaswami H, Bulbule A, Kundu GC. (2006) Osteopontin: role in cell signaling and cancer progression. Trends Cell Biol. 16:79-87.

Razzouk S, Brunn JC, Qin C, Tye CE, Goldberg HA, Butler WT. (2002) Osteopontin posttranslational modifications, possibly phosphorylation, are required for in vitro bone resorption but not osteoclast adhesion. Bone. 30:40-7. 
Renkl AC, Wussler J, Ahrens T, Thoma K, Kon S, Uede T, Martin SF, Simon JC, Weiss JM. (2005) Osteopontin functionally activates dendritic cells and induces their differentiation toward a Th1-polarizing phenotype. Blood. 106:946-55.

Rice J, Courter DL, Giachelli CM, Scatena M. (2006) Molecular mediators of alphavbeta3-induced endothelial cell survival. J Vasc Res. 43:422-36.

Rittling SR, Matsumoto HN, McKee MD, Nanci A, An XR, Novick KE, Kowalski AJ, Noda M, Denhardt DT (1998) Mice lacking osteopontin show normal development and bone structure but display altered osteoclast formation in vitro. J Bone Miner Res. 13:1101-11.

Rollo EE, Denhardt DT. (1996). Differential effects of osteopontin on the cytotoxic activity of macrophages from young and old mice. Immunology. 88:642-7

Rollo EE, Hempson SJ, Bansal A, Tsao E, Habib I, Rittling SR, Denhardt DT, Mackow ER, Shaw RD. (2005) The cytokine osteopontin modulates the severity of rotavirus diarrhea. J Virol. 79:3509-16.

Sakata M, Tsuruha JI, Masuko-Hongo K, Nakamura H, Matsui T, Sudo A, Nishioka K, Kato T. (2001) Autoantibodies to osteopontin in patients with osteoarthritis and rheumatoid arthritis. J Rheumatol. 28:1492-5.

Sato T, Nakai T, Tamura N, Okamoto S, Matsuoka K, Sakuraba A, Fukushima T, Uede T, Hibi T. (2005) Osteopontin/Eta-1 upregulated in Crohn's disease regulates the Th1 immune response. Gut. 54:1254-62

Scatena M, Almeida M, Chaisson ML, Fausto N, Nicosia RF, Giachelli CM. (1998)

NF-kappaB mediates alphavbeta3 integrin-induced endothelial cell survival. J Cell Biol. 141:1083-93.

Scott JA, Weir ML, Wilson SM, Xuan JW, Chambers AF, McCormack DG. (1998) Osteopontin inhibits inducible nitric oxide synthase activity in rat vascular tissue. Am J Physiol. 275:H2258-65.

Shin SL, Cha JH, Chun MH, Chung JW, Lee MY (1999) Expression of osteopontin mRNA in the adult rat brain. Neurosci Lett. 273:73-6.

Shinohara ML, Jansson M, Hwang ES, Werneck MB, Glimcher LH, Cantor H (2005) T-bet-dependent expression of osteopontin contributes to T cell polarization. Proc Natl Acad Sci U S A. 102:17101-6.

Shinohara ML, Lu L, Bu J, Werneck MB, Kobayashi KS, Glimcher LH, Cantor H. (2006) Osteopontin expression is essential for interferon-alpha production by plasmacytoid dendritic cells. Nat Immunol. 7:498-506. 
Singh M, Ananthula S, Milhorn DM, Krishnaswamy G, Singh K (2007) Osteopontin: a novel inflammatory mediator of cardiovascular disease. Front Biosci. 12:214-21.

Sodek J, Batista Da Silva AP, Zohar R. (2006) Osteopontin and mucosal protection. J Dent Res. 85:404-15.

Sodek J, Ganss B, McKee MD (2000) Osteopontin. Crit Rev Oral Biol Med. 11:279303.

Sonnenfeld G (2005) The immune system in space, including Earth-based benefits of space-based research. Curr. Phar. Biotech. 6:343-349.

Standal T, Borset M, Sundan A. (2004) Role of osteopontin in adhesion, migration, cell survival and bone remodeling. Exp Oncol. 26:179-84.

Steinman L, Martin R, Bernard C, Conlon P, Oksenberg JR. (2002) Multiple sclerosis: deeper understanding of its pathogenesis reveals new targets for therapy. Annu. Rev. Neurosci. 25, 491-505

Suzuki K, Zhu B, Rittling SR, Denhardt DT, Goldberg HA, McCulloch CA, Sodek J. (2002) Colocalization of intracellular osteopontin with CD44 is associated with migration, cell fusion, and resorption in osteoclasts. J Bone Miner Res. 17:1486-97

Terai K, Takano-Yamamoto T, Ohba Y, Hiura K, Sugimoto M, Sato M, Kawahata H, Inaguma N, Kitamura Y, Nomura S. (1999) Role of osteopontin in bone remodeling caused by mechanical stress. J Bone Miner Res. 14:839-49.

Vejda S, Piwocka K, McKenna SL, Cotter TG (2005) Autocrine secretion of osteopontin results in degradation of I kappa B in Bcr-Abl-expressing cells. Br J Haematol. 128:711-21.

Venihaki M, Zhao J, Karalis KP. (2003) Corticotropin-releasing hormone deficiency results in impaired splenocyte response to lipopolysaccharide. J Neuroimmunol. 141:39.

Viswanathan K, Daugherty C, Dhabhar FS (2005) Stress as an endogenous adjuvant: augmentation of the immunization phase of cell-mediated immunity. Int Immunol. $17: 1059-69$

Vogt MH, Lopatinskaya L, Smits M, Polman CH, Nagelkerken L. (2003) Elevated osteopontin levels in active relapsing-remitting multiple sclerosis. Ann Neurol. 53:81922

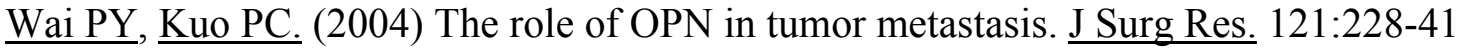


Wang KX, Shi Y, Denhardt DT. (2007) Osteopontin regulates hindlimb-unloadinginduced lymphoid organ atrophy and weight loss by modulating corticosteroid production. Proc Natl Acad Sci U S A. 104:14777-82.

Weber GF, Ashkar S, Glimcher MJ, Cantor H. (1996) Receptor-ligand interaction between CD44 and osteopontin (Eta-1). Science. 271:509-12.

Weber GF, Cantor H. (2001) Differential roles of osteopontin/Eta-1 in early and late 1pr disease. Clin Exp Immunol. 126:578-583

Wei LX, Zhou JN, Roberts AI, Shi YF (2003) Lymphocyte reduction induced by hindlimb unloading: distinct mechanisms in the spleen and thymus. Cell Res.13:465-71.

Weiss JM, Renkl AC, Maier CS, Kimmig M, Liaw L, Ahrens T, Kon S, Maeda M, Hotta H, Uede T, Simon JC. (2001) Osteopontin is involved in the initiation of cutaneous contact hypersensitivity by inducing Langerhans and dendritic cell migration to lymph nodes. J Exp Med. 194:1219-29.

Woodruff PG, Koth LL, Yang YH, Rodriguez MW, Favoreto S, Dolganov GM, Paquet AC, Erle DJ Am J (2005) A distinctive alveolar macrophage activation state induced by cigarette smoking. Respir Crit Care Med. 172:1383-92.

Wung JK, Perry G, Kowalski A, Harris PL, Bishop GM, Trivedi MA, Johnson SC, Smith MA, Denhardt DT, Atwood CS. (2007) Increased expression of the remodelingand tumorigenic-associated factor osteopontin in pyramidal neurons of the Alzheimer's disease brain. Curr Alzheimer Res. 4:67-72.

Xanthou G, Alissafi T, Semitekolou M, Simoes DC, Economidou E, Gaga M, Lambrecht BN, Lloyd CM, Panoutsakopoulou V. (2007) Osteopontin has a crucial role in allergic airway disease through regulation of dendritic cell subsets. Nat Med. 13:5708 .

Xu G, Nie H, Li N, Zheng W, Zhang D, Feng G, Ni L, Xu R, Hong J, Zhang JZ. (2005) Role of osteopontin in amplification and perpetuation of rheumatoid synovitis. J Clin Invest. 115:1060-7.

Yamamoto N, Nakashima T, Torikai M, Naruse T, Morimoto J, Kon S, Sakai F, Uede T. (2007) Successful treatment of collagen-induced arthritis in non-human primates by chimeric anti-osteopontin antibody. Int Immunopharmacol. 7:1460-70.

Yamamoto N, Sakai F, Kon S, Morimoto J, Kimura C, Yamazaki H, Okazaki I, Seki N, Fujii T, Uede T. (2003) Essential role of the cryptic epitope SLAYGLR within osteopontin in a murine model of rheumatoid arthritis. J Clin Invest. 112:147-9

Yin D, Tuthill D, Mufson RA, Shi Y (2000) Chronic restraint stress promotes lymphocyte apoptosis by modulating CD95 expression. J Exp Med 191:1423-1428 
Yokosaki Y, Tanaka K, Higashikawa F, Yamashita K, Eboshida A. (2005) Distinct structural requirements for binding of the integrins alphavbeta6, alphavbeta3, alphavbeta5, alpha5beta1 and alpha9beta1 to osteopontin. Matrix Biol. 24:418-27.

Yoshitake H, Rittling SR, Denhardt DT, Noda M. (1999) Osteopontin-deficient mice are resistant to ovariectomy-induced bone resorption. Proc Natl Acad Sci U S A. 96:8156-60.

Yumoto K, Ishijima M, Rittling SR, Tsuji K, Tsuchiya Y, Kon S, Nifuji A, Uede T, Denhardt DT, Noda M (2002) Osteopontin deficiency protects joints against destruction in anti-type II collagen antibody-induced arthritis in mice. Proc Natl Acad Sci U S A 99:4556-61.

Zandman-Goddard G, Shoenfeld Y. (2003) SLE and infections. Clin Rev Allergy Immunol. 25:29-40.

Zhao X, Johnson JN, Singh K, Singh M. (2007) Impairment of myocardial angiogenic response in the absence of osteopontin. Microcirculation. 14:233-40.

Zhu B, Suzuki K, Goldberg HA, Rittling SR, Denhardt DT, McCulloch CA, Sodek J. (2004) Osteopontin modulates CD44-dependent chemotaxis of peritoneal macrophages through G-protein-coupled receptors: evidence of a role for an intracellular form of osteopontin. J Cell Physiol. 198:155-67.

Zohar R, Suzuki N, Suzuki K, Arora P, Glogauer M, McCulloch CA, Sodek J. (2000) Intracellular osteopontin is an integral component of the CD44-ERM complex involved in cell migration. J Cell Physiol. 184:118-30.

Zohar R, Zhu B, Liu P, Sodek J, McCulloch CA. (2004) Increased cell death in osteopontin-deficient cardiac fibroblasts occurs by a caspase-3-independent pathway. Am J Physiol Heart Circ Physiol. 287:H1730-9. 
KATHRYN X. WANG

107 York Drive

Princeton, NJ 08540

\title{
EDUCATION
}

B.S. in Plant Physiology and Biochemistry, 1983

Nanjing University, Nanjing, China

M.S. in Forestry, 1989

Michigan Technological University, Houghton, MI

PROFESSIONAL EXPERIENCE

SANOFI-AVENTIS PHARMACEUTICALS, Bridgewater, NJ Research Investigator

Molecular Biologist

2001-present

\author{
Molecular Biologist
}

BRISTOL-MYERS SQUIBB COMPANY, Pennington, NJ

1998-2001

Research scientist

GENZYME CORPORATION, Framingham, MA

Principal research associate

1993-1998

Senior Research Associate

(1996-1998)

(1993-1996)

HARVARD MEDICAL SCHOOL, Boston, MA

Research Assistant III

Research Assistant

(1990-1991)

1990-1993

\section{PUBLICATIONS}

1. Wang KX, Denhardt DT. (2008) Osteopontin: Role in immune regulation and stress responses. Cytokine Growth Factor Rev. (In Press).

2. Wang KX, Shi Y, Denhardt DT. (2007) Osteopontin regulates hindlimb-unloadinginduced lymphoid organ atrophy and weight loss by modulating corticosteroid production. Proc Natl Acad Sci U S A. 104:14777-82. 
3.Coppola-V, Barrick-CA, Southon-EA, Celeste-A, Wang-K, Chen-B, Haddad-EB, Yin-J, Nussenzweig-A, Subramaniam-A, Tessarollo-L. Ablation of TrkA function in the immune system cause B cell abnormalities. Development 2004 131:5185-5195.

4. Jiang C, Finkbeiner WE, Widdicombe JH, Fang SL, Wang KX, Nietupski JB, Hehir $\mathrm{KM}$, Cheng SH. Restoration of cyclic adenosine monophosphate-stimulated chloride channel activity in human cystic fibrosis tracheobronchial submucosal gland cells by adenovirus-mediated and cationic lipid-mediated gene transfer.

Am J Respir Cell Mol Biol. 1999 20:1107-15

5. Yew-NS; Wang-KX; Przybylska-M; Nichols-MR; Gates-A; Akita-G; Marshall-J; Cheng-SH. The role of plasmid DNA in the inflammatory response associated with delivery of lipid:DNA complex to the lung. Human Gene therapy. 1999 10:223-234.

6. Yew-NS; Wysokenski-DM; Wang-KX; Ziegler-RJ; Marshall-J; McNeilly-D; Cherry-M; Cheng-SH. Optimization of plasmid vectors for higher level expression in lung epithelial cells. Human Gene therapy. 1997 8; 575-84.

7. Scheule-RK; St. George-A; Bagley-RG; Marshall-J; Wang-KX; Lee-ER; Harris-DJ; Yew-NS; Cheng-SH. Basis of pulmonary toxicity associated wit cationic lipidmediated gene transfer to the mammalian lung. Human Gene therapy. 1997 8; 689-707.

8. Lee-ER; Marshall-J; Siegal-S; Jiang-C; Yew-NS; Nichols-MR; Wang-KX; WanNC; Scheule-RK; Harris-DJ; Smith-AE; Cheng-SH. Detailed analysis of structures and formulations of cationic lipid for efficient gene transfer to the lung. Human Gene therapy. $19967 ; 1701-17$.

9. Scheule-RK; Bagley-RG; Wang-KX; fang-SL; Vaccaro-C; O'riordan-CR; Cheng$\mathrm{SH}$; Smith-AE. Delivery of purified, functional CFTR to epithelial cells in vitro using influenza hemaglutinin. American Journal of Respiratory Cell and Molecular Biology. $1995 ; 330-43$.

10. O'Riordan-CR; Erickson-A; Bear-C; Li-C; Wang-KX; Marshall-J; Scheule-RK; McPherson-JM; Cheng-SH; et-al. Purification and characterization of recombinant cystic fibrosis transmembrane conductance regulator from Chinese hamster ovary and insect cells. Journal of Biological Chemistry. 1995 270; 17033-43. 